\title{
Hydrostannation of alkynes
}

\author{
Mouad Alami, ${ }^{\text {** }}$ Abdallah Hamze, ${ }^{\mathrm{a}}$ Olivier Provot ${ }^{\mathrm{a}}$ \\ ${ }^{a}$ Univ. Paris-Sud, BioCIS, CNRS, University Paris-Saclay, Equipe Labellisée Ligue Contre Le Cancer, F-92296 Châtenay-Malabry, France \\ *monad.alami@u-psud.fror olivier.provot@u-psud.fr
}

Abstract: In this review, we present an overview of hydrostannation of alkynes until the end of
2018. Mechanism of the tin hydride addition on a triple bond is discussed at the beginning of
this review in the presence of metal catalysts as Pd, Ru-based complexes, Lewis acids and under
radical conditions. Then, stereoselectivity as well as regioselectivity aspects of tin hydride
addition on the carbon triple bond is discussed using metal-catalysis, radical conditions or Lewis
acids. In each of these items, the reactions will be studied for terminal alkynes and then, for
internal alkynes. Applications of hydrostannation of alkynes using metal-catalysis is presented
in a variety of total syntheses with Pd, Mo, $\mathrm{Rh}$ and $\mathrm{Ru}$-complexes to provide highly
functionalized vinyl stannanes derivatives as key-intermediates. Comparison with other
methods providing vinyl stannanes using metallostannation followed by protonation is
presented before the last section dealing with a summary of classical experimental conditions
used to achieve the hydrostannation of alkynes.
Keywords: hydrostannation, alkyne, catalysis, stereoselectivity, regioselectivity, tin

\section{Introduction.}

In view of the broad synthetic value of alkenylstannanes in organic chemistry, ${ }^{1-4}$ particularly for chemoselective Csp2-Csp2 bond formation through Kosugi-Migita-Stille cross-coupling, ${ }^{5,6}$ these substrates have emerged as highly valuable intermediates in organic synthesis. Numerous applications document the advantageous use of alkenylstannanes, which allow for the mild coupling with diverse electrophiles in the presence of sensitive functional groups of all kinds, and their application in the synthesis of a vast number of biologically active natural and unnatural compounds. ${ }^{7-14}$ Consequently, the development of convenient methods for forming $\mathrm{Csp}^{2}-\mathrm{Sn}$ bonds, especially in a catalytic process, has been an important subject in modern synthetic chemistry.

Although many methods exist for preparing alkenylstannanes (see Comparison with Other Methods), the direct addition of a tinhydrogen bond across the carbon-carbon triple bond, namely hydrostannation, ${ }^{15,16}$ is the most attractive one in view of the formation of functional group-rich alkenylstannanes. These products can be used in transition metal-catalyzed coupling reactions for the stereoselective synthesis of di- and trisubstituted olefins. From a synthetic point of view, addition of a tin hydride to an alkyne can be achieved with efficiency and atom-economy. The main drawbacks of the organotin compounds are their toxicity, ${ }^{17}$ their low solubility in water, and the difficulty in separating tin byproducts from nonpolar organic products.

As depicted in Scheme 1, three general ways are available to achieve the addition of $\mathrm{R}_{3} \mathrm{Sn}-\mathrm{H}$ across a $\mathrm{C}-\mathrm{C}$ triple bond: hydrostannation (i) with a transition metal catalyst; (ii) under radical conditions using either 2,2'-azobisisobutyronitrile (AIBN), triethylborane $\left(\mathrm{BEt}_{3}\right)$ or ultrasound as initiators; and (iii) with a Lewis acid, a protocol that is less widely used than the classical transition metal-catalyzed or radical-induced processes, but nevertheless leads to some significant results with respect to stereoselectivity. (ii)

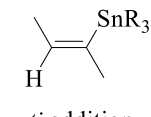

anti addition

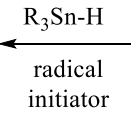
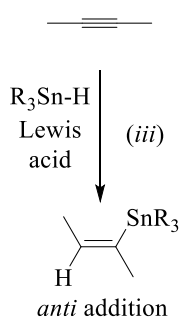

(i)

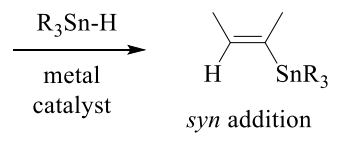

Scheme 1. Addition of $\mathrm{R}_{3} \mathrm{Sn}-\mathrm{H}$ across a $\mathrm{C}-\mathrm{C}$ triple bond: hydrostannation.

Among various transition metal catalysts for hydrostannation of alkynes, by far the most extensively developed are palladium complexes, first reported in $1987 .{ }^{18}$ To date, this method constitutes the most widely used procedure and has been the subject of several reviews. ${ }^{15,16,19}$ In comparison with radical reactions or those promoted by a Lewis acid, the palladiumcatalyzed hydrostannation generally proceeds under much milder conditions, resulting in higher yields of the products and excellent syn-stereoselectivity.

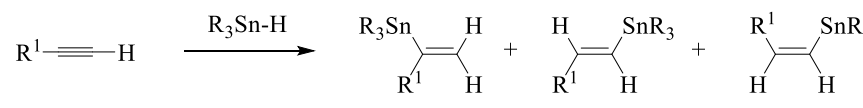

$$
\begin{aligned}
& \alpha \quad \beta-(E) \quad \beta-(Z) \\
& \text { syn addition anti addition } \\
& \mathrm{R}^{1}=\mathrm{R}^{2} \stackrel{\mathrm{R}_{3} \mathrm{Sn}-\mathrm{H}}{\longrightarrow}
\end{aligned}
$$

Scheme 2. Hydrostannation of terminal and internal alkynes.

Control of both regio- and stereochemistry is the main issue in the hydrostannation of alkynes, as in principle three different products can be produced from terminal alkynes, and four different ones can 
be formed from internal alkynes (Scheme 2). The product distribution is dependent on the nature of the alkyne substrate (i.e. terminal or internal), neighboring functional groups on the substrate, as well as the reaction conditions used (presence of a catalyst, solvent, additives, etc.). Of course, the challenge in this process is the ability to produce an alkenylstannane as a single isomer, which is a daunting task with an internal alkyne.

Stereochemical control has been achieved by employing catalytic amounts of a transition metal complex, which allows the hydrostannation of alkynes to proceed mainly in a syn-fashion (cisaddition) as a consequence of the reaction mechanism. Very recent advances, however, demonstrate that depending on the catalyst used, the addition of the $\mathrm{Sn}-\mathrm{H}$ bond may also occur with almost complete anti selectivity. With respect to regiochemical control, the hydrostannation reaction appears to be highly dependent on the alkyne. The use of symmetrical alkynes as substrates greatly simplifies many of the synthetic issues, but allows limited structural flexibility. With unsymmetrical alkynes, directing groups are routinely employed to avoid the formation of constitutionally isomeric mixtures. This directing ability may involve steric, electronic, or chelating influences. Figure 1 highlights the orientation of tin hydride in the addition to a carboncarbon triple bond in different situations, which is dictated by the substitution pattern on the alkyne substrate.

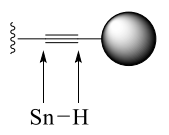

steric effect

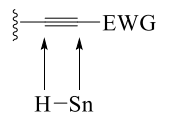

electronic effect

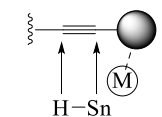

coordination effect

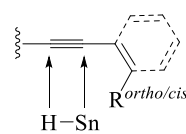

ortho-directing effect
Figure 1. Factors governing the regioselectivity for alkyne hydrostannation.

The literature covered by this review has been surveyed through the end of 2018. The review summarizes the most significant advances in $\mathrm{Csp}^{2}-\mathrm{Sn}$ bond formation through tin hydride addition to alkynes under transition metal catalysis, radical-induced processes, and Lewis acid-promoted reactions. Many of these reactions have been reviewed. ${ }^{20-22}$ However, some reviews are more general, covering not only alkynes as substrates but also other $\mathrm{C}-\mathrm{C}$ multiple bond systems, together with other type of addition processes such as hydrosilylation, hydroboration, metalometalation, etc. Although palladium complexes represent by far the most extensively used catalysts, this review also highlights synthetically useful protocols using other transition metal catalysts that constitute valuable alternatives to the established palladium catalyst systems. Whenever possible, comparison with palladium-catalyzed transformations will be presented.

As previously mentioned, regio- and stereocontrol are two key issues to be addressed in the hydrostannation process. Because the reaction selectivity exhibits a marked sensitivity to the alkyne substrates as well as to experimental conditions, this review surveys the influence of proximal (hetero)-functional groups attached to the $\mathrm{C}-\mathrm{C}$ triple bond on the crucial issue of regio- and stereocontrol in tin hydride addition. This part is organized by the type of hydrostannation reaction involved (metal-catalyzed tin hydride addition, radical-induced process, and Lewis acidpromoted reaction), by reactivity patterns and by functional groups within the alkyne substrates. In all sections, hydrostannation of terminal alkynes is presented first, followed by reactions with internal alkynes.
This section is intended to provide the practicing chemist with a basic understanding of the currently accepted mechanisms to aid in the rational selection and optimization of reaction conditions.

\subsection{Palladium catalysis.}

The palladium-catalyzed hydrostannation of alkynes ${ }^{18}$ constitutes the most widely used procedure for the synthesis of $E$ alkenylstannanes. Despite much effort in this field, the mechanism of this reaction is probably the least understood metalloid-hydride addition to alkynes because no kinetic study is available. Much has been assumed mechanistically on the basis of the distribution of products observed in the hydrostannation of alkynes and related substrates. The reaction proceeds with exclusive syn-addition, producing the $\beta$-E-adduct and the $\alpha$-isomer (Scheme 3 ). The regiochemistry of addition is controlled by many factors, of which the structure of the alkyne substrate plays a critical role.

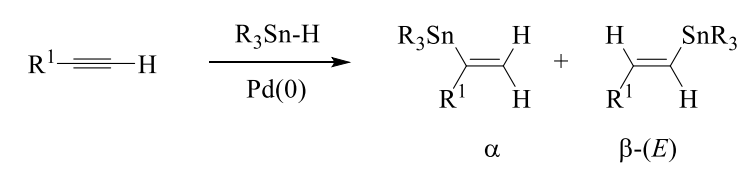

Scheme 3. Palladium-catalyzed hydrostannation of terminal alkynes.

Hydrostannation reaction may be achieved using a $\operatorname{Pd}(0)$ or a $\mathrm{Pd}(\mathrm{II})$ catalyst. In this latter case, the Pd-complex is reduced to $\operatorname{Pd}(0)$ by $\mathrm{R}_{3} \mathrm{SnH}^{15,23}$ The palladium-catalyzed hydrostannation is believed to take place through oxidative addition of $\mathrm{R}_{3} \mathrm{Sn}-\mathrm{H}$ to a 14-electron $\mathrm{L}_{2} \mathrm{Pd}(0)$ species, formed by reduction of various palladium-(II) complexes with $\mathrm{R}_{3} \mathrm{SnH}$, to generate a $\mathrm{Pd}(\mathrm{II})-$ hydrido stannyl intermediate 1 (Scheme 4). ${ }^{15,16}$ Subsequently, reversible coordination of the alkyne with a vacant orbital on the metal atom, followed by addition of the coordinated palladiumhydride bond of $\mathbf{2}$ into the alkyne $\pi$-bond delivers complexes $\mathbf{3 a}$ and/or 3b. As shown in Scheme 4, two competing pathways may be involved in this process. Hydropalladation would lead to complex 3a, whereas stannylpalladation ${ }^{18,24}$ would deliver alkenylstannane complex 3b. Finally, reductive elimination of palladium from either $\mathbf{3 a}$ or $\mathbf{3 b}$ would afford the $\beta-E-$ alkenylstannane and regenerate the palladium(0) catalyst.

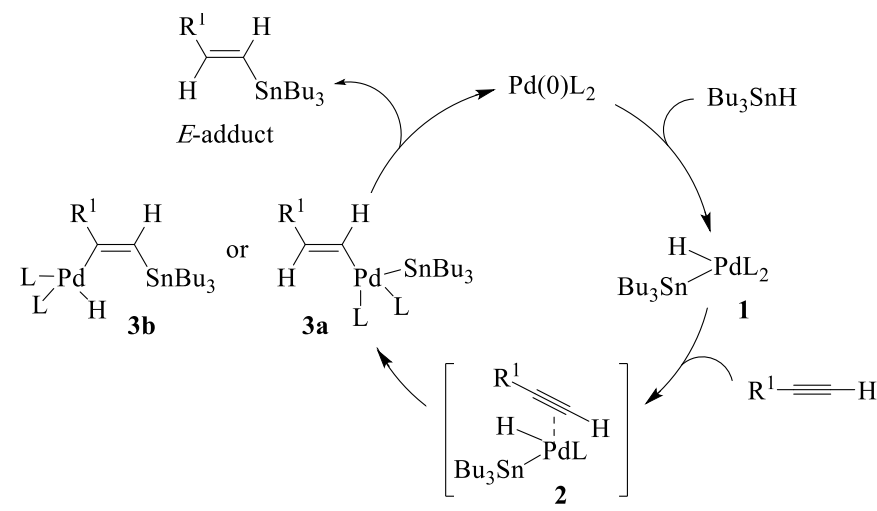

Scheme 4. Proposed Mechanism of the Pd-catalyzed hydrostannation of alkynes.

The proposed in situ formation of intermediate $\mathbf{1}$ has been supported by the isolation ${ }^{25}$ of cis Pd(II) hydrido trialkylstannyl intermediate 4 , facilitated by stabilizing the complex with bulky bidentate phosphine ligands. It was shown that complex 4 reacts further with $\mathrm{Me}_{3} \mathrm{SnH}$, even at $-120{ }^{\circ} \mathrm{C}$, to yield complex $\mathbf{5}$ and molecular hydrogen (Scheme 5).

\subsection{Mechanism and stereochemistry.}




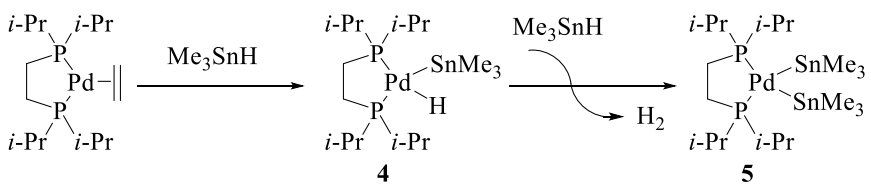

Scheme 5. Isolation of cis $\mathrm{Pd}(\mathrm{II})$ hydrido trialkylstannyl intermediate 4 and its reaction with $\mathrm{Me}_{3} \mathrm{SnH}$.

Questions persist about the possibility that a $\mathrm{Pd}(\mathrm{II})$ hydrido stannyl intermediate 1 can undergo cis-addition of either the $\mathrm{Pd}-\mathrm{H}$ (hydropalladation) or $\mathrm{Pd}-\mathrm{Sn}$ (stannylpalladation) bond to the alkyne triple bond, and to date little convincing evidence exists to distinguish between these pathways. Evidence in favor of the hydropalladation pathway ${ }^{26}$ is available from a report on a hydrostannation-cyclization sequence of 1,6-enynes 6 (Scheme 6). In this process, the reaction begins by hydropalladation of the triple bond of 6 (an alkyne is more reactive in Pd-catalyzed hydrostannation than an alkene $)^{26}$ to form intermediate 7 , which then undergoes an intramolecular carbopalladation leading to species $\mathbf{8}$, followed by reductive elimination to produce exomethylenecyclopentane $\mathbf{9}$.

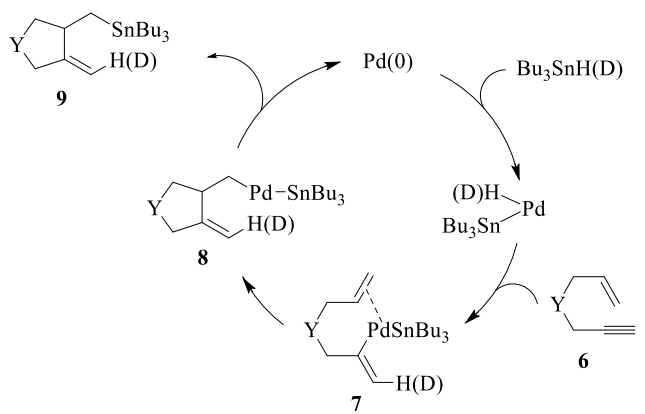

Scheme 6. Hydrostannation-cyclization sequence of 1,6-enynes 6.

As opposed to the behavior of 1,6-enyne derivatives, 1,7-enyne $\mathbf{1 0}$ does not lead to ring formation, likely because the carbopalladation step for the construction of six-membered rings may be unfavorable because of the size of the chelate formed when the olefin coordinates to the palladium. Instead, the reaction furnishes the internal alkenylstannane 11 (Scheme 7), ${ }^{26}$ a result that is consistent with a mechanism involving a hydropalladation pathway as depicted in Scheme 6.

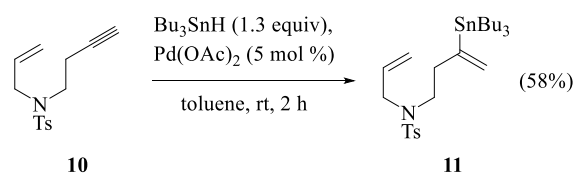

Scheme 7. Pd-catalyzed hydrostannation of $\mathbf{1 0}$.

Another argument in favor of the hydropalladation pathway (formation of intermediate $\mathbf{1 3}$ vs 14, Scheme 8) is the report describing the palladium-catalyzed hydrostannation of terminal or internal aromatic alkynes 12, in which the triple bond is significantly polarized by the presence of a nitro group on the aryl nucleus. ${ }^{27}$ Thus, the results depicted in Scheme 8 illustrate how electronic differentiation of the $\mathrm{C} \equiv \mathrm{C}$ triple bond can affect the regioselectivity of the process, furnishing exclusively alkenylstannanes 15 regardless of the nature of the $\mathrm{R}^{1}$ group $\left(\mathrm{R}^{1}=\right.$ $\left.\mathrm{H}, \mathrm{C}_{5} \mathrm{H}_{11}, \mathrm{Ph}\right)$. The overall preference for the formation of tributylstannyl derivatives $\mathbf{1 5}$ is consistent with a mechanism wherein tributyltin hydride formally acts as a hydride donor ${ }^{28}$ (Cf. Alkynes with Electron-Withdrawing Substituents).

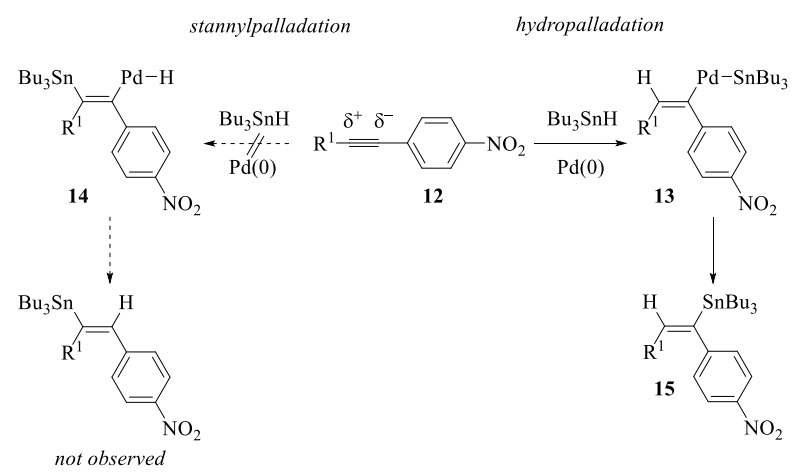

Scheme 8. Pd-catalyzed hydrostannation of $p-\mathrm{NO}_{2}$ arylalkyne 12.

2.2 The particularity of $[\mathrm{Cp} * \mathrm{Ru}]$-based complexes in the hydrostannation of alkynes.

In contrast to all other transition-metal-catalyzed hydrostannation reactions documented in the literature, it was recently reported that ruthenium complexes $\mathbf{1 6 - 1 8}{ }^{29-31}$ (Scheme 9) provide unique antiselectivity across various types of internal alkyne substrates to afford (Z)-alkenylstannane product (Scheme 10).

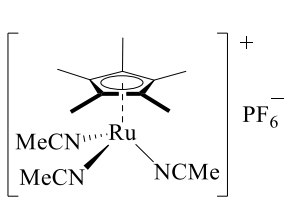

16

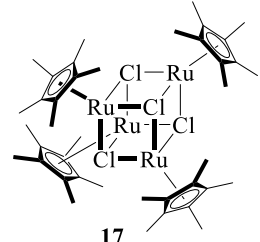

17

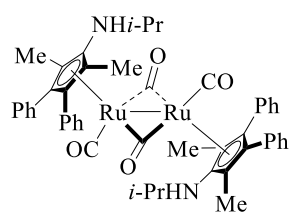

18
Scheme 9. Ruthenium catalysts 16-18.

$$
\mathrm{R}^{1}=\mathrm{R}^{1} \underset{[\mathrm{Cp} * \mathrm{Ru}] \text {-based complexes }}{\mathrm{R}_{3} \mathrm{Sn}-\mathrm{H}} \mathrm{R}_{\mathrm{R}} \underset{\mathrm{H}}{\longrightarrow}
$$

( $Z$ )-adduct

Scheme 10. Ru-catalyzed hydrostannation of alkynes.

A mechanistic hypothesis explaining this unique transhydrostannation of symmetrical and unsymmetrical internal alkynes in the presence of a transition metal has been reported by Fürstner (Scheme 11). ${ }^{29,32,33}$ The proposed mechanism gives a new lighting and complete the reaction mechanism proposed by Trosts concerning his pionner work dealing with the transhydrosilylation of di-substituted alkynes in the presence of $[\mathrm{Cp} * \mathrm{Ru}]$-based complex $\left(\mathrm{Cp} *=\eta^{5}-\mathrm{C}_{5} \mathrm{Me}_{5}\right) \cdot{ }^{34}$ Firstly, the reaction began with the coordination of the alkyne triple bond with the electrophilic metal center of $\mathbf{1 6}$ to give intermediate $\mathbf{1 9}$ which then favors a subsequent coordination of the tribubyltin hydride to provide $\mathbf{2 0}$ in which the alkyne triple bond is supposed to act as a four-electron donor. Then, subsequent inner-sphere hydride delivery forms a metallacyclopropene intermediate $\mathbf{2 1}$ in which the alkyne $\mathrm{R}^{1}$ group is oriented towards the bulky $\mathrm{Cp}^{*}$ ligand. Congested metallacyclopropene 21 may isomerize into $\mathbf{2 3}$ in a reversible fashion in which the $\mathrm{R}^{1}$ substituent is further away from the $\mathrm{Cp}^{*}$ ligand. These steric factors are at the origin of the transhydrostannation as a final reductive elimination of $\mathbf{2 3}$ via $\mathbf{2 4}$ places the tin metal anti to the hydride leading to $(E)$-vinylstannanes. Nevertheless, a concerted mechanism from $\mathbf{2 0}$ to $\mathbf{2 3}$ cannot be totally excluded without the participation of an open cationic 


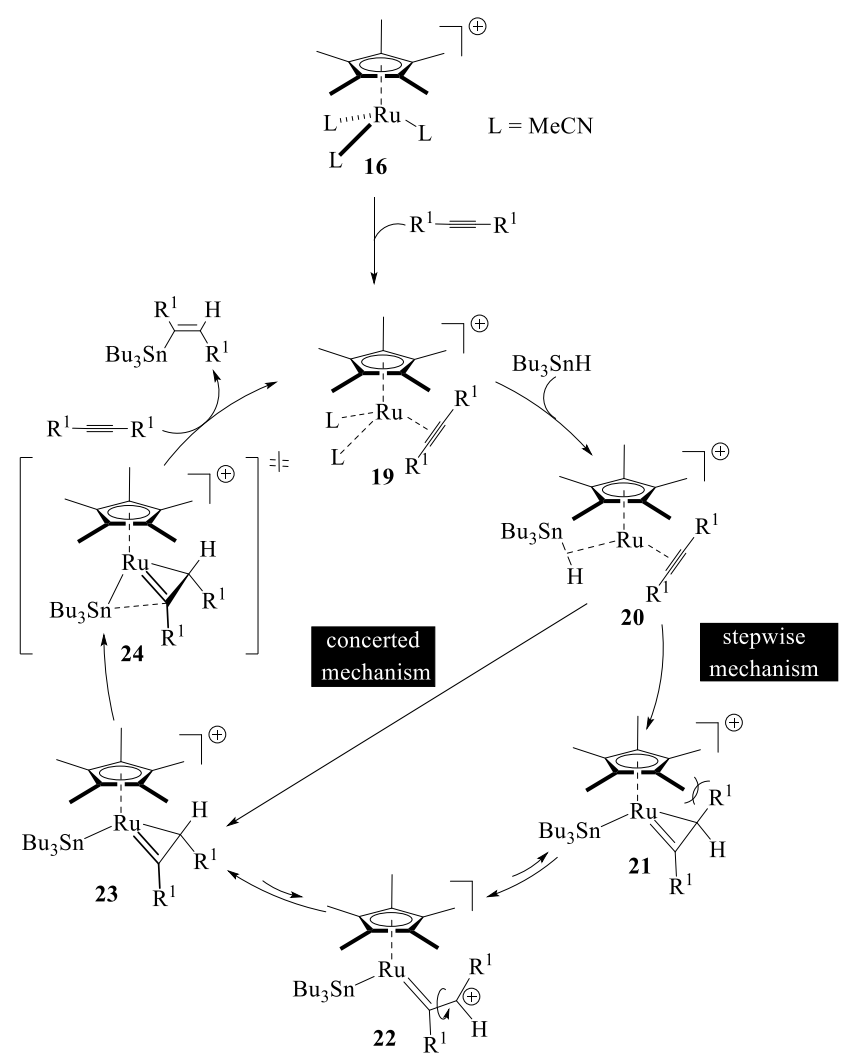

Scheme 11. Proposed mechanism hypothesis explaining the transhydrostannation of symmetrical and unsymmetrical internal alkynes using Ru-complexe $\mathbf{1 6}$.

intermediate $\mathbf{2 2}$ as a hydride could be delivered from $\mathbf{2 0}$ to provide a less congested metallacyclopropene 23 . ${ }^{29,35}$ Mechanistic insights explaining the stereo- as well as the regioselective outcomes of the $\mathrm{Bu}_{3} \mathrm{SnH}$ trans-addition on internal alkynes having vicinal alcohols or amines and using chloride pre-catalyst $\mathbf{1 7}$ are fully detailed and reported. ${ }^{32,33}$

\subsection{Radical conditions.}

The radical-induced hydrostannation of alkynes has been extensively studied and often affords regio- and stereoisomeric mixtures of alkenylstannanes. The reaction follows a radical chain mechanism involving trialkyltin radical addition to the $\mathrm{C}-\mathrm{C}$ triple bond to produce a mixture of alkenyl radicals (Scheme 9). 2,36-39 In this case, the initial regiochemistry is controlled by the relative stability of the alkenyl radical species that gives rise to the corresponding alkenylstannanes (the more substituted alkenyl radical is favored). With respect to stereoselectivity, the initially formed product from $s y n$-addition ( $Z$-adduct) is equilibrated to the thermodynamically more stable $E$-isomer in the presence of tin radicals under the reaction conditions ${ }^{40}$ In general, the products observed in radical hydrostannation often reflect thermodynamic rather than kinetic selectivities because of the reversibility and product isomerization through addition-elimination reactions. Good stereoselectivities may be obtained if the equilibration process leads to a product favored by other factors (often steric). Recently, good syn selectivity furnishing the $E$-adduct has been reported with the use of catalytic amounts of $\mathrm{Et}_{3} \mathrm{~B}$ or sonochemical initiation of the radical cycle. Regio- and stereoselectivity of radical reactions can be predicted by radicalstabilizing effects, ${ }^{41}$ and steric effects. ${ }^{2,42}$

Although this mechanism is widely accepted (Scheme 12), several lines of evidence suggest that radical-mediated hydrostannation of alkynes does not involve radical intermediates exclusively, but more likely proceeds through a hybrid single-electron transfer $(\mathrm{SET}) /$ radical propagation mechanism ${ }^{43}$ shown in Scheme 13

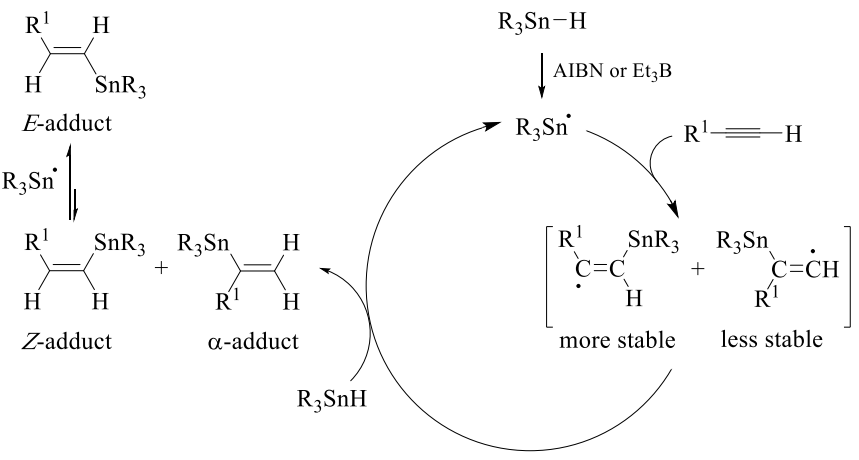

Scheme 12. Proposed mechanism of the hydrostannation of alkynes under radical conditions.

Recent reports highlight the crucial role played by molecular oxygen in radical-mediated hydrostannation of alkynes employing any radical initiator (e.g., $\mathrm{AIBN}, \mathrm{Et}_{3} \mathrm{~B}$, etc). The $\mathrm{O}_{2}$-free $\mathrm{AIBN}-$ mediated $\mathrm{Bu}_{3} \mathrm{Sn}-\mathrm{H}$ addition to internal propargylic alcohols fails to proceed, whereas the addition of even a trace of $\mathrm{O}_{2}$ into these same reactions allows the hydrostannation to proceed readily. A combination of control experiments, including the polar solvent studies, deuterium-labeling studies, and DFT calculations provide crucial insights into the mechanistic details of the hydrostannation. Because the addition of $\mathrm{Bu}_{3} \mathrm{Sn}-\mathrm{H}$ to a wide selection of alkynes proceeds only in the presence of $\mathrm{O}_{2},{ }^{44}$ and is faster in polar solvents, ${ }^{45}$ it has been concluded that the reaction does not proceed exclusively by a radical process. Instead, it is suggested to involve the formation of cationic species $\mathbf{2 7}$ through $\mathrm{O}_{2}$-promoted singleelectron transfer (SET) oxidation of alkenyl radicals 26 (Scheme 13).

The stannyl radical $25\left(\mathrm{Bu}_{3} \mathrm{Sn}^{\circ}\right)$ addition to the triple bond need not be regioselective and will provide a constitutional mixture of alkenyl radicals 26a,b. A SET from these radicals to $\mathrm{O}_{2}$ coalesces to form the same three-centered alkenyl cation species 27 and

superoxide $\left(\mathrm{O}_{2}{ }^{-}\right)$. Further hydride transfer from $n \mathrm{Bu}_{3} \mathrm{SnH}$ ultimately affords the $Z$-adduct under kinetic control and $n \mathrm{Bu}_{3} \mathrm{Sn}^{+}$ $\mathbf{2 8}$, which is rapidly reduced by superoxide to regenerate the chain carrying radical $\mathrm{Bu}_{3} \mathrm{Sn}$. Note that this mechanism has been questioned as being inconsistent with other mechanistic studies and computational data. ${ }^{46-48}$

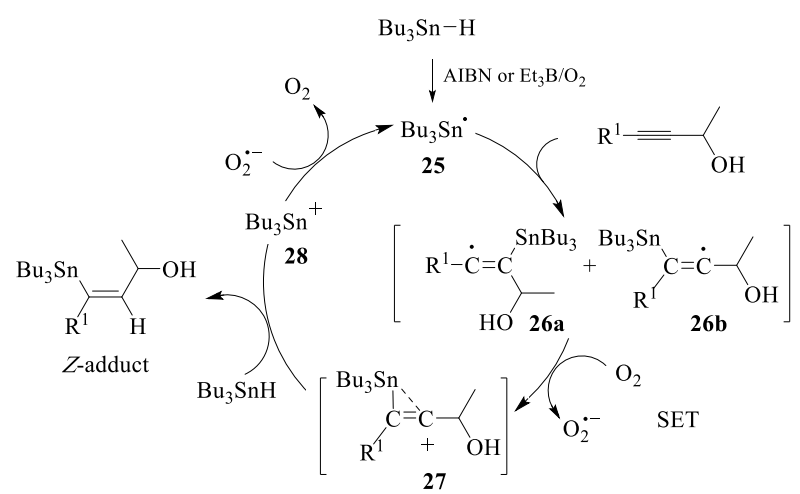

Scheme 13. Proposed mechanism for the hydrostannation of propargylic alcohols under radical conditions.

\subsection{Lewis acid conditions.}

Contrary to the standard radical-induced hydrostannation shown in Scheme 12, the use of a Lewis acid such as $\mathrm{ZrCl}_{4}$ enables the anti-addition of $\mathrm{Bu}_{3} \mathrm{SnH}$, furnishing the $\mathrm{Z}$-adduct with excellent 
regio- and stereoselectivity. ${ }^{49}$ This outcome is general for terminal alkynes and enyne derivatives. The reaction must be kept at $0{ }^{\circ} \mathrm{C}$, because both the yield and stereoselectivity decrease if the reaction is carried out at room temperature. Indeed, $\mathrm{Bu}_{3} \mathrm{SnH}$ reacts with $\mathrm{ZrCl}_{4}$ at room temperature to form a complex, which leads to a rapid equilibrium between $\mathrm{Bu}_{3} \mathrm{SnH}, \mathrm{Bu}_{2} \mathrm{SnH}_{2}$, and $\mathrm{Bu}_{4} \mathrm{Sn}^{5}{ }^{50}$ The mechanism of this $\mathrm{ZrCl}_{4}$-catalyzed reaction (Scheme 14$)^{50}$ is claimed to proceed by coordination to the triple bond to produce the $\pi$-complex 29. Hydride transfer from $\mathrm{Bu}_{3} \mathrm{SnH}$ to an electron deficient carbon from the side opposite to $\mathrm{ZrCl}_{4}$ stereoselectively produces the pentacoordinate zirconium ate-complex 30. The latter undergoes a transmetalation from zirconium to tin with retention of configuration to afford a $Z$-adduct and regenerates $\mathrm{ZrCl}_{4}$. It is noteworthy that $\mathrm{ZrCl}_{4}$ also catalyzes hydrostannations with $\mathrm{Bu}_{2} \mathrm{SnH}_{2}$ to form regio- and stereodefined dialkenyltin derivatives. ${ }^{50}$

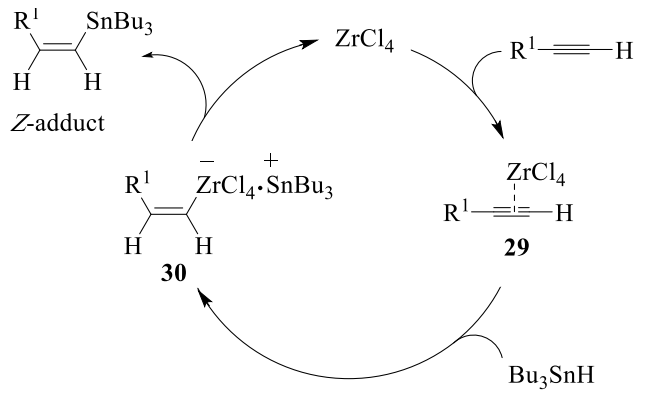

Scheme 14. Proposed mechanism for the hydrostannation of alkynes under Lewis acid conditions.

\section{Scope and limitations.}

\subsection{Palladium-catalyzed hydrostannation of alkynes.}

The primary challenge for hydrostannation of alkynes is the ability to control both the regio- and stereochemical course of the tin hydride addition. Since the discovery of transition metal-catalyzed reactions, particularly with Pd-based systems, the stereoselectivity in hydrostannation is largely predictable and proceeds sterospecifically in a syn-fashion. The control of the regioselectivity, however, remains a daunting task that depends on the alkyne substrate and its neighboring functional groups (ester, heteroatom, etc.). With such considerations in mind, this section is organized according to the reacting alkyne (terminal and internal) and then further subdivided according to nearby functional groups. In addition, comments regarding the influence of the groups on tin will be presented when appropriate.

\subsubsection{Terminal alkynes.}

\subsubsection{Aliphatic Alkynes.}

Unbranched linear alkyl-substituted alkynes have not been extensively studied, and reactions with these substrates are usually considered cumbersome under palladium catalysis. Oshima and co-workers ${ }^{18}$ reported the first example of a palladium-catalyzed hydrostannation of alkynes. Their studies revealed that in the presence of a catalytic amount of $\mathrm{Pd}\left(\mathrm{PPh}_{3}\right)_{4}$, triphenyltin hydride adds to 1-dodecyne to afford a mixture of isomers $(\mathbf{3 1} / \mathbf{3 2}=11: 89)$ in which the $\beta$-constitutional isomer 32 predominates (Scheme $15)$.

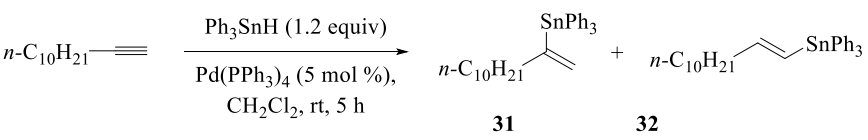

$$
\begin{aligned}
& \text { (77\%) } 31: 32=11: 89
\end{aligned}
$$

Almost no selectivity $(\mathbf{3 3 a} / \mathbf{3 4 a}=57: 43)$ is observed with 1-octyne when using $\mathrm{Bu}_{3} \mathrm{SnH}$ instead of $\mathrm{Ph}_{3} \mathrm{SnH}$ and $\mathrm{PdCl}_{2}\left(\mathrm{PPh}_{3}\right)_{2}$ as the catalyst. ${ }^{28}$ However, increasing the steric bulk at the propargylic position has a profound effect on the hydrostannation regioselectivity. For example, the reaction of 3-pentyl-1-octyne delivers a single compound, $E$ - $\beta$ product $34 \mathrm{~b}$, in excellent yield (Scheme 16).

$$
\begin{aligned}
& \mathrm{R}^{1}=\frac{\mathrm{Bu}_{3} \mathrm{SnH}(1.2 \text { equiv })}{\begin{array}{c}
\mathrm{PdCl}_{2}\left(\mathrm{PPh}_{3}\right)_{2}(2 \mathrm{~mol} \%), \\
\mathrm{THF}, \mathrm{rt}, 10 \mathrm{~min}
\end{array}} \mathrm{R}_{\mathbf{3 3}} \overbrace{\mathrm{R}^{1}}^{\mathrm{SnBu}_{3}}+\mathrm{SnBu}_{3} \\
& \begin{array}{llcc}
\text { product } & \mathrm{R}^{1} & \text { Yield (\%) 34 } & \mathbf{3 3 : 3 4} \\
\hline \text { 33a, 34a } & n-\mathrm{C}_{6} \mathrm{H}_{13} & (-) & 57: 43
\end{array} \\
& \text { 33b, 34b } \quad \mathrm{CH}\left(n-\mathrm{C}_{5} \mathrm{H}_{11}\right)_{2} \quad \text { (90) } 0: 100
\end{aligned}
$$

Scheme 16. Pd-catalyzed hydrostannation of terminal alkynes.

Functional groups on alkynes can substantially modify the regioselectivity through coordination of the metal center to heteroatom groups. ${ }^{51}$ An early study ${ }^{52}$ describes attempts to perform selective tributyltin hydride addition to a propargyl glycine derivative 35. Despite an extensive survey of $\mathrm{PdCl}_{2} \mathrm{~L}_{2}$ catalysts $\left[\mathrm{L}=\mathrm{PPh}_{3}, \mathrm{P}(2 \text {-tolyl })_{3}, \mathrm{PMe}_{3}, \mathrm{PBu}_{3}\right.$, dppe, $\left.\mathrm{AsPh}_{3}\right]$, the reaction failed to achieve good yields of either constitutional isomer 36 and 37 (Scheme 17). ${ }^{53} \mathrm{~A}$ later study ${ }^{54}$ demonstrates that the use of a bulky electron-rich phosphine ligand, such as $\mathrm{Cy}_{3} \mathrm{P} \cdot \mathrm{HBF}_{4}$ in the presence of a catalytic amount of $i-\mathrm{Pr}_{2} \mathrm{NEt}$ leads to selective formation of the $\beta-(E)$-alkenylstannanes with regioselectivities up to $>99 \%$. With $\mathrm{Ph}_{3} \mathrm{P}$, these substrates show much lower regioselectivities (Schemes 17 and 18). The role of Hünig's base is not obvious, but it has been speculated that it minimizes the formation of the reduction by-product resulting from protodestannylation processes.

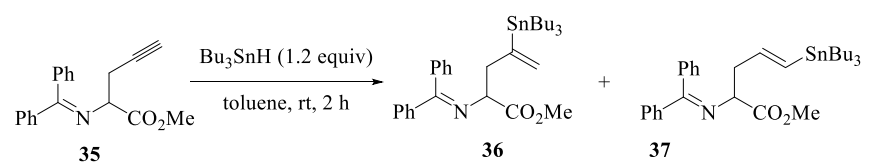

$\begin{array}{lcr}\text { Catalyst, Ligand, Additive } & \text { Yield (\%) } 36+37 & \mathbf{3 6 : 3 7} \\ \mathrm{PdCl}_{2}\left(\mathrm{PPh}_{3}\right)_{2}(1 \mathrm{~mol} \%) & (43) & 50: 50 \\ \mathrm{Pd}_{2}(\mathrm{dba})_{3}(0.5 \mathrm{~mol} \%), \mathrm{Cy}_{3} \mathrm{P} \cdot \mathrm{HBF}_{4}(2 \mathrm{~mol} \%), i-\mathrm{PrNEt}_{2}(4 \mathrm{~mol} \%) & (-) & 16: 84\end{array}$

Scheme 17. Pd-catalyzed hydrostannation of 35 .

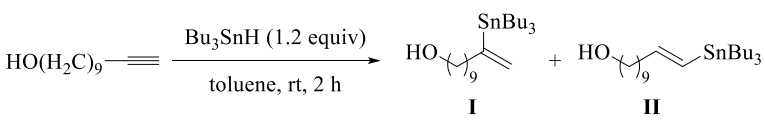

Catalyst, Ligand, Additive Yield (\%) I + II $\quad$ I:II $\mathrm{PdCl}_{2}\left(\mathrm{PPh}_{3}\right)_{2}(1 \mathrm{~mol} \%)$ (50) $\quad 33: 67$ $\mathrm{Pd}_{2}(\mathrm{dba})_{3}(0.5 \mathrm{~mol} \%), \mathrm{Cy}_{3} \mathrm{P} \cdot \mathrm{HBF}_{4}(2 \mathrm{~mol} \%), i-\mathrm{PrNEt}_{2}(4 \mathrm{~mol} \%) \quad$ (87)

Scheme 18. Pd-catalyzed hydrostannation of undec-10-yn-1-ol.

Because organotin hydrides are expensive and are prone to oxidation, strategies to generate such species in situ to perform hydrostannations of alkynes have been reported. The use of either $\mathrm{Bu}_{3} \mathrm{SnCl} / \mathrm{PMHS} / \mathrm{KFaq}$ or the combination of $\mathrm{Bu}_{3} \mathrm{SnF}$, PMHS, and catalytic amounts of tetrabutylammonium fluoride can serve as in situ sources of tributyltin hydride for palladium-catalyzed hydrostannation reactions. ${ }^{55}$

Scheme 15. Pd-catalyzed hydrostannation of dodec-1-yne. 


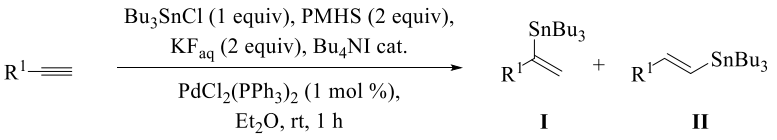

$$
\begin{aligned}
& \begin{array}{lcc}
\mathrm{R}^{1} & \text { Yield (\%) I + II } & \text { I:II } \\
\hline\left(\mathrm{CH}_{2}\right)_{4} \mathrm{OH} & (72) & 42: 58
\end{array} \\
& \left(\mathrm{CH}_{2}\right)_{3} \text { OTBS } \quad \text { (51) } 50: 50 \\
& \left(\mathrm{CH}_{2}\right)_{3} \mathrm{Cl} \quad \text { (84) } 42: 58 \\
& t \text {-Bu (59) } 1: 99
\end{aligned}
$$

Scheme 19. Pd-catalyzed hydrostannation of terminal alkynes using $\mathrm{Bu}_{3} \mathrm{SnCl} / \mathrm{PMHS} / \mathrm{KFaq}$.

In agreement with a previous report, ${ }^{28}$ the regioselectivity remains poor with alkyl-substituted alkynes, even for functionalized substrates. Only hindered tert-butylacetylene affords excellent selectivity for the $\beta-(E)$-alkenylstannane (Scheme 19).

Propargylic alcohols constitute another class of aliphatic alkyne substrates that have been particularly well exploited for the formation of functionalized alkenylstannanes. The first studies $^{23,28,56}$ on the palladium-catalyzed hydrostannation of propargylic alcohol and ether derivatives employed substrates having no substitution at the propargylic position. An approximately 60:40 mixture of $\alpha$ - and $\beta$-constitutional isomers is usually obtained in the presence of $\mathrm{Pd}\left(\mathrm{PPh}_{3}\right)_{4}$ or $\mathrm{PdCl}_{2}\left(\mathrm{PPh}_{3}\right)_{2}$ (Scheme 20). The use of modified stannanes such as trineophenyltin $\left[\left(\mathrm{PhMe}_{2} \mathrm{CCH}_{2}\right)_{3} \mathrm{SnH}\right]^{57}$ instead of $\mathrm{Bu}_{3} \mathrm{SnH}$ has no significant effect on regioselectivity. However, changing the catalyst and, in particular, the steric bulk of the ligands (e.g., $\left.\mathrm{Cy}_{3} \mathrm{P} \cdot \mathrm{HBF}_{4}\right),{ }^{54}$ leads to the opposite regioselectivity in favor of the $\beta$ - $(E)$-constitutional isomer $(\alpha / \beta=30: 70)$ probably because of steric considerations. In summary, the results shown in Scheme 20 clearly illustrate how the selectivity is influenced by the steric bulk of the phosphine ligand, whereas coordination factors appear to be negligible because propargyl alcohols and propargyl ethers (e.g., silyl ether or benzyl ether) provide similar selectivities.

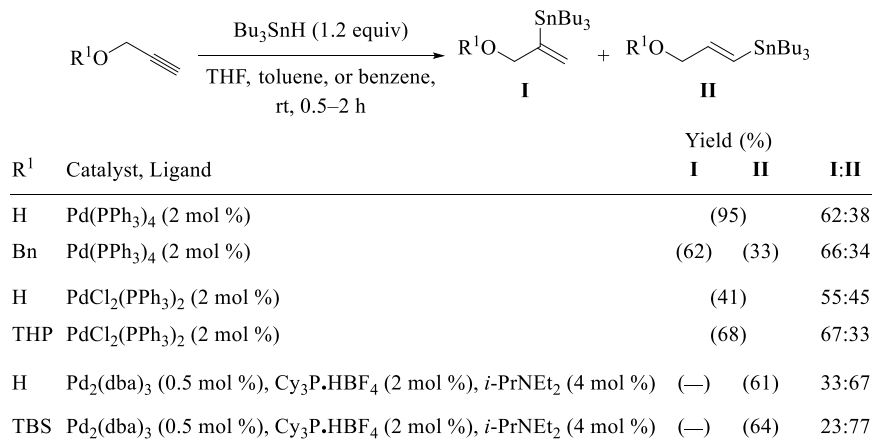

Scheme 20. Pd-catalyzed hydrostannation of propargylic alcohols.

As a general rule, increasing the steric bulk of the substituent at the propargylic position provides better levels of $\beta$-(E)alkenylstannane selectivity. Terminal secondary propargyl alcohols $^{23}$ and their corresponding ethers show some $\beta-(E)$ selectivity, whereas tertiary propargyl alcohols ${ }^{58}$ undergo highly regioselective $\beta-(E)$-hydrostannation (Scheme 21 ).

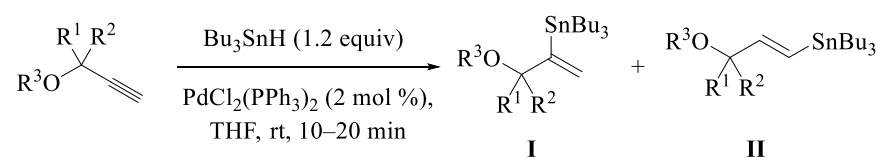

\begin{tabular}{lllcc}
$\mathrm{R}^{1}$ & $\mathrm{R}^{2}$ & $\mathrm{R}^{3}$ & Yield (\%) I + II & I:II \\
\hline $\mathrm{H}$ & $\mathrm{Me}$ & $\mathrm{H}$ & $(-)$ & $20: 80$ \\
$\mathrm{H}$ & $\mathrm{Ph}$ & $\mathrm{H}$ & $(-)$ & $24: 76$ \\
$\mathrm{H}$ & $n-\mathrm{C}_{5} \mathrm{H}_{11}$ & $\mathrm{H}$ & $(-)$ & $25: 75$ \\
$\mathrm{H}$ & $n-\mathrm{C}_{5} \mathrm{H}_{1}$ & $\mathrm{TBS}$ & $(94)$ & $28: 72$ \\
$\mathrm{Me}$ & $\mathrm{Me}$ & $\mathrm{H}$ & $(85)$ & $0: 100$ \\
$\mathrm{CH}_{2}\left(\mathrm{CH}_{2}\right)_{3} \mathrm{CH}_{2}$ & $\mathrm{H}$ & $(72)$ & $0: 100$ \\
$\mathrm{CH}_{2}\left(\mathrm{CH}_{2}\right)_{3} \mathrm{CH}_{2}$ & MOM & $(65)$ & $0: 100$
\end{tabular}

Scheme 21. Pd-catalyzed hydrostannation of congested propargylic alcohols.

As mentioned previously, it should be noted that in the case of secondary propargyl alcohols high selectivities to produce synthetically useful $\beta$-(E)-alkenylstannanes may be achieved by using $\mathrm{Pd}_{2}(\mathrm{dba})_{3} / \mathrm{Cy}_{3} \mathrm{P} \cdot \mathrm{HBF}_{4} / i-\mathrm{PrNEt}_{2}$ (Scheme 22). ${ }^{54}$ These results shown in Schemes 21 and 22, highlight the fact that steric effects are the only determining factor in product selectivity under palladium catalysis.

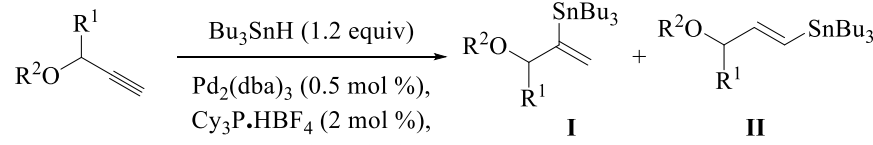

$$
\begin{aligned}
& i \text {-PrNEt } 2 \text { (4 mol \%), } \\
& \text { toluene, rt, } 2 \mathrm{~h}
\end{aligned}
$$

\begin{tabular}{llcc}
$\mathrm{R}^{1}$ & $\mathrm{R}^{2}$ & Yield (\%) II & I:II \\
\hline$n-\mathrm{C}_{5} \mathrm{H}_{11}$ & $\mathrm{H}$ & $(82)$ & $5: 95$ \\
$n-\mathrm{C}_{5} \mathrm{H}_{11}$ & $\mathrm{TBS}$ & $(77)$ & $4: 96$ \\
$i-\mathrm{Bu}$ & $\mathrm{H}$ & $(83)$ & $4: 96$ \\
$i-\mathrm{Pr}$ & $\mathrm{H}$ & $(86)$ & $3: 97$
\end{tabular}

Scheme 22. Pd-catalyzed hydrostannation of secondary propargylic alcohols.

Excellent regioselectivity for $\beta$ - $(E)$-isomer 39 may be achieved in the hydrostannation of functionalized tertiary propargyl alcohol $\mathbf{3 0}$ performed with in situ-generation of $\mathrm{R}_{3} \mathrm{SnH}$ from $\mathrm{R}_{3} \mathrm{SnCl}$ and PMHS as the reducing agent (Scheme 23). ${ }^{59}$ These conditions avoid the handling of highly toxic $\mathrm{Me}_{3} \mathrm{SnH}$ and allow the formation of alkenylstannanes $\mathbf{3 9} \mathbf{a}, \mathbf{b}$ selectively without reduction of the $\mathrm{C}-\mathrm{I}$ bond.

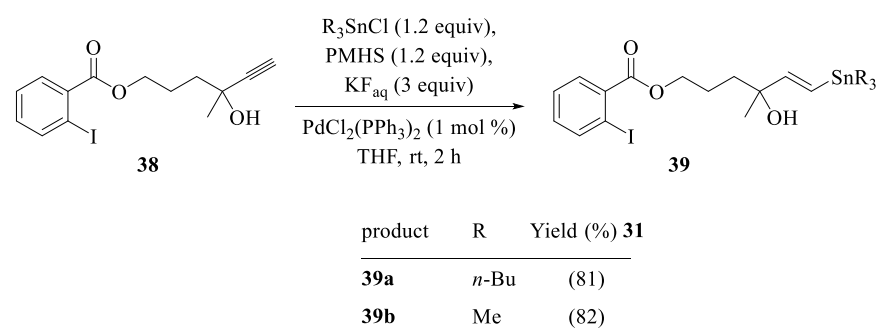

Scheme 23. Pd-catalyzed hydrostannation of $\mathbf{3 8}$.

\subsubsection{Aromatic alkynes.}

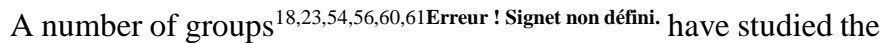
hydrostannation of phenylacetylene under palladium catalysis. In most reports, the reactions are not regioselective and an almost 1:1 mixture of $\alpha$ - and $\beta$-(E)-isomers is obtained employing $\mathrm{Bu}_{3} \mathrm{SnH}$ in the presence of $\mathrm{PdCl}_{2}\left(\mathrm{PPh}_{3}\right)_{2}{ }^{54}$ or $\mathrm{Pd}\left(\mathrm{PPh}_{3}\right)_{4}{ }^{56}$ (Scheme 24). Performing the reaction with the catalytic system 
$\mathrm{Pd}_{2}(\mathrm{dba})_{3} / \mathrm{Cy}_{3} \mathrm{P} \cdot \mathrm{HBF}_{4} / i-\mathrm{PrNEt}_{2}{ }^{54}$ or using $\mathrm{Ph}_{3} \mathrm{SnH}^{18}$ give the $\beta-(E)-$ adduct preferentially. These observations suggest the importance of steric factors in controlling the regioselectivity of addition in this substrate class.

In addition to steric effects, the nature and position of substituents on the aromatic ring ${ }^{27,61,62}$ are also factors that play a crucial role on the hydrostannation regioselectivity.

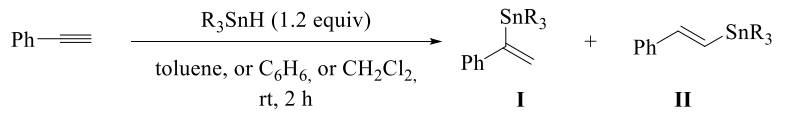

\begin{tabular}{llcc}
$\mathrm{R}$ & Catalyst & Yield $(\%) \mathbf{I}+\mathbf{I I}$ & I:II \\
\hline$n$ - $\mathrm{Bu}$ & $\mathrm{PdCl}_{2}\left(\mathrm{PPh}_{3}\right)_{2}(1 \mathrm{~mol} \%)$ & $(88)$ & $49: 51$ \\
$n$ - $\mathrm{Bu}$ & $\mathrm{Pd}\left(\mathrm{PPh}_{3}\right)_{4}(2 \mathrm{~mol} \%)$ & $(96)$ & $50: 50$ \\
$n$ - $\mathrm{Bu}$ & $\mathrm{Pd}_{2}\left(\mathrm{dba}_{3}(0.5 \mathrm{~mol} \%), \mathrm{Cy}_{3} \mathrm{P}_{2} \cdot \mathrm{HBF}_{4}(2 \mathrm{~mol} \%), i\right.$ - $\mathrm{PrNEt}_{2}(4 \mathrm{~mol} \%)$ & $(74)$ & $19: 81$ \\
$\mathrm{Ph}$ & $\mathrm{Pd}\left(\mathrm{PPh}_{3}\right)_{4}(5 \mathrm{~mol} \%)$ & $(61)$ & $12: 88$
\end{tabular}

Scheme 24. Pd-catalyzed hydrostannation of terminal arylalkynes.

With 4-substituted phenylacetylenes bearing an electronwithdrawing group (e.g., $\mathrm{CO}_{2} \mathrm{Me}, \mathrm{CN}, \mathrm{CHO}$ ) the reaction selectively furnishes the $\alpha$-isomer (Scheme 25). This outcome is likely because of strong polarization of the carbon-carbon triple bond resulting in addition of hydride to the more electron-deficient $\beta$-carbon of the acetylenic bond. This $\alpha$-regioselectivity decreases upon substitution with an electron-donating group (e.g., $\mathrm{R}=4$ $\mathrm{OBn})$. However, under identical reaction conditions, switching the electron-donating group from the para to the ortho position affords exclusively the $\alpha$-branched styrylstannanes wherein the tin moiety is delivered to the carbon proximal to the ortho-substituted aryl nucleus. This ortho-directing effect $(\mathrm{ODE})^{61,62}$ is general for various terminal 2-substituted arylalkynes regardless of the electronic nature of the ortho-substituent or its cordinating effect because this trend is followed for simple alkyl substituents as well (e.g., $\mathrm{R}=2-\mathrm{Me})$.

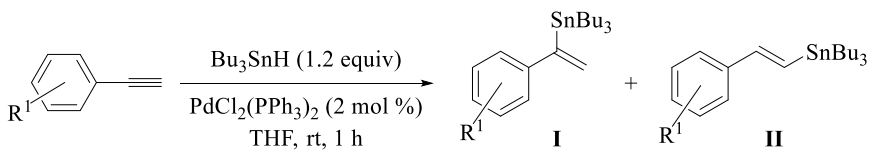

\begin{tabular}{lcc}
$\mathrm{R}^{1}$ & Yield (\%) I + II & I:II \\
\hline $4-\mathrm{CO}_{2} \mathrm{Me}$ & $(86)$ & $85: 15$ \\
$4-\mathrm{CN}$ & $(78)$ & $93: 7$ \\
$4-\mathrm{CHO}$ & $(95)$ & $100: 0$ \\
$4-\mathrm{OBn}$ & $(77)$ & $61: 39$ \\
$2-\mathrm{OBn}$ & $(65)$ & $100: 0$ \\
$2-\mathrm{OMe}$ & $(65)$ & $100: 0$ \\
$2-\mathrm{CH}_{2} \mathrm{OH}$ & $(64)$ & $100: 0$ \\
$2-\mathrm{Me}$ & $(76)$ & $100: 0$ \\
$2-\mathrm{Br}$ & $(93)$ & $100: 0$ \\
$2-\mathrm{CO}_{2} \mathrm{Me}$ & $(87)$ & $100: 0$ \\
$2-\mathrm{CN}$ & $(73)$ & $100: 0$
\end{tabular}

Scheme 25. Pd-catalyzed hydrostannation of substituted terminal arylalkynesand ortho-directing effect (ODE).

Furthermore, exclusive $\alpha$-regioselectivity is also observed with sterically congested ortho,ortho'-disubstituted terminal aryl alkynes (Scheme 26). ${ }^{63}$

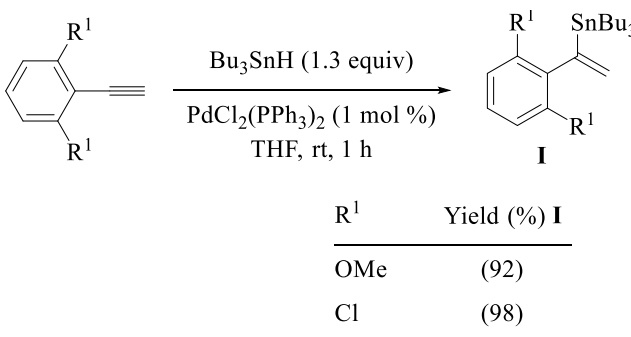

Scheme 26. Pd-catalyzed hydrostannation of ortho,ortho'disubstituted terminal aryl alkynes.

Hydrostannation of heteroaromatic alkynes is poorly documented with only the $\alpha$-stannylcupration of 2-ethynylpyridine in the presence of water, $\left(\mathrm{SnMe}_{3}\right)_{2}, \mathrm{PtBu}_{3}$ and $\mathrm{Cu}(\mathrm{OAc})_{2}{ }^{64}$ During the synthesis of Scalaridine A, a symmetrical bis-indole isolated from the marine sponge Scalarispongia sp., ${ }^{65}$ it was reported that hydrostannation of 3,5-diethynylpyridine ${ }^{66}$ was achieved under Pd-catalysis with a total $\alpha$-selectivity (Scheme 27).
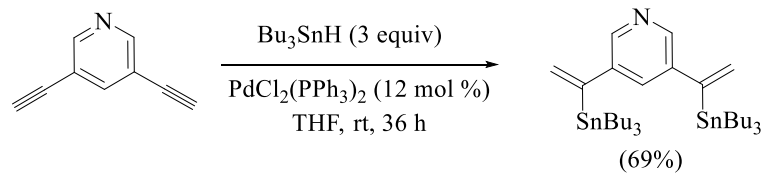

Scheme 27. Pd-catalyzed hydrostannation of 2-ethynylpyridine.

\subsubsection{Enynes.}

With respect to $\alpha$-selectivity, the result obtained with 2-methylsubstituted phenylacetylene (Scheme 25) is related to those reported with terminal conjugated enynes $\mathbf{4 0}$ and $\mathbf{4 3}$ (Schemes 28 and 29). The Pd-catalyzed hydrostannation of hindered $Z$-enynes 40 is highly regioselective for the $\alpha$-isomers $41 \mathbf{a}, \mathbf{b}$ even when the alkene substituent is non-chelating (Scheme 28). However, an extra stabilizing interaction between the oxygen atom and the palladium center cannot be disregarded as a rationale for the $\alpha$ -<smiles>[R]C1OC(=O)OC12CCC(C)=C(C)C2=C</smiles>

40

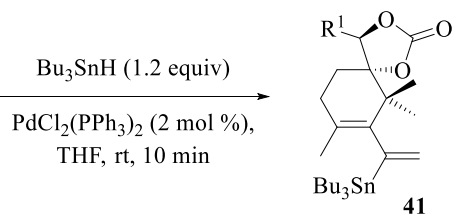

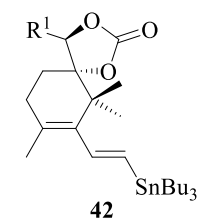

\begin{tabular}{llcc} 
Product & $\mathrm{R}^{1}$ & Yield (\%) 41 & $\mathbf{4 1 : 4 2}$ \\
\hline 41a & $\mathrm{Me}$ & $(80)$ & $100: 0$ \\
42b & $2-\mathrm{CHOC}_{6} \mathrm{H}_{4}$ & $(65)$ & $100: 0$
\end{tabular}

Scheme 28. Pd-catalyzed hydrostannation of enyne $\mathbf{4 0 .}$<smiles>[18OH]</smiles><smiles>C#CC(C)=CCO</smiles>
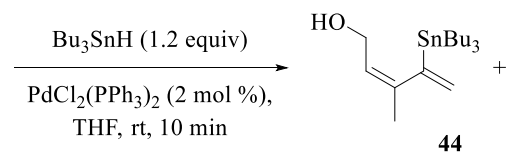

44

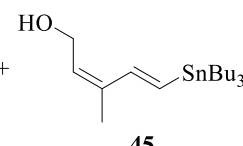

$(54 \%) 44: 45=88: 12$

Scheme 29. Pd-catalyzed hydrostannation of enyne 43.

regioselectivity $(\mathbf{4 4 : 4 5}=88: 12)$ obtained with Z-enyne $\mathbf{4 3}$. (Scheme 29). The corresponding $E$-isomer produces the $\beta$ constitutional isomer as the major product. Altogether, the results shown in Schemes 25, 26, 29 clearly highlight how the presence of conjugated olefins influence the regioselectivity of alkyne hydrostannation

\subsubsection{Diynes.}

Although very few examples of diyne hydrostannylation have been reported, some basic information on steric and electronic effects is apparent. Unsymmetrical terminal diyne 46 reacts 
specifically at the terminal triple bond to give the $\alpha$-addition product 47 chemo- and regioselectively (Scheme 30$).{ }^{23}$ Even when including additional equivalents of tributyltin hydride, no further hydrostannation of the remaining alkyne is observed, presumably because of steric considerations. From these results it seems that the presence of a second acetylenic group can exert a directing effect on the hydrostannation selectivity.

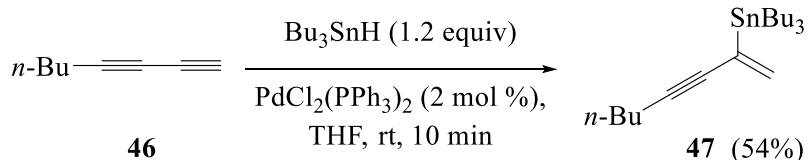

Scheme 30. Pd-catalyzed hydrostannation of conjugated diyne 46.

The hydrostannation of 1,6-diynes provides additional support for this hypothesis (Scheme 31). ${ }^{24}$ These substrates react with $\mathrm{Bu}_{3} \mathrm{SnH}$ in the presence of $\mathrm{Pd}(\mathrm{OH})_{2} / \mathrm{C}$ through a hydrostannation/cyclization sequence to furnish 1,2bis(methylene)cyclopentanes containing a tributylstannyl moiety. The authors rationalize their findings by invoking the plausible formation of a chelate (see Scheme 6) between the palladium center and both alkyne groups prior to the cyclization. This hypothesis is supported by experiments conducted in the presence of strongly coordinating phosphine ligands, which preclude any cyclization from occurring.

\subsubsection{Alkynes with electron-withdrawing substituents.}

In early reports $23,56,68$ on the hydrostannation of conjugated alkynoic esters ${ }^{67}$ and alkynones, both substrates react with clean, predictable regioselectivity. The overall preference for the formation of $\alpha$-isomers is consistent with a mechanism wherein tributyltin hydride formally acts as a hydride donor. With alkynoic esters bearing a methoxycarbonyl group, the tributyltin hydride addition across the $\mathrm{C} \equiv \mathrm{C}$ triple bond provides exclusively the $\alpha$ isomer.

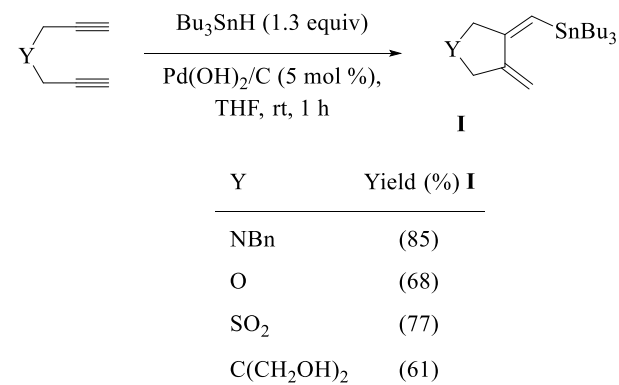

Scheme 31. Pd-catalyzed hydrostannation of unconjugated diynes.

Conjugated alkynones ${ }^{23,68}$ also exhibit good to excellent regioselectivity for the formation of the $\alpha$-isomer, but the level of selectivity seems to depend on the nature of the tin hydride employed. The reaction with $\mathrm{Bu}_{3} \mathrm{SnH}^{23}$ provided a 82:18 mixture of $\alpha$ - and $\beta$ - $(E)$-isomers whereas the use of $\mathrm{Me}_{3} \mathrm{SnH}^{68}$ furnishes exclusively the $\alpha$-isomer (Scheme 32). Although the reaction with $\mathrm{Me}_{3} \mathrm{SnD}$ is also regioselective, it is not stereoselective and provides a 1:1 mixture of $\alpha-(Z)$ and $\alpha-(E)$-isomers. ${ }^{69}$ Of note is the chemical fragility of $\alpha$-tributylstannyl conjugated enones during purification, leading to protodestannylation products. It is best to use such products without delay following the hydrostannation step.

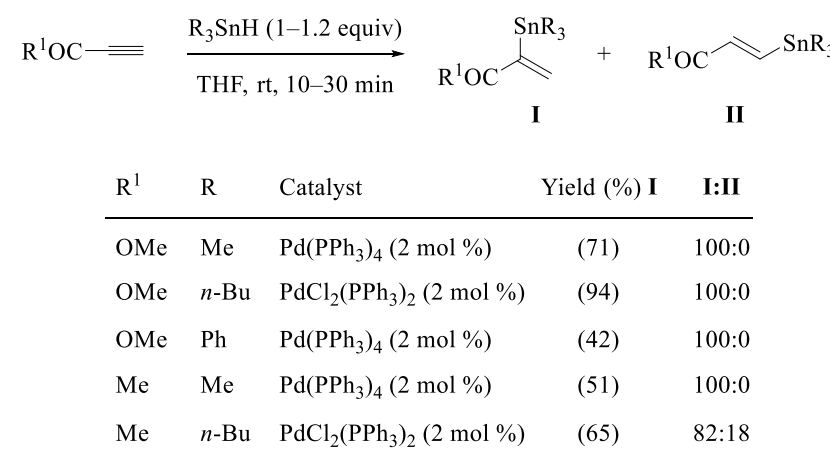

Scheme 32. Pd-catalyzed hydrostannation of conjugated alkynones.

\subsubsection{Alpha-hetero substituted alkynes.}

The presence of a heteroatom directly attached to the $\mathrm{C} \equiv \mathrm{C}$ triple bond should induce electronic perturbations of the alkyne and therefore should impact the hydrostannation selectivity. Only a few examples have been published concerning the palladiumcatalyzed hydrostannation of heterosubstituted terminal acetylenic compounds. No doubt one reason for the paucity of data is the comparative instability of 1-(dialkylamino)-1-alkynes and 1alkoxy-1-alkynes, making them difficult compounds to handle and prepare.

The palladium-catalyzed hydrostannation of ethoxyethyne is not regioselective $\mathrm{e}^{70}$ and produces $\alpha$ - and $\beta-(E)$-isomers in a 58:42 ratio (Scheme 33). ${ }^{23}$ In contrast to 1-(dialkylamino)-1-alkynes, ynamides are more stable substrates and their reactivity has been reported. The reaction of $N$-benzyl- $N$-benzoylaminoacetylene with $\mathrm{Bu}_{3} \mathrm{SnH}$ gives an 85:15 mixture in which the $\alpha$-isomer predominates. ${ }^{71}$ The pure $\alpha$-isomer can be easily obtained by column chromatography on silica gel. The same authors ${ }^{72}$ later found that the use of oxazolidino ynamides (Scheme 33) also furnish the $\alpha$-stannylated enamide but with a slightly diminished selectivity (70:30). Interestingly, the replacement of the nitrogen or oxygen atom on the triple bond with a sulfur atom has a profound effect on the selectivity. Thus, the hydrostannation works well with 1-phenylthioacetylene, leading to complete regioselectivity in favor of the $\alpha$-stannylated product (Scheme 29). ${ }^{73}$ It seems that the phenylthio moiety acts as an electronwithdrawing group ${ }^{21}$ and polarizes the alkyne in a sense opposite to that observed with alkoxyalkynes or ynamides. Of note, the hydrostannation of alkynes with silicon substituents [e.g., (trimethylsilyl)acetylene] does not proceed with tributyltin hydride in the presence of a palladium catalyst. ${ }^{23}$

\begin{tabular}{|c|c|c|c|c|}
\hline \multirow[b]{3}{*}{$\mathrm{R}^{1}$} & $\mathrm{Bu}_{3} \mathrm{SnH}(1.05-1.2$ equiv) & $\mathrm{SnBu}_{3}$ & $\mathrm{R}^{1} \mathrm{SnBu}$ & \\
\hline & \multirow[t]{2}{*}{$\begin{array}{c}\mathrm{THF}, \text { or } \mathrm{C}_{6} \mathrm{H}_{6}, \\
10 \mathrm{~min}-3 \mathrm{~h}\end{array}$} & $\begin{array}{l}\mathrm{R}^{1} \\
\quad\end{array}$ & \multicolumn{2}{|l|}{ K } \\
\hline & & Temperature & Yield (\%) I & I:II \\
\hline OEt & $\mathrm{PdCl}_{2}\left(\mathrm{PPh}_{3}\right)_{2}(2 \mathrm{~mol} \%)$ & $\mathrm{rt}$ & $(-)$ & $58: 42$ \\
\hline $\mathrm{NBnCOPh}$ & $\mathrm{Pd}\left(\mathrm{PPh}_{3}\right)_{4}(5 \mathrm{~mol} \%)$ & $50^{\circ} \mathrm{C}$ & $(80)$ & $85: 15$ \\
\hline O & $\mathrm{Pd}\left(\mathrm{PPh}_{3}\right)_{4}(5 \mathrm{~mol} \%)$ & $50^{\circ} \mathrm{C}$ & $(55)$ & $70: 30$ \\
\hline $\mathrm{SPh}$ & $\mathrm{Pd}\left(\mathrm{PPh}_{3}\right)_{4}(1 \mathrm{~mol} \%)$ & $\mathrm{rt}$ & $(87)$ & $100: 0$ \\
\hline
\end{tabular}

Scheme 33. Pd-catalyzed hydrostannation of terminal alkynes linked to a $\mathrm{N}$ or O-atom.

\subsubsection{Internal alkynes.}

\subsubsection{Aliphatic alkynes.}

Hydrostannations of dialkylalkynes have proven less satisfactory than terminal aliphatic alkynes owing to diminished reactivity and 
low regioselectivity. However, the presence of propargylic heteroatom substitution enhances the reactivity. Reaction with internal propargyl alcohols and ethers leads to more useful results with respect to $\alpha / \beta$-regioselectivity than do simple dialkylalkynes. The selectivity is influenced by the relative size of proximal substituents, although some results suggest that neighboring hydroxyl groups might have a directing effect.

With respect to steric bulk at the propargylic position, the results shown in Scheme 34 clearly illustrate how the selectivity is influenced by the steric differentiation of the two alkyne substituents. With primary propargyl alcohols (e.g., but-2-yn-1ol), two constitutional isomers are obtained in fair yield (58\%) and a 25:75 ratio. ${ }^{58}$ Upon increasing steric bulk of the substituent at $\mathrm{C} \beta$, the reaction gives high selectivity for the $\alpha$-alkenylstannanes. Thus, the sec-butyl-substituted propargylic alcohol gives rise to a single $\alpha$-adduct (>95:5) in $75 \%$ yield. ${ }^{74}$ Switching to propargylic secondary alcohols, a different selectivity in favor of the $\beta$ constitutional isomers is observed and this $\beta$-regioselectivity increases with increasing steric bulk of the substituent at $\mathrm{C} \alpha{ }^{75}$

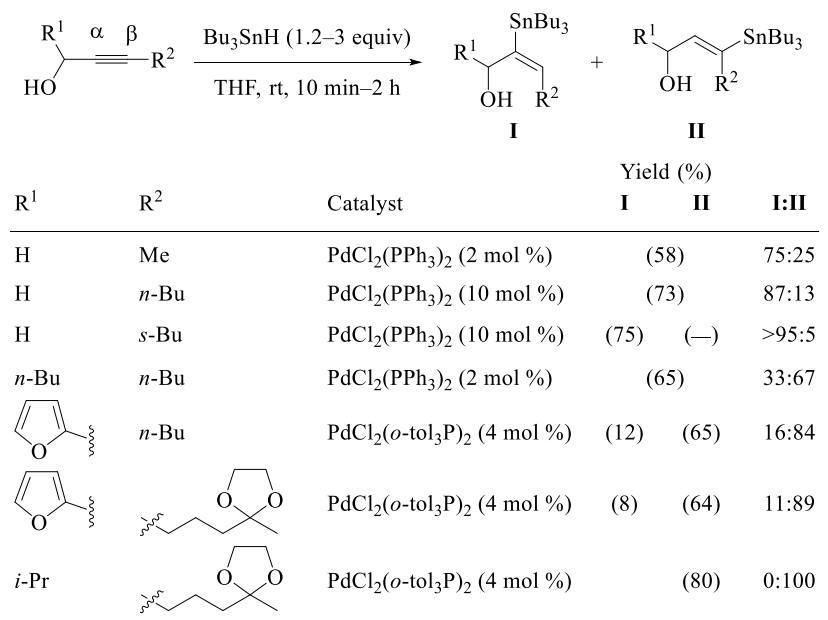

Scheme 34. Pd-catalyzed hydrostannation of internal propargylic alkynes.

With diol-containing alkyne substrates, a propargylic primary alcohol more effectively directs regioselectively than a secondary alcohol function (Scheme 35) ${ }^{74}$ Better selectivities are obtained in analogous hydrostannation reactions of the methyl- or silyl ether compounds. The general trend in Scheme 35 is best explained by a steric effect stemming from the substituent at the $\mathrm{C} \alpha$ position reinforced by a cooperative $\mathrm{OH}$-directing effect.

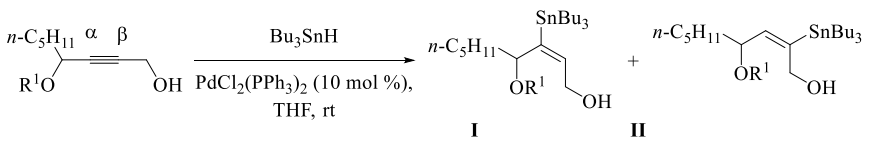

$$
\begin{aligned}
& \begin{array}{lcc}
\mathrm{R}^{1} & \text { Yield (\%) I + II } & \text { I:II } \\
\hline \mathrm{H} & (71) & 26: 74 \\
\mathrm{Me} & (66) & 14: 86 \\
\text { TBS } & (69) & >5: 95
\end{array}
\end{aligned}
$$

Scheme 35. Pd-catalyzed hydrostannation of functionalized propargylic alcohols.

In the case of highly hindered propargylic substrates the hydrostannation is slow, but the regioselectivity is high. A single product is formed in which the tributyltin moiety is delivered to the less sterically demanding $C \beta$ position (Scheme 36). The replacement of polar solvents (e.g., THF, $\left.\mathrm{Et}_{2} \mathrm{O}\right)$ by a hydrocarbon solvent (e.g., hexanes), together with the use of $\mathrm{Pd}(\mathrm{OAc})_{2}$ or $\operatorname{Pd}(\mathrm{TFA})_{2}$ in combination with the bulky tricyclohexylphosphine, greatly enhances the hydrostannation efficacy (Scheme 36) ${ }^{76}$
Internal alkynes bearing sterically demanding substituents, such as a cyclohexyl group, undergo hydrostannation at reduced rates even when using large amounts $(30 \mathrm{~mol} \%)$ of $\mathrm{Pd}(\mathrm{TFA})_{2} / \mathrm{Cy}_{3} \mathrm{P}$, which has been shown to be as effective as $\mathrm{Pd}(\mathrm{OAc})_{2}$

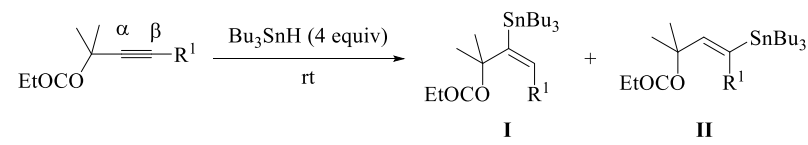

$\begin{array}{llllcc}\mathrm{R}^{1} & \text { Solvent } & \text { Time }(\mathrm{h}) & \text { Catalyst } & \text { Yield (\%) I } & \text { I:II } \\ \mathrm{Me} & \mathrm{THF} & 18 & \mathrm{PdCl}_{2}\left(\mathrm{PPh}_{3}\right)_{2}(5 \mathrm{~mol} \%) & (35) & 0: 100 \\ \mathrm{Me} & \text { hexanes } & 24 & \mathrm{Pd}(\mathrm{OAc})_{2}(5 \mathrm{~mol} \%), \mathrm{Cy}_{3} \mathrm{P}(10 \mathrm{~mol} \%) & (91) & 0: 100 \\ \mathrm{Et} & \text { hexanes } & 3 & \mathrm{Pd}(\mathrm{OAc})_{2}(10 \mathrm{~mol} \%), \mathrm{Cy}_{3} \mathrm{P}(20 \mathrm{~mol} \%) & (86) & 0: 100 \\ \text { cyclohexyl } & \text { hexanes } & 24 & \mathrm{Pd}(\mathrm{TFA})_{2}(30 \mathrm{~mol} \%), \mathrm{Cy}_{3} \mathrm{P}(60 \mathrm{~mol} \%) & (35) & 0: 100\end{array}$

Scheme 36. Pd-catalyzed hydrostannation of internal propargylic esters.

\subsubsection{Aliphatic aromatic alkynes.}

In contrast to dialkylalkynes, the palladium-catalyzed hydrostannation of aromatic alkylalkynes, ${ }^{23,62,77}$ is much easier to achieve and does not require the presence of propargylic heteroatoms for reactivity. In addition, the reaction is completely regioselective delivering a single product ( $\alpha$-isomer) suggesting that aromatic rings are excellent directing groups probably for electronic reasons. For example, 1-phenyl-1-heptyne ${ }^{62}$ or 1-4'methoxyphenyl-1 pentyne ${ }^{78}$ are excellent substrates, giving a single product ( $\alpha$-isomer) in good yields (Scheme 37). However, this regioselectivity decreases in the case of 1-phenyl-1-propyn-3-ol $(\alpha / \beta=80 / 20)$, indicating a probable directing effect of the $\mathrm{CH}_{2} \mathrm{OH}$ substituent (Scheme 37). Substituents on the aromatic ring have interesting effects on reaction selectivity. Although meta and para substituents have only a minor influence on regioselectivity, ortho substituents, including non-chelating alkyl substituents (e.g., Me, $i$-Pr), lead to extremely high selectivity for the same $\alpha-(E)$ alkenylstannanes, clearly indicating that coordinating factors are not the cause of this remarkable regioselectivity. This orthodirecting effect (ODE) is general with several other substituted arylalkynes. Highly hindered alkyl groups $\left(e . g ., \mathrm{R}^{1}=2-i\right.$-Pr $)$ affect the $\alpha / \beta$-distribution and enhance the $\alpha$-regioselectivity, thus providing a single adduct in $66 \%$ yield.

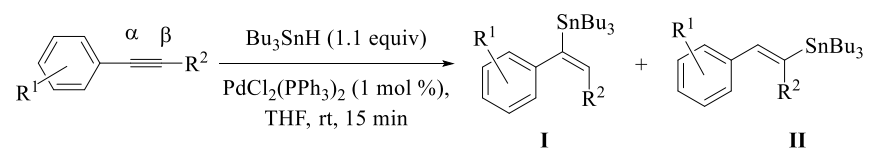

\begin{tabular}{|c|c|c|c|c|}
\hline $\mathrm{R}^{1}$ & $\mathrm{R}^{2}$ & Yield (\%) I & Yield (\%) II & I:II \\
\hline $\mathrm{H}$ & $n-\mathrm{C}_{5} \mathrm{H}_{11}$ & (89) & & 100:0 \\
\hline 4-OMe & $n-\mathrm{C}_{3} \mathrm{H}_{7}$ & (75) & & $100: 0$ \\
\hline $\mathrm{H}$ & $\mathrm{CH}_{2} \mathrm{OH}$ & (69) & (19) & $80: 20$ \\
\hline 4-OMe & $\mathrm{CH}_{2} \mathrm{OH}$ & (65) & (20) & $76: 24$ \\
\hline 4-Me & $\mathrm{CH}_{2} \mathrm{OH}$ & (64) & (19) & $77: 23$ \\
\hline 3-Me & $\mathrm{CH}_{2} \mathrm{OH}$ & (59) & (11) & $84: 16$ \\
\hline 2-Me & $\mathrm{CH}_{2} \mathrm{OH}$ & (92) & (5) & $95: 5$ \\
\hline $2-i-\operatorname{Pr}$ & $\mathrm{CH}_{2} \mathrm{OH}$ & (66) & & $100: 0$ \\
\hline 2- $\mathrm{CH}_{2} \mathrm{OMe}$ & $\mathrm{CH}_{2} \mathrm{OH}$ & (51) & & $100: 0$ \\
\hline $2-\mathrm{Cl}$ & $\mathrm{CH}_{2} \mathrm{OH}$ & (76) & & $100: 0$ \\
\hline 2-Br & $\mathrm{CH}_{2} \mathrm{OH}$ & (88) & & $100: 0$ \\
\hline $2-\mathrm{Br}$ & $\mathrm{CH}_{2} \mathrm{CH}_{2} \mathrm{OH}$ & (86) & & $100: 0$ \\
\hline 2-OMe & $\mathrm{CH}_{2} \mathrm{NMe}_{2}$ & (66) & & $100: 0$ \\
\hline 2-OMe & $\mathrm{CH}(\mathrm{Me}) \mathrm{OH}$ & (97) & & $100: 0$ \\
\hline $2-\mathrm{Br}$ & $\mathrm{C}(\mathrm{Me})_{2} \mathrm{OH}$ & (96) & & $100: 0$ \\
\hline
\end{tabular}

Scheme 37. Pd-catalyzed hydrostannation of substituted arylalkynes. 
This effect is further illustrated in the hydrostannation of sterically congested arylalkyne 48 having ortho/ortho' methyl substituents (Scheme 38). ${ }^{62}$ This result clearly highlights the role of steric hindrance in directing the exclusive $\alpha$-addition of the $\mathrm{Bu}_{3} \mathrm{Sn}$ group to the more hindered alkyne carbon atom $(\mathrm{C} \alpha)$.
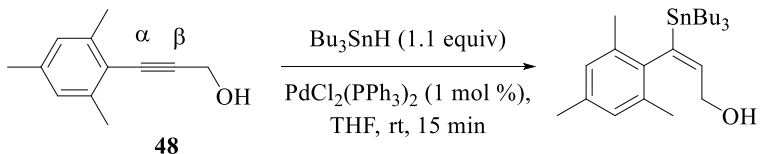

Scheme 38. Pd-catalyzed hydrostannation of 48 .

\subsubsection{Aromatic and heteroaromatic alkynes.}

Hydrostannation of alkynes with two different aromatic (or heteroaromatic) rings has received less attention than aliphatic aromatic alkynes probably because of the difficulties in controlling the regioselectivity of the tin hydride addition. In the case of substrates having a single electron-withdrawing group in the para position of one ring, electronic effects prevail, and the palladiumcatalyzed hydrostannation formally proceeds by conjugate addition of the hydride providing the $\alpha$-isomers (Scheme 38). ${ }^{27}$ This regioselectivity decreases upon substitution with an electrondonating group. However, it is established that the presence of an ortho substituent on an aromatic ring on one side of the alkyne dictates the sense of regioselectivity. The hydrostannation provides high selectivity for a single $\alpha$-isomer, regardless of the electronic nature, coordinating ability or steric hindrance of the ortho substituent (Scheme 39). ${ }^{27,63}$

The hydrostannation of highly hindered alkynes having ortho/ortho' substituents provides additional support for this hypothesis. Thus, this ortho-directing effect has been successfully extended to control the regioselectivity of ortho/ortho' diarylalkynes 49 leading to a single constitutional isomer (Scheme 40). ${ }^{63,79}$ The regiocontrolled synthesis of alkenylstannane products has been applied to subsequent cross-coupling chemistry to provide selective access to diaryl- and triaryl-substituted olefins. ${ }^{79}$

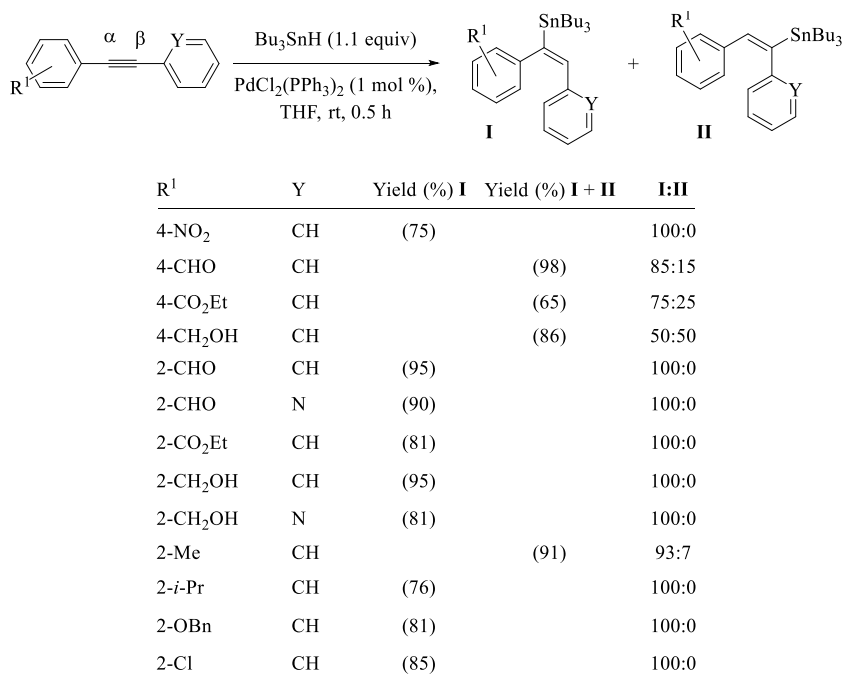

Scheme 39. Pd-catalyzed hydrostannation of substituted diarylalkynes.

Although the origin of this unique ortho directing effect is not immediately clear, it was observed that ortho substituents, regardless of their electronic properties, induce chemical shift perturbations of the ethyne carbon atoms. The ${ }^{13} \mathrm{C}$ NMR signal of the $\alpha$-sp-carbon appears at higher field relative to the $\beta$-carbon for all ortho-substituted diarylalkynes. ${ }^{27,81}$ In addition, DFT calculations $^{81}$ and theoretical NBO (Natural Bond Orbital) /NCS

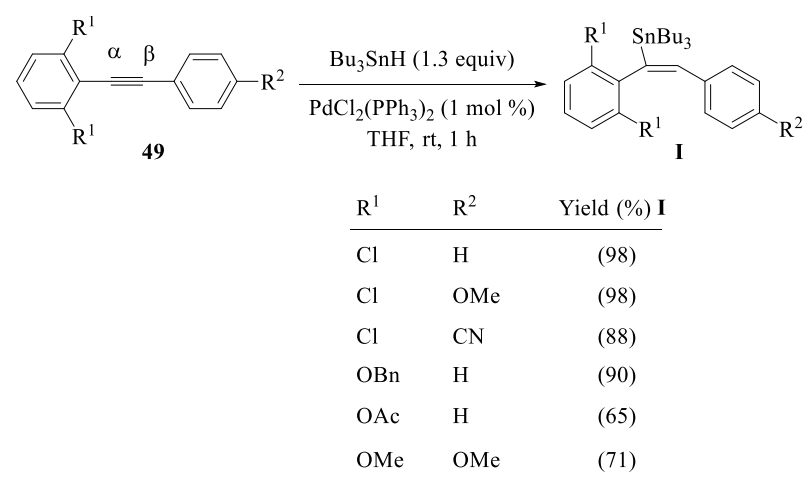

Scheme 40. ortho-Directing effects (ODE) in tolans.

(Natural Chemical Shielding) studies ${ }^{82}$ reveal that the selectivities obtained are not a result of the magnetic anisotropic effects due to the ortho substituent, but rather, are the result of structural perturbations of the ethyne carbon atoms induced by steric strain.

\subsubsection{1,3-Conjugated alkynes.}

Trost et al. ${ }^{83}$ first reported the hydrostannation of internal 1,3enynes. To achieve high regiochemical control, enyne substrates require the presence of an activating group (e.g., COOR) on the carbon-carbon double bond in a manner analogous to that observed with alkynyl esters (Scheme 41).

$$
\begin{gathered}
\begin{array}{c}
\mathrm{Pd}_{2}(\mathrm{dba})_{3}(2.5 \mathrm{~mol} \%), \\
\mathrm{Ph}_{3} \mathrm{P}(20 \mathrm{~mol} \%), \\
\mathrm{C}_{6} \mathrm{H}_{6}, \mathrm{rt}, 0.5 \mathrm{~h}
\end{array} \\
\frac{\mathrm{R}^{1}}{\mathrm{CH}_{2} \mathrm{OH}} \\
\mathrm{CH}_{2} \mathrm{OTBDMS} \\
n \text { - } \mathrm{Pr} \\
\left(\mathrm{CH}_{2}\right)_{3} \mathrm{CHO}
\end{gathered}
$$

Scheme 41. Pd-catalyzed hydrostannation of electron-poor internal enynes.

Inverting ester and alkyl groups on the double bond of enynes had no influence on the $\alpha$-regioselectivity as (1E,3E)-2ethoxycarbonyl-3-tributylstannyl-substituted 1,3 dienes were obtained as single isomers (Scheme 42) ${ }^{84}$

$$
\stackrel{\mathrm{EtO}_{2} \mathrm{C}}{\stackrel{\alpha \beta}{=} \mathrm{R}^{2} \frac{\mathrm{Bu}_{3} \mathrm{SnH}(1.1 \text { equiv })}{\begin{array}{c}
\mathrm{Pd}\left(\mathrm{PPh}_{3}\right)_{4}(2 \mathrm{~mol} \%), \\
\mathrm{THF}, \mathrm{rt}, 4 \mathrm{~h}
\end{array}}}
$$

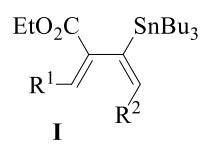

\begin{tabular}{llc}
$\mathrm{R}^{1}$ & $\mathrm{R}^{2}$ & Yield (\%) I \\
\hline$n-\mathrm{Bu}$ & $\mathrm{CH}_{2} \mathrm{OEt}$ & $(81)$ \\
$n-\mathrm{Bu}$ & cyclopropyl & $(73)$ \\
$\mathrm{Ph}$ & $\mathrm{CH}_{2} \mathrm{OEt}$ & $(79)$ \\
$\mathrm{Ph}$ & cyclopropyl & $(78)$ \\
$\mathrm{Ph}$ & $n-\mathrm{C}_{6} \mathrm{H}_{13}$ & $(82)$ \\
$\mathrm{Ph}$ & $\mathrm{Ph}$ & $(79)$
\end{tabular}

Scheme 42. Pd-catalyzed hydrostannation of internal enynes.

A similar trend in $\alpha$-regioselectivity was obtained with conjugated enynes bearing a sulfonyl substituent on the double bond, affording 1-sulfonyl-3-tributylstannyl-substituted 1,3-dienes. ${ }^{85}$ 
Other conjugated enynes also function well in regioselective hydrostannations. In an initial study of chloroenynes as building blocks for the synthesis of enediyne natural products such as neocarzinostatin, it was found that the regioselectivity favoring the $\alpha$-constitutional isomer is dependent on the alkyne substituent for $E$-chloroalkynes, whereas the Z-chloro isomers exhibited uniformly complete $\alpha$-stannane selectivity regardless of the nature of the R substituent (Scheme 43). ${ }^{86}$

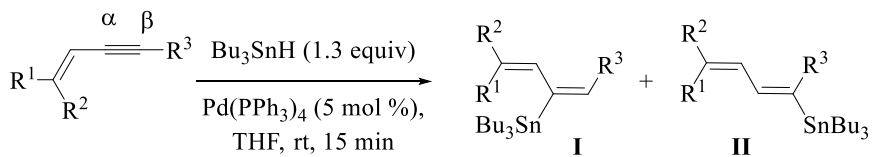

\begin{tabular}{cllccc}
$\mathrm{R}^{1}$ & $\mathrm{R}^{2}$ & $\mathrm{R}^{3}$ & Yield (\%) $\mathbf{I}$ & Yield (\%) II & I:II \\
\hline $\mathrm{Cl}$ & $\mathrm{H}$ & $\mathrm{CH}_{2} \mathrm{OH}$ & $(62)$ & $(19)$ & $77: 23$ \\
$\mathrm{Cl}$ & $\mathrm{H}$ & $\left(\mathrm{CH}_{2}\right)_{2} \mathrm{OH}$ & $(70)$ & $(16)$ & $81: 19$ \\
$\mathrm{Cl}$ & $\mathrm{H}$ & $n-\mathrm{C}_{5} \mathrm{H}_{11}$ & $(86)$ & & $100: 0$ \\
$\mathrm{H}$ & $\mathrm{Cl}$ & $\mathrm{CH}_{2} \mathrm{OH}$ & $(92)$ & & $100: 0$ \\
$\mathrm{H}$ & $\mathrm{Cl}$ & $\left(\mathrm{CH}_{2}\right)_{2} \mathrm{OH}$ & $(85)$ & & $100: 0$ \\
$\mathrm{H}$ & $\mathrm{Cl}$ & $n-\mathrm{C}_{5} \mathrm{H}_{11}$ & $(91)$ & & $100: 0$ \\
$\mathrm{H}$ & $\mathrm{Cl}$ & $\mathrm{C}_{6} \mathrm{H}_{5}$ & $(93)$ & & $100: 0$
\end{tabular}

Scheme 43. Pd-catalyzed hydrostannation of $(E)$ and $(Z)$ enynes and the origin of the (Z)-directing effect (ZDE).

Replacement of the chlorine atom of the enyne with an alkyl group ${ }^{86}$ gives the same trend with $Z$-enyne substrates high $\alpha$ selectivity and $E$-enynes producing mixtures of products. ${ }^{87}$ Remarkably, this regiocontrol has been successfully extended to a wide range of enynes, ${ }^{57,86,87}$ including those having a tri- or tetrasubstituted double bond. These results clearly suggest that the regioselectivity of $\mathrm{H}-\mathrm{Sn}$ bond addition to enynes is controlled by the geometry of the double bond, the so-called Z-directing effect (ZDE) rather than the electronic, steric, or chelating properties of the substituents ${ }^{87}$ (Scheme 44). Although the exact origin of this ZDE remains unclear, the factors governing this regioselectivity would be close to those observed in the hydrostannation of orthosubstituted arylalkynes (ODE). In a similar manner, it was observed that switching from the $E$ - to Z-enyne isomers induced chemical shift perturbations $\left({ }^{13} \mathrm{C} \mathrm{NMR}\right)$ of the ethyne carbon atoms, thus increasing the difference in the chemical shift of the resonances (a steric compression shift) arising from the $\Delta \delta \mathrm{C} \alpha-$ $\mathrm{C} \beta$ atom from 5.0 to $7.9 \mathrm{ppm} .{ }^{87}$ In sum, this study shows that it is possible to predict the major (or exclusive) $\alpha$-isomer formation when a substituent (regardless of its nature) and the alkyne are on the same side of the double bond.

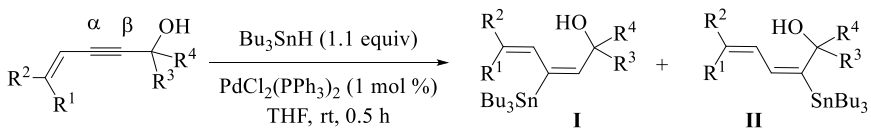

\begin{tabular}{llllccc}
$\mathrm{R}^{1}$ & $\mathrm{R}^{2}$ & $\mathrm{R}^{3}$ & $\mathrm{R}^{4}$ & Yield (\%) I & Yield (\%) II & I:II \\
\hline $\mathrm{H}$ & $n-\mathrm{C}_{4} \mathrm{H}_{9}$ & $\mathrm{H}$ & $\mathrm{H}$ & $(20)$ & $(45)$ & $31: 69$ \\
$\mathrm{H}$ & $c-\mathrm{C}_{6} \mathrm{H}_{11}$ & $\mathrm{H}$ & $\mathrm{H}$ & $(26)$ & $(54)$ & $35: 65$ \\
$\mathrm{H}$ & $c-\mathrm{C}_{6} \mathrm{H}_{11}$ & $\mathrm{H}$ & $\mathrm{Me}$ & $(58)$ & $(32)$ & $65: 35$ \\
$n-\mathrm{C}_{4} \mathrm{H}_{9}$ & $\mathrm{H}$ & $\mathrm{H}$ & $\mathrm{H}$ & $(83)$ & $(-)$ & $91: 9$ \\
$c-\mathrm{C}_{6} \mathrm{H}_{11}$ & $\mathrm{H}$ & $\mathrm{H}$ & $\mathrm{H}$ & $(93)$ & $(-)$ & $96: 4$ \\
$c-\mathrm{C}_{6} \mathrm{H}_{11}$ & $\mathrm{H}$ & $\mathrm{H}$ & $\mathrm{Me}$ & $(91)$ & & $100: 0$ \\
$c-\mathrm{C}_{6} \mathrm{H}_{11}$ & $\mathrm{H}$ & $\mathrm{Me}$ & $\mathrm{Me}$ & $(91)$ & & $100: 0$ \\
$\mathrm{C}_{6} \mathrm{H}_{5}$ & $\mathrm{H}$ & $\mathrm{H}$ & $\mathrm{H}$ & $(50)$ & & $100: 0$
\end{tabular}

Scheme 44. Pd-catalyzed hydrostannation of $(E)$ and $(Z)$ enynols.

In a more direct route to the dienediyne system related to neocarzinostatin, ${ }^{88}$ this $Z$-directing effect has been extended to include various symmetrical enediyne substrates in which the presence of a second triple bond on the $Z$-double bond dictates the sense of the regioselectivity (Scheme 45$).{ }^{89}$ Even on addition of further equivalents of tin hydride, no further hydrostannation of the remaining alkyne is observed, presumably because of steric constraints. Notably, the reaction with the corresponding $E$ isomers furnishes a mixture of $\alpha / \beta$-isomers. With unsymmetrical silyl-enediynes, the two triple bonds exhibit appreciably different reactivities toward $\mathrm{Bu}_{3} \mathrm{SnH}$. Chemo- and regioselective hydrostannation furnishes exclusively the $\alpha$-addition product (Scheme 45).

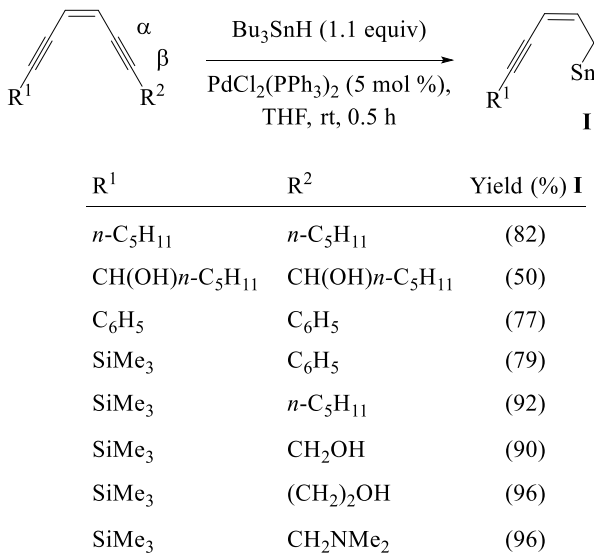

Scheme 45. Pd-catalyzed hydrostannation of $(Z)$-enediynes.

Among other conjugated alkynes studied, 1,3-diynes are also suitable substrates for chemo- and regioselective hydrostannation. ${ }^{23}$

The presence of a second alkyne group seems to exert a directing effect on the reaction selectivity (Scheme 46). In the case of silyl1,3-diyne derivatives, the TMS group block the hydrostannation as discussed previously.

$$
\begin{aligned}
& \mathrm{R}^{1}=\mathrm{R}^{2} \frac{\mathrm{Bu}_{3} \operatorname{SnH}(1.2 \text { equiv })}{\underset{\mathrm{PdCl}}{\mathrm{PdF}_{2}\left(\mathrm{PPh}_{3}\right)_{2}(2 \mathrm{~mol} \%), 10 \mathrm{~min}}} \\
& \begin{array}{llc}
\mathrm{R}^{1} & \mathrm{R}^{2} & \text { Yield (\%) I } \\
\hline n-\mathrm{C}_{4} \mathrm{H}_{9} & n-\mathrm{C}_{4} \mathrm{H}_{9} & (78) \\
\mathrm{SiMe}_{3} & n-\mathrm{C}_{6} \mathrm{H}_{13} & (86)
\end{array}
\end{aligned}
$$

Scheme 46. Pd-catalyzed hydrostannation of conjugated internal diynes.

\subsubsection{Alkynes with electron-withdrawing substituents.}

Conjugated internal alkynes are a generally reliable substrate class under palladium catalysis and their hydrostannation shows good regioselectivity for the $\alpha$-addition product (Scheme 43). A number of groups have studied the hydrostannation of alkynyl esters. ${ }^{23,90-}$ ${ }^{95}$ As shown in the following representative examples, electronic effects prevail in controlling the hydrostannation regioselectivity, and steric considerations play a lesser role (Scheme 47). ${ }^{90}$ In contrast to alkynyl esters, alkynyl ketones are more challenging substrates for selective hydrostannation because of unwanted protodestannylation. This problem has been addressed by the use of the more hindered trineophyltin hydride, which circumvents many of the protodestannylation and isomerization problems that plague reactions with tributyl- and trimethyltin analogues (Scheme 47)..$^{57,96}$ 


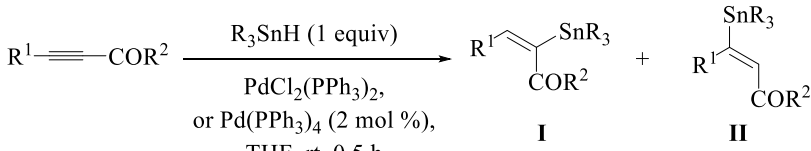

$$
\begin{aligned}
& \begin{array}{lllcc}
\mathrm{R}^{1} & \mathrm{R}^{2} & \mathrm{R} & \text { Yield (\%) } \mathbf{I} & \text { I:II } \\
\hline n-\mathrm{C}_{5} \mathrm{H}_{11} & \text { OMe } & n \text {-Bu } & (85) & 92: 8
\end{array} \\
& s \text {-Bu OEt } n \text {-Bu } \quad \text { (93) } \\
& \mathrm{TBSOCH}_{2} \text { OEt } n \text {-Bu } \quad \text { (84) } \\
& \mathrm{Ph} \quad \mathrm{OEt} \quad n \text {-Bu } \quad 90: 10 \\
& n \text { - } \mathrm{Bu} \quad \mathrm{Me} \quad \mathrm{PhMe}_{2} \mathrm{CCH}_{2} \quad \text { (90) 100:0 } \\
& \begin{array}{llll}
\mathrm{Me} & \mathrm{Ph} & \mathrm{PhMe}_{2} \mathrm{CCH}_{2} & \text { (80) }
\end{array} \\
& \begin{array}{llll}
\mathrm{Ph} & \mathrm{Ph} & \mathrm{PhMe}_{2} \mathrm{CCH}_{2} & \text { (88) }
\end{array}
\end{aligned}
$$

Scheme 47. Pd-catalyzed hydrostannation of alkynyl ketones.

The first hydrostannation of $\beta-\mathrm{CF}_{3}$-alkynes under Pd-catalysis was recently reported. ${ }^{97} \mathrm{Using} \mathrm{Pd}\left(\mathrm{PPh}_{3}\right)_{4}$, hydrostannation of $\beta-\mathrm{CF}_{3}-$ alkynes led to $(E)$-vinylstannanes with a good to excellent $\beta$ priority (Scheme 48). Experiments achieved at various temperatures revealed that the $\beta$-regioselectivity was enhanced at low temperatures with good yields.

$\mathrm{R}^{1 \stackrel{\alpha \beta}{=}} \mathrm{CF}_{3} \frac{\left.\mathrm{Pd}_{3} \mathrm{PPh}_{3}\right)_{4}(1 \mathrm{~mol} \%)}{\mathrm{THF}, 0{ }^{\circ} \mathrm{C}, 2 \mathrm{~h}} \mathrm{R}^{1} \underset{\mathbf{I}}{\mathrm{SnBu}_{3}}+\mathrm{CF}_{3}{ }_{\mathbf{I I}}^{\mathrm{CF}_{3}}$

$\begin{array}{llll} & \text { Yield (\%) I+II } & \text { I:II } & \\ \mathrm{R}^{1} & (99) & 95: 5 & \\ \mathrm{C}_{10} \mathrm{H}_{21} & (85) & 73: 27^{a} & { }^{a} \text { reaction achieved at } 65^{\circ} \mathrm{C} \\ \mathrm{CH}_{2} \mathrm{CH}(\mathrm{OPMB})(i-\mathrm{Pr}) & (99) & 92: 8 & \\ \mathrm{CH}_{2} \mathrm{CH}(\mathrm{OPMB})(i-\mathrm{Pr}) & (99) & 96: 4^{b} & { }^{b} \text { reaction achieved at }-30{ }^{\circ} \mathrm{C} \text { for } 12 \mathrm{~h}\end{array}$

Scheme 48. Pd-catalyzed hydrostannation of $\beta-\mathrm{CF}_{3}$-alkynes.

\subsubsection{Alpha-hetero and alpha-haloalkynes.}

The palladium-catalyzed hydrostannation reaction of alkynes bearing an electron-deficient heteroatomic group such as sulfonyl $^{98-100}$ or phosphonyl ${ }^{101}$ are also known. Excellent regioselectivity for the $\alpha$-addition of the stannyl group is again observed whatever the nature of the $\mathrm{R}$ substituent (Scheme 49). ${ }^{98,101}$ Hydrostannation of alkynyl sulfones in the ionic liquid [bmim] $\left[\mathrm{PF}_{6}\right]$ gives rise to the $\alpha$-adducts. ${ }^{102}$ The advantages of the ionic liquid compared to typical organic solvents (e.g., THF, $\mathrm{C}_{6} \mathrm{H}_{6}$ ) include increased yields, higher regioselectivities, ease of product isolation, and facile catalyst recycling.

The hydrostannation of chiral alkynyl sulfoxides has also been reported (Scheme 50) ${ }^{103}$ and leads to high levels of $\alpha$ regioselectivity when the reaction is carried out at low temperature $\left(-78{ }^{\circ} \mathrm{C}\right.$ to rt over $\left.3 \mathrm{~h}\right)$. The resulting 1 -stannylalkenyl sulfoxides have been used in subsequent cross-coupling reactions as a selective access to stereodefined 2-sulfinyl diene derivatives. ${ }^{104}$

Other $\alpha$-hetero-substituted alkynes ${ }^{102,105-107}$ are good substrates for regioselective hydrostannations. Phenylthioalkynes, for example, add tin hydrides with high regio- and stereoselectivity, irrespective of steric contributions or chelation abilities of the substituents (Scheme 51) ${ }^{73}$ Interestingly, the triple bond of 1-trimethylsilyl-2-

\begin{tabular}{|c|c|c|}
\hline $\mathrm{R}^{1}$ & $\mathrm{R}^{2}$ & Yield (\%) I \\
\hline$n$-Bu & $\mathrm{SO}_{2} \mathrm{Ph}$ & (90) \\
\hline $\mathrm{MeOCH}_{2}$ & $\mathrm{SO}_{2} \mathrm{Ph}$ & (83) \\
\hline $\mathrm{Ph}$ & $\mathrm{SO}_{2} \mathrm{Ph}$ & (82) \\
\hline$n-\mathrm{Bu}$ & $\mathrm{P}(\mathrm{O})(\mathrm{OEt})_{2}$ & (83) \\
\hline $\mathrm{MeOCH}_{2}$ & $\mathrm{P}(\mathrm{O})(\mathrm{OEt})_{2}$ & (72) \\
\hline $\mathrm{Ph}$ & $\mathrm{P}(\mathrm{O})(\mathrm{OEt})_{2}$ & (87) \\
\hline
\end{tabular}
phenylthioethyne is not deactivated by the presence of silicon, in contrast to the deactivating effect observed in the case of unsymmetrical silyl-enediyne and silyl-diyne derivatives. Similar levels of $\alpha$-regioselectivity are observed in the case of $\alpha$ selenoalkynes (Scheme 51). ${ }^{108}$

$$
\mathrm{R}^{1}=\mathrm{R}^{2} \underset{\begin{array}{c}
\mathrm{Pd}\left(\mathrm{PPh}_{3}\right)_{4}(1-5 \mathrm{~mol} \%), \\
\mathrm{THF} \text { or } \mathrm{C}_{6} \mathrm{H}_{6}, \mathrm{rt}, 0.5-4 \mathrm{~h}
\end{array}}{\stackrel{\mathrm{Bu}_{3} \mathrm{SnH}(1.1 \text { equiv) }}{\longrightarrow}} \mathrm{R}^{1 \uparrow} \underset{\mathrm{I}}{\mathrm{R}^{2}} \mathrm{SnBu}_{3}
$$

Scheme 49. Pd-catalyzed hydrostannation of alkynes bearing an electron-deficient heteroatomic group.

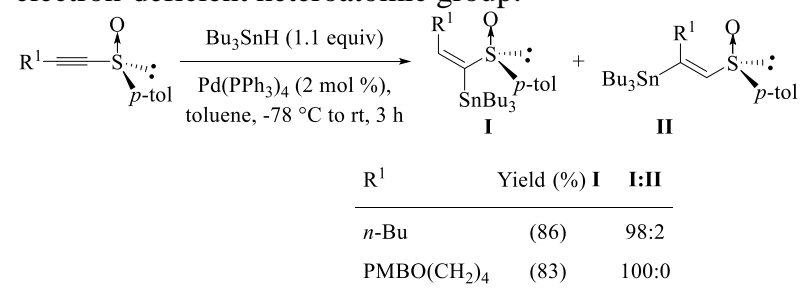

Scheme 50. Pd-catalyzed hydrostannation of chiral alkynyl sulfoxides.

A detailed study of the hydrostannation of 1-alkoxy-1-alkynes demonstrates that the regioselectivity is controlled predominantly by the steric bulk of the substituents on the triple bond. As shown in Scheme 52, ${ }^{109}$ upon increasing the steric demand of the $\mathrm{R}^{1}$ substituent, the proportion of the $\alpha$-constitutional isomer increases.

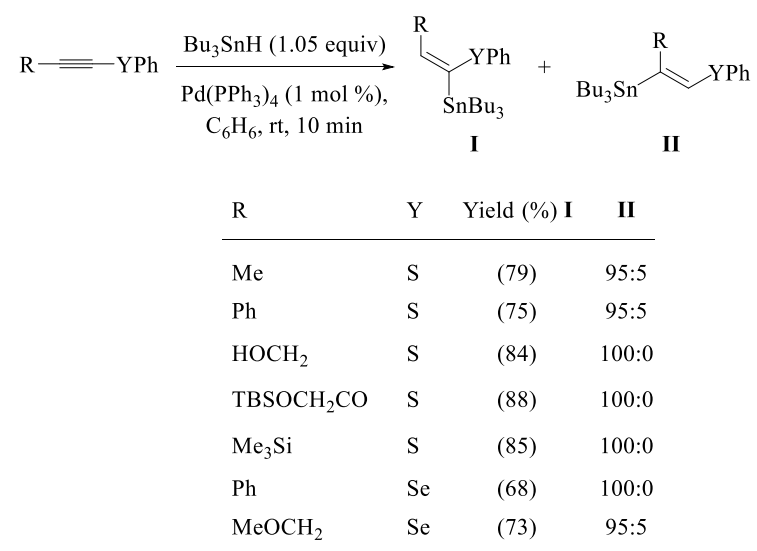

Scheme 51. Pd-catalyzed hydrostannation of thio- and selenoalkynes.

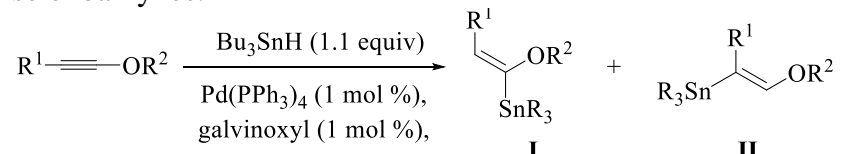

$$
\begin{aligned}
& \mathrm{C}_{6} \mathrm{H}_{6}, \mathrm{rt}, 0.5 \mathrm{~h} \\
& \begin{array}{llcc}
\mathrm{R}^{1} & \mathrm{R}^{2} & \text { Yield (\%) } \mathbf{I} & \text { I:II } \\
\hline n-\mathrm{Bu} & \mathrm{BnOCH}_{2} \mathrm{O} & (46) & 64: 36
\end{array} \\
& s \text { - } \mathrm{Bu} \quad \mathrm{BnOCH}_{2} \mathrm{O} \quad(57) \quad 84: 16 \\
& t \text { - } \mathrm{Bu} \quad \mathrm{BnOCH}_{2} \mathrm{O} \quad \text { (71) } \quad 100: 0 \\
& n \text {-Bu OTHP (28) } 55: 45 \\
& s \text {-Bu OTHP } \quad \text { (46) } \quad 80: 20 \\
& t \text { - } \mathrm{Bu} \quad \text { OTHP } \quad \text { (51) } 93: 7
\end{aligned}
$$

Scheme 52. Pd-catalyzed hydrostannation of 1-alkoxy-1-alkynes.

The resulting alkoxyalkenylstannanes are highly unstable toward purification, and the chromatographic lability of the $\beta$ - 
constitutional isomer serendipitously allows easy isolation of the $\alpha$-isomer.

It is worth noting that internal ynamides can be subjected to palladium-catalyzed hydrostannation. The best isomeric ratios are obtained with oxazolidinyl ynamides. In this case, intramolecular coordination of the carbonyl oxygen atom to the metal center could favor the formation of the $\alpha$-isomer (Scheme 53). ${ }^{110}$

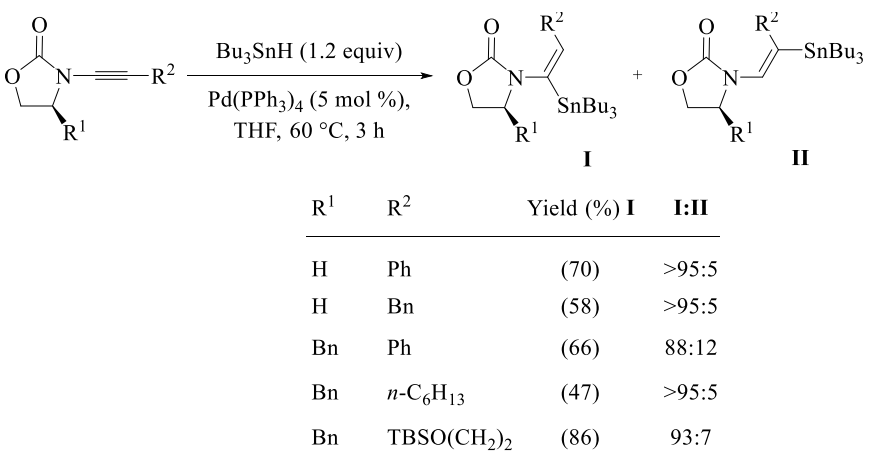

Scheme 53. Pd-catalyzed hydrostannation of oxazolidinyl ynamides.

The stability and chemical properties of alkynyl halides vary broadly depending on the halogen. In contrast to alkynyl fluorides, alkynyl chlorides, bromides and iodides are relatively stable species. ${ }^{111}$ Hydrostannation of 1-bromoalkynes, including silylated 1-bromoalkynes, leads to selective formation of the corresponding $E$-alkenylstannanes with only trace amounts of the $Z$-isomers. ${ }^{23}$ This finding is further extended to a broad range of 1bromoalkyne substrates giving good yields and selectivities for the desired $\beta$-E-isomer (Scheme 54). ${ }^{112}$

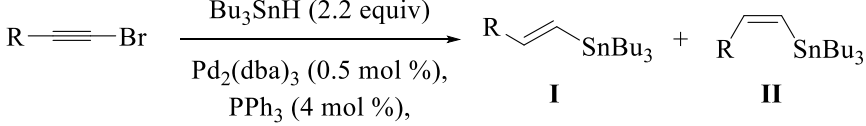

$$
\begin{aligned}
& \text { THF, rt, } 2 \text { h }
\end{aligned}
$$

\begin{tabular}{lcc}
$\mathrm{R}$ & Yield (\%) I & I:II \\
\hline $\mathrm{BzOCO}\left(\mathrm{CH}_{2}\right)_{2}$ & $(84)$ & $92: 8$ \\
$\mathrm{THPO}\left(\mathrm{CH}_{2}\right)_{3}$ & $(77)$ & $92: 8$ \\
$\mathrm{Ph}\left(\mathrm{CH}_{2}\right)_{2}$ & $(83)$ & $93: 7$
\end{tabular}

Scheme 54. Pd-catalyzed hydrostannation of bromoalkynes.

To be successful, the reaction requires the use of 2 equiv of $\mathrm{Bu}_{3} \mathrm{SnH}$. The first equivalent of hydride adds to the triple bond and the second equivalent is used to achieve palladium-catalyzed $\mathrm{C}$ $\mathrm{Br}$ bond cleavage through an alkylidene carbenoid intermediate. This mechanistic proposal involving a hydrostannation-reduction sequence is supported by the isolation of 1-chloro-1tributylstannyl alkene $\mathbf{5 0}$ when 1-chloro-oct-1-yne is subjected to tributyltin hydride under palladium catalysis (Scheme 55). ${ }^{23}$ In this case, no reduction of the $\mathrm{C}-\mathrm{Cl}$ bond is observed upon the addition of further equivalents of hydride. Alltogether, hydrostannation of 1-bromoalkynes constitutes a solution, albeit an indirect one, to the problem of poor regiocontrol with unbranched linear terminal alkynes.

$$
n-\mathrm{C}_{6} \mathrm{H}_{13}=\mathrm{Cl} \underset{\substack{\mathrm{PdCl}_{2}\left(\mathrm{PPh}_{3}\right)_{2}(2 \mathrm{~mol} \%) \\ \mathrm{THF}, \mathrm{rt}, 10 \mathrm{~min}}}{\stackrel{\mathrm{Bu}_{3} \mathrm{SnH} \text { (1.2 equiv) }}{=}} \stackrel{\mathbf{5 0} \mathrm{C}_{6} \mathrm{H}_{13}}{\mathrm{Cl}}
$$

3.2 Other metal-catalyzed hydrostannation reactions of alkynes.

Apart from the predominant use of palladium catalysts in the hydrostannation of alkynes, a number of other catalysts based on Mo and Rh have been reported, in addition to a limited number of examples using $\mathrm{Ni}, \mathrm{Co}, \mathrm{Pt}$ and $\mathrm{Ru} .{ }^{113}$ Pioneering reports have reported good comparative studies of various catalyst sources. Among these transition metals, molybdenum has emerged as a selective alternative to palladium if the $\alpha$-alkenylstannane isomer is desired. A molybdenum complex of the type $\operatorname{MoBr}(\pi$ allyl $)(\mathrm{CO})_{2}(\mathrm{MeCN})_{2}$ is a suitable catalyst for the hydrostannation of terminal alkynes such as phenylacetylene and propargylic alcohols via a clean syn addition, but without significant regioselectivity. ${ }^{23}$ In contrast to palladium complexes, the use of this Mo-based complex allows the hydrostannation of trimethylsilyl acetylene, furnishing mainly the $\alpha$-vinyl stannane adduct $(\alpha / \beta=85 / 15){ }^{23}$

An important advance was the identification of the isocyanide complex $\mathrm{MoBI}_{3}\left[\mathrm{MoBI}_{3}=\mathrm{Mo}(\mathrm{CO})_{3}(t-\mathrm{BuNC})_{3}\right]$, that exhibits increased catalyst selectivity, turnover and stability. ${ }^{114}$ The tertbutylisonitrile ligand was selected due to its steric bulk, with the expectation that the large tert-butyl groups would influence the regiochemical outcome of the reaction. Thus, using $\mathrm{MoBI}_{3}$ together with hydroquinone (to suppress radical hydrostannation), useful $\alpha$-regioselectivities are observed for a wide range of terminal propargylic substrates regardless of their substitution patterns (Scheme 56). ${ }^{115}$ Efforts to tune the reactivity of molybdenum catalysts by altering their structure have been pursued. Investigation of the steric and electronic influence of the isonitrile ligand reveals that the related phenyl derivatives [e.g., $\left.\mathrm{Mo}(\mathrm{CO})_{3}(\mathrm{PhNC})_{3}\right]$ give comparable yields, although the selectivities are lower than the tert-butyl derivatives in all cases studied. ${ }^{116}$

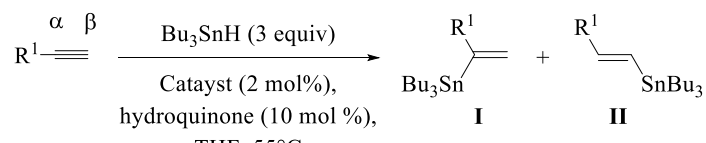

$$
\begin{aligned}
& \text { THF, } 55^{\circ} \mathrm{C} \\
& \begin{array}{llcc}
\mathrm{R} & \text { Catalyst } & \text { Yield (\%) I + II } & \text { I:II } \\
\hline \mathrm{HOCH}_{2} & \mathrm{Mo}(\mathrm{CO})_{3}(t-\mathrm{BuNC})_{3} & \text { (94) } & 89: 11
\end{array} \\
& \text { AllylOCH }_{2} \quad \mathrm{Mo}(\mathrm{CO})_{3}(t-\mathrm{BuNC})_{3} \quad \text { (43) }>95: 5 \\
& \mathrm{Me}(\mathrm{OTBDPS}) \mathrm{CH} \quad \mathrm{Mo}(\mathrm{CO})_{3}(t-\mathrm{BuNC})_{3} \quad \text { (88) } \quad 90: 10 \\
& \mathrm{THPOCH}_{2} \quad \mathrm{Mo}(\mathrm{CO})_{3}(t-\mathrm{BuNC})_{3} \quad(91) \quad>95: 5 \\
& \begin{array}{llll}
\mathrm{THPOCH}_{2} & \mathrm{Mo}(\mathrm{CO})_{3}(\mathrm{PhNC})_{3} & \text { (70) } & 85: 15
\end{array}
\end{aligned}
$$

Scheme 56. Mo-catalyzed hydrostannation of terminal alkynes.

In situ-generation of organotin hydrides, together with molybdenum catalysts, ${ }^{117}$ afford similar levels of $\alpha$ regioselectivity for several substrates. ${ }^{118}$ Excellent $\alpha$-selectivity in the hydrostannation of propargylic substrates may be achieved through the use of an (isonitrile)tungsten carbonyl complex of the type $\mathrm{W}(\mathrm{CO})_{3}(\mathrm{CNR})_{3}$, which gives comparable or even better results than $\mathrm{MoBI}_{3}$ (Scheme 57). ${ }^{119}$

Scheme 55. Pd-catalyzed hydrostannation of chloroalkynes. 
14

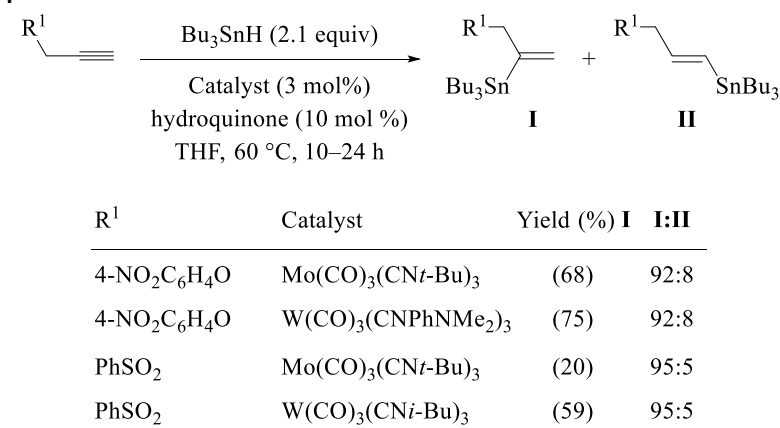

Scheme 57. Mo-and W catalyzed hydrostannation of terminal alkynes.

In the molybdenum-catalyzed hydrostannation of terminal alkynes, ${ }^{120,121}$ the addition mode of $\mathrm{Bu}_{3} \mathrm{SnH}$ has a strong effect on the outcome of the reaction as it is believed that $\mathrm{MoBI}_{3}$ catalyzes the decomposition of tributyltin hydride. Slow addition over $7 \mathrm{~h}$ increases the yield, even if the amount of tributyltin hydride is reduced to only one equivalent (Scheme 58). ${ }^{122}$

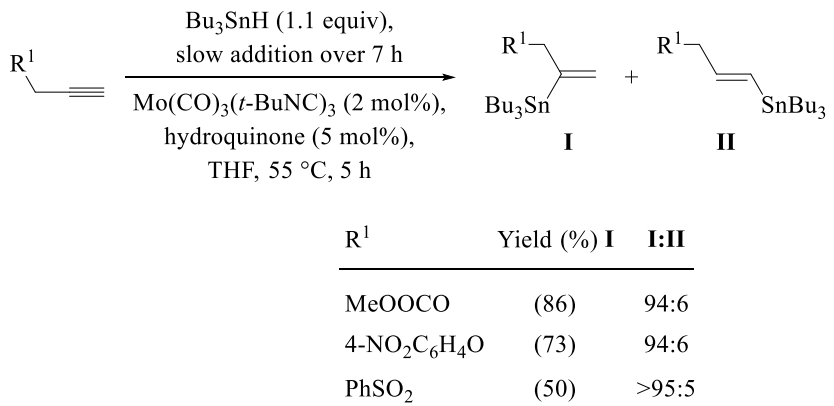

Scheme 58. Mo-catalyzed hydrostannation of functionalized terminal alkynes.

As a class, alkynyl phosphonate ${ }^{123}$ and ester ${ }^{114,115}$ derivatives exhibit excellent selectivity for the production of the $\alpha$ alkenylstannanes with all substrates studied, independent of the substitution pattern of the triple bond (Scheme 59).

Of note is the compatibility of the Mo catalyst toward an allyl ester, which is incompatible with $\operatorname{Pd}(0)$ catalysis. In addition, high chemoselectivity is achieved in the hydrostannation of a diynoic ester having a terminal $\mathrm{C}-\mathrm{C}$ triple bond (Scheme 59). ${ }^{114}$ Molybdenum-catalyzed hydrostannation of $\alpha$-heteroalkynes such as ynamides ${ }^{124}$ is also highly regio- and stereoselective, furnishing exclusively the $\alpha$-isomer for a range of substrates (Scheme 60).

\begin{tabular}{|c|c|c|c|c|c|c|}
\hline \multirow{3}{*}{$\mathrm{R}^{1}=\mathrm{R}^{2}$} & $\mathrm{Bu}_{3} \mathrm{Sn}$ & ( 3 equiv) & & & \multirow{2}{*}{\multicolumn{2}{|c|}{ II }} \\
\hline & \multicolumn{2}{|c|}{$\begin{array}{c}\mathrm{Mo}(\mathrm{CO})_{3}(t-\mathrm{BuNC})_{3}(2 \mathrm{~mol} \%) \\
\text { hydroquinone }(10 \mathrm{~mol} \%) \\
\mathrm{THF}, 55^{\circ} \mathrm{C}, 6-15 \mathrm{~h}\end{array}$} & I & $\mathrm{SnBu}_{3}$ & & \\
\hline & \multirow[b]{2}{*}{$R^{1}$} & \multirow[b]{2}{*}{$\mathrm{R}^{2}$} & \multicolumn{2}{|c|}{ Yield (\%) } & \multirow[b]{2}{*}{ I:II } & \\
\hline $\mathrm{R}$ & & & I & II & & \\
\hline & $-P r$ & $\mathrm{CO}_{2}$ allyl & (80) & $(-)$ & $91: 9$ & \\
\hline & $\mathrm{IC} \equiv \mathrm{C}\left(\mathrm{CH}_{2}\right)_{4}$ & $\mathrm{CO}_{2} \mathrm{Bn}$ & & & $82: 18$ & \\
\hline $\mathrm{H}$ & I & $\mathrm{PO}(\mathrm{OEt})_{2}$ & (57) & $(-)$ & $92: 8$ & \\
\hline & $-P r$ & $\mathrm{PO}(\mathrm{OEt})_{2}$ & (61) & $(-)$ & $>95: 5$ & \\
\hline & h & $\mathrm{PO}(\mathrm{OEt})_{2}$ & (77) & $(-)$ & $93: 7$ & \\
\hline
\end{tabular}

Scheme 59. Mo-catalyzed hydrostannation of functionalized internal alkynes.

Several applications in subsequent tin-iodine exchange/crosscouplings have been demonstrated. 1-Chloroalkynes ${ }^{125}$ are also viable substrates. Whereas alkyl-substituted chloroalkynes give comparable results, the corresponding phenyl derivative provides a mixture of the two constitutionally isomeric products in a 70:30 ratio (the reaction does not go to completion, yield not given).

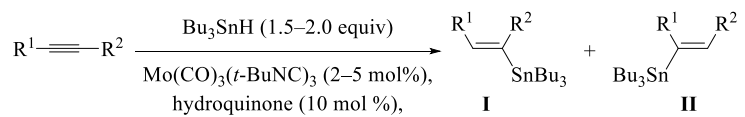

$$
\begin{aligned}
& \text { THF, 55-60 }{ }^{\circ} \mathrm{C}, 16-24 \mathrm{~h} \\
& \begin{array}{llcc}
\mathrm{R}^{1} & \mathrm{R}^{2} & \text { Yield (\%) I } & \text { I:II } \\
\hline n \text {-Hex } & \text { NMeTs } & (87) & 100: 0
\end{array} \\
& c \text {-Pr NMeTs } \quad \text { (68) } 100: 0 \\
& \operatorname{TBDPSO}\left(\mathrm{CH}_{2}\right)_{2} \quad \mathrm{NMeTs} \quad \text { (71) 100:0 } \\
& \mathrm{Ph} \quad \mathrm{NBnBoc} \quad \text { (83) } \quad 100: 0 \\
& n \text {-Pr } \quad \mathrm{Cl} \quad \text { (69) } 100: 0 \\
& n \text {-Pent } \quad \mathrm{Cl} \quad(76) \quad 100: 0 \\
& n \text {-Hex } \quad \mathrm{Cl} \quad \text { (78) } \quad 100: 0 \\
& \begin{array}{llll}
\mathrm{Ph} & \mathrm{Cl} & (-) & 70: 30
\end{array}
\end{aligned}
$$

Scheme 60. Mo-catalyzed hydrostannation of chloro and amino terminal alkynes.

Very recently, a molybdenum-based pre-catalyst system $\left(\mathrm{MoI}_{2}-\right.$ $(\mathrm{CO})_{2}\left(\mathrm{CNAr}^{\mathrm{Dipp} 2}\right)_{2} \quad \mathbf{5 1} ; \quad\left(\mathrm{Ar}^{\mathrm{Dipp} 2}\right)=2,6-\left(2,6-(i-\mathrm{Pr})_{2} \mathrm{C}_{6} \mathrm{H}_{3}\right) \mathrm{C}_{6} \mathrm{H}_{3}$ featuring two encumbering $m$-terphenyl isocyanides ligands was used to deliver $(E)$ - $\beta$-vinylstannanes with an excellent regioselectivity from a variety of terminal and internal alkynes (Scheme 61). ${ }^{126}$ Under the conditions depicted in Scheme 61, Pre-catalyst 51 converts phenylacetylene into the corresponding $(E)$ - $\beta$-vinylstanne with an excellent regioselectivity $(\beta: \alpha=$ $87 / 13)$ which is markedly superior to that of classical $\mathrm{Pd}$ catalysts as $\mathrm{PdCl}_{2}\left(\mathrm{PPh}_{3}\right)_{2}$ and $\mathrm{Pd}\left(\mathrm{PPh}_{3}\right)_{4} ;(\beta: \alpha=54 / 46)$ and $(\beta: \alpha$ $=50 / 40)$, respectively. ${ }^{16}$ Terminal aryl alkynes having electronrich substituents (e.g. 4-Me; 4-OEt) were transformed into $(E)$ $\beta$-vinylstannes with regioselectivities greater than $91 \%$. One note that the presence of EWG on the phenyl ring as a $4-\mathrm{NO}_{2}$ substituent is critical as the $(E)$ - $\alpha$-vinylstanne derivative predominated. Internal alkynes are excellent substrates under these conditions as $(E)$ - $\beta$-vinylstannes were obtained with a good regioselectivity ranging from 80 to $92 \%$.Pre-catalyst $\mathbf{5 1}$ produced with a high regioselectivity $(E)$ - $\beta$-vinylstannes isomers using propargyl alcohols as substrates $(\beta: \alpha=97 / 3$ to 90/10), depending of substrates. These results clearly indicate that pre-catalyst $\mathbf{5 1}$ impose strong steric constraints during hydrostannation with a good to excellent discrimination.

$$
\begin{aligned}
& \mathrm{R}^{1} \stackrel{\alpha \beta}{=} \mathrm{R}^{2} \frac{\mathrm{Bu}_{3} \mathrm{SnH}(1.05 \text { equiv })}{\begin{array}{c}
\mathbf{5 1}(2 \mathrm{~mol} \%) \\
\mathrm{C}_{6} \mathrm{D}_{6}, \mathrm{rt}, 30 \mathrm{~min}
\end{array}} \underbrace{\mathrm{R}^{1}}_{\mathbf{I}}\left\langle_{\mathrm{SnBu}_{3}}^{\mathrm{R}^{2}}+\underset{\mathrm{Bu}_{3} \mathrm{Sn}}{\mathrm{R}_{\mathbf{I I}}^{1}}=\mathrm{R}^{\mathrm{R}^{2}}\right. \\
& \text { (1) } \\
& \begin{array}{llll} 
& & \text { Yield (\%) } & \text { I:II } \\
\mathrm{R}^{1} & \mathrm{R}^{2} & \text { I + II } & \text { I:I } \\
\hline \text { Ph } & \mathrm{H} & (95) & 87: 13
\end{array} \\
& \begin{array}{llll}
\mathrm{Ph} & \mathrm{H} & (95) & 87: 13 \\
\text { 4-MePh } & \mathrm{H} & (92) & 91: 9
\end{array} \\
& \text { 4-OEtPh H } \quad \text { (94) } 98: 2 \\
& 4-\mathrm{NO}_{2} \mathrm{Ph} \quad \mathrm{H} \quad \text { (86) 45:55 } \\
& \mathrm{Ph} \quad \mathrm{Me} \quad \text { (94) 92:8 } \\
& \mathrm{Ph} \quad \mathrm{Et} \quad \text { (96) 80:20 } \\
& n \text {-Pr } \quad \text { Me (94) 89:11 } \\
& \mathrm{C}(\mathrm{OH})(\mathrm{Me})(\mathrm{Et}) \quad \mathrm{H} \quad \text { (92) } \quad 83: 17
\end{aligned}
$$

Scheme 61. Molybdenum complexe 51-catalyzed hydrostannation of alkynes. 
Although Ni, Pt, and Co catalysts give poor regioselectivity $(\alpha / \beta \sim$ $1: 1), \mathrm{Rh}$ catalysts $\left[\right.$ e.g., $\left.\mathrm{RhCl}\left(\mathrm{PPh}_{3}\right)_{3}\right]$ give good $\alpha$-selectivity $(\alpha / \beta \sim 88: 12)$ in the hydrostannation of phenylacetylene and several propargylic ethers. ${ }^{60}$ The use of a cationic Rh complex $\left\{\right.$ e.g., $\left.\left[\mathrm{Rh}(\operatorname{cod})_{2}\right]\left[\mathrm{BF}_{4}\right]\right\}$ in the hydrostannation of propargylic alcohols proceeds with very low regio- and stereoselectivity. However, switching to allyl propargyl ether derivatives, the reaction with $\mathrm{Bu}_{3} \mathrm{SnH}$ occurs selectively, delivering a single $\alpha$ isomer adduct (Scheme 62) ${ }^{127}$ Under the same reaction conditions, but using $\mathrm{Et}_{3} \mathrm{SnH}$ and $\mathrm{Ph}_{3} \mathrm{SnH}$ under otherwise identical reaction conditions provides good yields but poor regio- and stereoselectivities.

Other metals have also been employed for alkyne hydrostannation. A copper-catalyzed reaction was reported with alkynyl esters. ${ }^{128}$ As in palladium-catalyzed reactions, only syn adducts are formed in comparably good yields and in fact exclusive under catalysis by $\left[\mathrm{Ph}_{3} \mathrm{PCuH}\right]_{6}$

$$
\begin{aligned}
& \mathrm{R}^{1} \mathrm{O} \smile \frac{\mathrm{Bu}_{3} \mathrm{SnH}(1.5 \text { equiv })}{\left[\mathrm{Rh}(\operatorname{cod})_{2}\right] \mathrm{BF}_{4}(5 \mathrm{~mol} \%),} \mathrm{R}^{1} \mathrm{O} \mathrm{SnBu}_{3} \\
& \mathrm{PPh}_{3}(10 \mathrm{~mol} \%) \text {, I } \\
& \text { acetone, } 50{ }^{\circ} \mathrm{C}, 16 \mathrm{~h} \\
& \begin{array}{ll}
\mathrm{R}^{1} & \text { Yield (\%) I } \\
\hline
\end{array} \\
& (E)-\mathrm{MeCH}=\mathrm{CHCH}_{2} \\
& \text { (E) }-\mathrm{PhCH}=\mathrm{CHCH}_{2} \\
& \mathrm{CH}_{2}
\end{aligned}
$$

Scheme 62. Rh-catalyzed hydrostannation of terminal alkynes.

Even for the challenging case of an alkynyl ester bearing a bulky $\mathrm{O} i$-Bu group, in which directing effects from steric and electronic factors are working in opposition, the $\mathrm{Cu}$-catalyzed hydrostannation shows complete selectivity for the $\alpha$-adduct (Scheme 63). ${ }^{129}$ With less electrophilic alkynyl amides, ${ }^{129}$ excellent $\alpha$-regioselectivity is observed, but the reaction rate is very slow, furnishing the $\alpha$-adduct in only $41 \%$ yield after $18 \mathrm{~h}$ (Scheme 63). With this particular substrate, the Pd-catalyzed hydrostannation is much more efficient. The catalyst $\left[\mathrm{Ph}_{3} \mathrm{PCuH}\right]_{6}$ is unreactive with nonpolar alkynes such as diphenylacetylene. To circumvent the need to separately prepare, isolate, and purify $\left[\mathrm{Ph}_{3} \mathrm{PCuH}\right]_{6}$, an alternative protocol using a more common and convenient source of copper for hydrostannation has been developed involving the use of catalytic amounts of $\mathrm{CuCl}(10 \mathrm{~mol} \%)$, potassium tertbutoxide $(10 \mathrm{~mol} \%)$ and triphenylphosphine $(15 \mathrm{~mol} \%)$ in the presence of tributyltin hydride ( 1.5 equiv). The reactions catalyzed by the in situ-generated copper hydride provide alkenylstannanes with similar yields and regioselectivities to hydrostannation catalyzed by $\left[\mathrm{Ph}_{3} \mathrm{PCuH}\right]_{6}{ }^{130}$

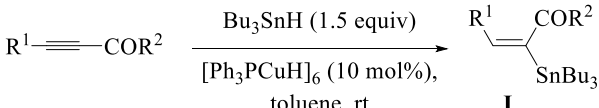

$$
\begin{aligned}
& \begin{array}{llc}
\mathrm{R}^{1} & \mathrm{R}^{2} & \text { Yield (\%) } \mathrm{I} \\
\hline \mathrm{Me} & \mathrm{OMe} & (62)
\end{array} \\
& n \text {-Bu OEt (75) } \\
& n-\mathrm{C}_{6} \mathrm{H}_{13} \quad \text { OMe } \quad \text { (70) } \\
& n-\mathrm{C}_{6} \mathrm{H}_{13} \quad \mathrm{O} i-\mathrm{Bu} \quad \text { (77) } \\
& \mathrm{TBSOCH}_{2} \quad \text { OEt (83) } \\
& \mathrm{Me} \quad \mathrm{N}\left(\mathrm{CH}_{2}\right)_{5} \quad \text { (41) }
\end{aligned}
$$

Scheme 63. Cu-catalyzed hydrostannation of alkynoates.
The reaction with the more challenging alkynyl ketones shows high regioselectivity for $\alpha$-stannation, and no $\beta$-isomer is observed. In contrast to the syn-selective hydrostannation of alkynyl esters, the major stannylated enone results from the antiaddition of $\mathrm{Bu}_{3} \mathrm{SnH}^{129}$ As shown in Scheme 64, syn- and antiadditions appear to be governed in part by the steric demands of the $\mathrm{R}^{2}$ substituent on the electron-withdrawing group. Protodestannylation on silica gel chromatography of the product is mainly responsible for the lower yields.

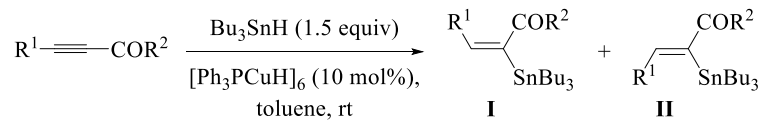

$$
\begin{aligned}
& \begin{array}{ccccc}
\mathrm{R}^{1} & \mathrm{R}^{2} & \text { Yield (\%) } \mathbf{I}+\mathbf{I I} & \text { Yield (\%) II } & \text { I:II } \\
\hline \mathrm{Et} & \mathrm{Me} & & (55) & 0: 100
\end{array} \\
& n-\mathrm{C}_{6} \mathrm{H}_{13} \quad \mathrm{Me} \quad \text { (48) } \quad 0: 100 \\
& n \text {-Bu } \quad \text { Et } \quad(69) \quad 12: 88 \\
& n \text {-Bu } \quad t \text {-Bu } \quad(61) \quad 21: 79
\end{aligned}
$$

Scheme 64. Cu-catalyzed hydrostannation of ynones.

In the hydrostannation catalyzed by $\left[\mathrm{Ph}_{3} \mathrm{PCuH}\right]_{6}$, the excellent $\alpha$-regioselectivity observed is suggested to arise from polarization of the acetylenic bond resulting in the addition of a stannylated copper hydride (syn-hydrocupration, 52), to the more electrondeficient $\beta$-carbon of the triple bond. Subsequent transmetalation of the resulting (E)-alkenylcopper $\mathbf{5 3}$ produces the alkenylstannane. In the case of alkynones, the observed anti addition has been rationalized by the isomerization from $(E)$ alkenylcuprate $\mathbf{5 3}$ to $(Z)$ - alkenylcuprate $\mathbf{5 5}$ through the formation of allenoate species 54 (Scheme 65). ${ }^{129}$

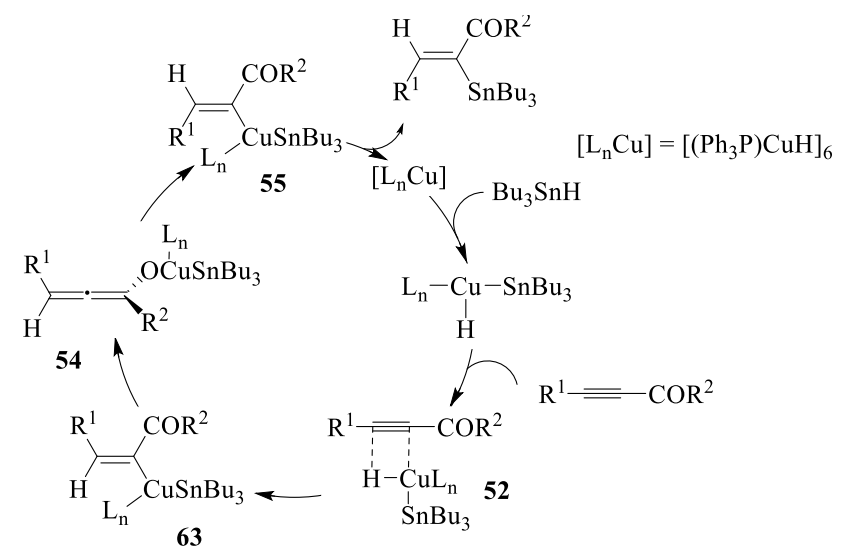

Scheme 65. Plausible mechanism for the $\mathrm{Cu}$-catalyzed hydrostannation of ynones.

Among other metals employed for alkyne hydrostannation, $\mathrm{RuCl}_{2}\left(\mathrm{PPh}_{3}\right)_{4}$ gives good and complementary selectivities favoring the $\beta$-stannane product 57 (vs 56), but as a nearly 1:1 mixture of $E$ - an $Z$-isomers (Scheme 66) ${ }^{60}$

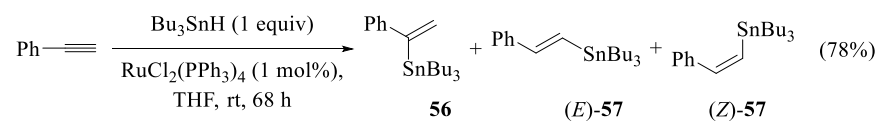

$$
\begin{aligned}
& \text { 56: }(E)-\mathbf{5 7}:(Z)-\mathbf{5 7}=11: 42: 47
\end{aligned}
$$

Scheme 66. $\mathrm{RuCl}_{2}\left(\mathrm{PPh}_{3}\right)_{4}$-catalyzed hydrostannation of phenylacetylene.

\subsection{Ruthenium-Catalyzed trans-selective hydrostannation of alkynes.}

The pionner works concerning the hydrostannation of alkynes using $[\mathrm{Cp} *-\mathrm{Ru}]$-based pre-catalysts highlighted the trans- 
hydrostannation of symmetrical internal alkynes using the cationic pre-catalyst 16. ${ }^{29}$ Under mild conditions (depicted in Scheme 67), Fürstner showed that reaction is compatible with a variety of functional groups and is applicable to substrates containing esters, ketones, phthalimides, Weinreb amides, primary tosylates, primary bromides, unprotected alcohols and acids (Scheme 67). ${ }^{29}$

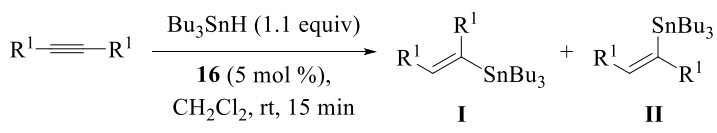

\begin{tabular}{llcl} 
& $\mathrm{R}^{1}$ & Yield (\%) II & I:II \\
\cline { 2 - 4 }$n$ & $n$-Bu & $(96)$ & $1: 99$ \\
& $\left(\mathrm{CH}_{2}\right)_{2} \mathrm{OTs}$ & $(80)$ & $1: 99$ \\
& $\left(\mathrm{CH}_{2}\right)_{5} \mathrm{Br}$ & $(80)$ & $3: 97$ \\
& $\left(\mathrm{CH}_{2}\right)_{5} \mathrm{~N}_{3}$ & $(56)$ & $2: 98$ \\
& $\left(\mathrm{CH}_{2}\right)_{6} \mathrm{COMe}$ & $(94)$ & $1: 99$ \\
& $\left(\mathrm{CH}_{2}\right)_{2} \mathrm{CONMe}(\mathrm{OMe})$ & $(88)$ & $1: 99$ \\
& $4-\mathrm{CF}_{3} \mathrm{C}_{6} \mathrm{H}_{4}$ & $(98)$ & $2: 98$
\end{tabular}

Scheme 67. Ru-complex 16 catalyzed trans-hydrostannation of internal alkynes.

Hydrostannation of unsymmetrical internal alkynes in the presence of cationic complex $\mathbf{1 6}$ provides exclusively the antiaddition products, but as a mixture of $\alpha / \beta$-isomers. Replacement of the cationic complex 16 by other $\mathrm{Cp}^{*}$-containing pre-catalysts provides more satisfactory outcomes. For instance, the use of the tetrameric cluster $[\mathrm{Cp} * \mathrm{RuCl}]_{4} \mathbf{1 7}$ results in an almost exclusive formation of a single $\alpha$-isomer resulting from an anti-addition process. ${ }^{29}$ This trend in regioselectivity is found to be independent of whether the propargylic alcohol site is primary, secondary, or tertiary, suggesting that the reaction selectivity is not under steric control. ${ }^{29,30}$ Reaction with the corresponding acetate derivative results in a mixture of $\alpha / \beta$-isomers, clearly indicating that the regioselectivity is intimately related to the presence of an unprotected hydroxyl group. This Ru-catalyzed, antihydrostannation is also successfully applied to internal alkynes having a TMS group, 1-chloroalkyne substrates, as well as terminal aliphatic alkynes, and in all cases studied, excellent $\alpha$ regioselectivity is observed (Scheme 68). ${ }^{29}$

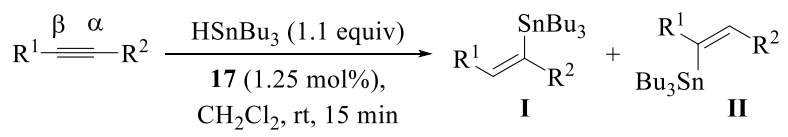

\begin{tabular}{lllcl}
$\mathrm{R}^{1}$ & $\mathrm{R}^{2}$ & Yield (\%) I & I:II \\
\hline $\mathrm{Et}$ & $\mathrm{CH}_{2} \mathrm{OH}$ & $(83)$ & $95: 5$ \\
$\mathrm{Et}$ & $\mathrm{CH}(\mathrm{OH}) \mathrm{Me}$ & $(84)$ & $98: 2$ \\
$\mathrm{Ce}$ & $\mathrm{C}(\mathrm{OH})\left(\mathrm{CH}_{2}\right)_{5}$ & $(97)$ & $99: 1$ \\
& $\mathrm{CH}(\mathrm{NHTs}) \mathrm{Me}$ & $(90)$ & $99: 1$ \\
& $\left(\mathrm{CH}_{2}\right)_{2} \mathrm{OH}$ & $\mathrm{SiMe}_{3}$ & $(82)$ & $96: 4$ \\
$\left(\mathrm{CH}_{2}\right)_{3} \mathrm{SiEt}_{3}$ & $\mathrm{Cl}_{2}$ & $(82)$ & $96: 4$ \\
& & $\left(\mathrm{CH}_{2}\right)_{3} \mathrm{CO}_{2} \mathrm{Me}$ & $(73)$ & $97: 3$
\end{tabular}

Scheme 68. Ru-complex 17 catalyzed trans-hydrostannation of functionalized internal alkynes.

The hydrostannation of conjugated and non-conjugated diynes (not showed) having a propargylic or homopropargylic alcohol function were recently studied in the presence of pre-catalyst $\mathbf{1 7}$ (Scheme 69). ${ }^{131}$

$$
\begin{aligned}
& \mathrm{R}^{1} \stackrel{\alpha \beta}{=} \mathrm{R}^{2} \frac{\mathrm{HSnBu}_{3}(1.15 \text { equiv })}{\mathbf{1 7}(1.25 \mathrm{~mol} \%),} \underset{\mathrm{SnBu}_{3}}{\mathrm{R}^{1}} \mathrm{R}^{2} \\
& \begin{array}{llc}
\mathrm{R}^{1} & \mathrm{R}^{2} & \text { Yield (\%) } \\
\hline c-\mathrm{C}_{6} \mathrm{H}_{10}(\mathrm{OH}) & i-\mathrm{Pr} & (66)
\end{array} \\
& c-\mathrm{C}_{6} \mathrm{H}_{10}(\mathrm{OH}) \quad n-\mathrm{Bu} \\
& \mathrm{CH}(i-\mathrm{Pr})(\mathrm{OH}) \quad i \text {-Pr } \\
& \mathrm{CH}(i-\mathrm{Pr})(\mathrm{OH}) \quad n-\mathrm{Bu} \\
& \mathrm{CH}_{2} \mathrm{OH} \quad i \text {-Pr } \\
& \left(\mathrm{CH}_{2}\right) \mathrm{OH} \quad n \text {-Bu } \\
& \mathrm{C}(\mathrm{Me})_{2}(\mathrm{OH}) \quad \mathrm{SiMe}_{3}
\end{aligned}
$$

Scheme 69. Ru-complex 17 catalyzed trans-hydrostannation of conjugated diynes.

When the reaction was achieved at $\mathrm{rt}$ in DCM, transhydrostannation of diynes having a propargylic alcohol function furnished the $\alpha$-trans monostannylated adduct in equal proportion with the distannylated product. Surprisingly, heating the mixture at $80{ }^{\circ} \mathrm{C}$ in 1,2-dichloroethane led to monostannylated compounds in good yields with only traces of distannylated compounds, even by achieving with a larger excess of $\mathrm{Bu}_{3} \mathrm{SnH}$. As a consequence, it has been showed that achieving the hydrostannation by lowering the temperature led a mixture of mono-and di-stannylated products in which di-stannylated adducts predominated. It is interesting and surprising to note that by achieving the reaction with diynes in the presence of 17 and 2.5 equiv of $\mathrm{Bu}_{3} \mathrm{SnH}$ at $-40{ }^{\circ} \mathrm{C}$, distannylated products were obtained as a mixture of regioisomers as the hydrostannylation of the distal triple bond $\left(\mathrm{C}_{\delta} \equiv \mathrm{C}_{\gamma}\right)$ is governed by steric factors. ${ }^{131}$ It was also showed that pre-catalyst $\mathbf{1 7}$ was effective to discriminate two triple bonds in non-conjugated diynes in which a propargylic alcohols function is much more cooperative for hydrostannation than a dialkyl alkyne or a protected (OTES)propargylic function. ${ }^{130}$

An equally pronounced effect is seen for acetylene carboxylate derivatives most likely because of a steering mechanism that echoes the results of the propargylic alcohol series. In the presence of complex 17 (Scheme 70), an alkynyl carboxylic acid reacts with high preference for stannation at the $\alpha$-position, suggesting a cooperative effect between the protic functional group and the catalyst. If this cooperativity with the protic functional groups is lacking, the outcome is different. Thus, acetylenic esters exhibit the opposite preference for the $\beta$-stannane product (Scheme 70).

$$
\begin{aligned}
& \mathrm{R}^{1} \stackrel{\beta \alpha \alpha}{=} \mathrm{CO}_{2} \mathrm{R}^{2} \frac{\mathrm{HSnBu}_{3}(1.1 \text { equiv) }}{\substack{\mathbf{1 7}(6 \mathrm{~mol} \%), \mathrm{CH}_{2} \mathrm{Cl}_{2}, \mathrm{rt}, 15 \mathrm{~min}}} \mathrm{R}^{1} \underset{\mathbf{I}}{\mathrm{CO}_{2} \mathrm{R}^{2}}+\underset{\mathbf{I I}}{\mathrm{SnBu}_{3}}{\underset{\mathrm{SnBu}}{\mathrm{CO}_{2} \mathrm{R}^{2}}}^{\mathrm{R}^{1}} \\
& \begin{array}{llccr} 
& \multicolumn{4}{c}{\text { Yield (\%) }} \\
\mathrm{R}^{1} & \mathrm{R}^{2} & \text { I } & \text { II } & \text { I:II } \\
\hline n-\operatorname{Pr} & \mathrm{H} & (87) & (-) & 90: 10 \\
\mathrm{Me} & \mathrm{Et} & (-) & (71) & 5: 95
\end{array}
\end{aligned}
$$

Scheme 70. Ru-complex 17 catalyzed trans-hydrostannation of alkynoates.

In the case of internal aliphatic alkynes, complex 17 provides similar results with respect to yield and $\alpha$-selectivity to those obtained with complex 16. The efficiency of complex $\mathbf{1 7}$ is not limited to aliphatic alkynes because carbonyl-conjugated alkynes and internal aromatic alkynes offer similar high yields and complete $\alpha$-selectivity for a range of substrates (Scheme 71). ${ }^{30}$ 


$$
\begin{aligned}
& \mathrm{R}^{1 \stackrel{\beta \alpha}{=}} \mathrm{R}^{2} \frac{\begin{array}{c}
\mathrm{HSnBu}_{3}(1.2 \text { equiv), } \\
\text { fluorescent light (30 W) }
\end{array}}{\mathbf{1 7}(1 \mathrm{~mol} \%),} \mathrm{R}_{\mathrm{THF}, \mathrm{rt}, 10 \mathrm{~min}}^{1} \mathrm{R}^{2} \\
& \begin{array}{llr}
\mathrm{R}^{1} & \mathrm{R}^{2} & \text { Yield (\%) I } \\
\hline n \text {-Pr } & n \text {-Pr } & (93)
\end{array} \\
& n-\mathrm{C}_{6} \mathrm{H}_{13} \quad \mathrm{C}(\mathrm{OTBS}) \mathrm{Me} \quad \text { (87) } \\
& \mathrm{Ph} \quad \mathrm{CONHPh} \quad \text { (89) } \\
& 4-\mathrm{FC}_{6} \mathrm{H}_{4} \quad \mathrm{CO}_{2} \mathrm{Et} \quad \text { (94) } \\
& \mathrm{Ph} \quad \mathrm{C}(\mathrm{OTBS}) \mathrm{Me} \text { (92) }
\end{aligned}
$$

Scheme 71. Ru-complex 17 catalyzed trans-hydrostannation of functionalized internal alkynes.

Under similar reaction conditions to those for internal alkynes, terminal aromatic alkynes react with almost complete regio- and stereoselectivity to give the corresponding $E$ - $\beta$-alkenylstannanes in high yields (Scheme 72).$^{30}$ Notably, the ortho-substituent on the aromatic ring does not play any role in the reaction regioselectivity, contrary to what happens under palladium catalysis (see Scheme 25). The regio- and stereoselectivity of hydrostannation reactions using ruthenium complex 17 resembles those in radical-mediated hydrostannation using AIBN or $\mathrm{BEt}_{3}$ initiators, but has clear advantages in reaction efficiency The

\begin{tabular}{|c|c|c|}
\hline $\mathrm{R}^{1 \stackrel{\alpha \beta}{\underline{\underline{\underline{n}}}}}$ & $\begin{array}{l}\mathrm{HSnBu}_{3}(1.2 \text { equiv }) \text {, } \\
\text { fluorescent light }(30 \mathrm{~W})\end{array}$ & \\
\hline & $\begin{array}{l}17(1 \mathrm{~mol} \%), \\
\text { THF, rt, } 10 \mathrm{~min}\end{array}$ & I \\
\hline & $\mathrm{R}^{1}$ & Yield (\%) I \\
\hline & $\mathrm{Ph}$ & (92) \\
\hline & 4- $\mathrm{FC}_{6} \mathrm{H}_{4}$ & (86) \\
\hline & 4- $\mathrm{MeOC}_{6} \mathrm{H}_{4}$ & (89) \\
\hline & $2-\mathrm{MeOC}_{6} \mathrm{H}_{4}$ & (95) \\
\hline
\end{tabular}
stable complex 17, under illumination by household fluorescent light $(30 \mathrm{~W})$ at room temperature, generates a ruthenium hydride species. The authors postulate that the reaction proceedes via a radical pathway in which $\mathrm{Ru}-\mathrm{H}$ species, rather than $\mathrm{Bu}_{3} \mathrm{SnH}$, donates a hydrogen atom to the alkenyl radical. ${ }^{30}$

Scheme 72. Ru-complex 17 catalyzed trans-hydrostannation of terminal alkynes.

It should be noted that a global comparison of hydrostannation with the relative hydrosilylation, hydrogermylation and hydroboration will not be studied in this review, for lack of space. However, various studies evoking these comparisons or showing their complementarity have been reported. ${ }^{16,32,97,132}$

\subsection{Hydrostannation under radical conditions.}

The hydrostannation of alkynes under free-radical conditions is the oldest and most reliable method for preparing alkenylstannanes. In general, the reaction gives a mixture of stereoisomers. The outcome is usually controlled by the stability of the radical precursor that gives rise to the corresponding alkenylstannanes. Radical hydrostannation of unsaturated bonds is not applicable to all substrate types as discrimination between other sites of unsaturation (e.g., alkyne vs alkene), or reduction (alkyne vs halogen) in the molecule led to undesired side reactions. Propargylic alcohols constitute an important substrate class that offers good selectivity. ${ }^{133}$ The amounts of $\mathrm{Bu}_{3} \mathrm{SnH}$ employed with respect to terminal propargylic alcohol and ether substrates strongly effects the regio- and stereoselectivity of hydrostannation. The use of a slight excess of $\mathrm{Bu}_{3} \mathrm{SnH}$ (1.3 equiv) together with heating at $80^{\circ} \mathrm{C}$ results in the formation of $\beta-(E)$-alkenylstannanes as the major isomers (Scheme 73). ${ }^{\text {Erreur } ! \text { Signet non défini. }}$

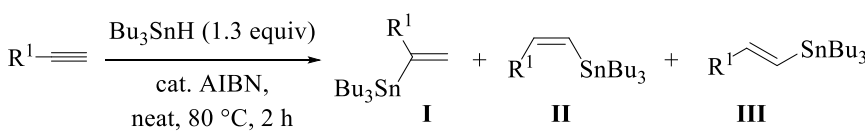

\begin{tabular}{lcc}
$\mathrm{R}^{1}$ & Yield (\%) I + II + II & I:II:III \\
\hline $\mathrm{HOCH}_{2}$ & $(89)$ & $7: 5: 88$ \\
$\mathrm{BnOCH}_{2}$ & $(90)$ & $7: 0: 93$
\end{tabular}

Scheme 73. Hydrostannation of terminal alkynols under radical conditions.

The reaction selectivity strongly depends on the nature of the terminal propargylic alcohol substrates employed (Scheme 74) ) $^{134}$ Thus, under thermally initiated radical hydrostannation alkynol 56 provides $\alpha$-stannyl isomer $\mathbf{5 7}$, whereas protection of the alcohol as its TMS derivative $\mathbf{5 8}$ leads to the formation of the kinetic $(Z)-\beta$ alkenylstannane product 59. Unfortunately, rigorous identification of product selectivity shown in Scheme 74 is not given.

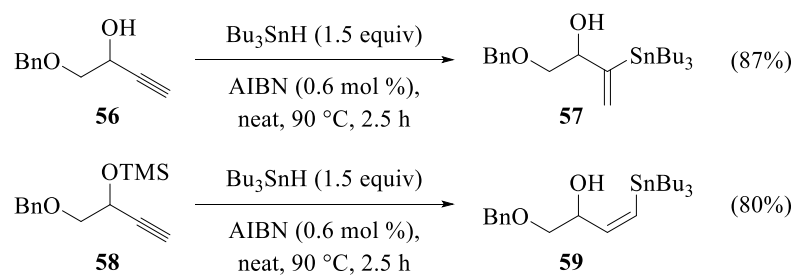

Scheme 74. Hydrostannation of propargylic alkynols under radical conditions.

Although disubstituted alkyl propargyl alcohols ${ }^{38,135,136}$ and amines ${ }^{137}$ are reported to undergo highly regio- and stereoselective, O-directed free-radical hydrostannation reactions, the high temperatures necessary for the reaction $\left(60-120{ }^{\circ} \mathrm{C}\right)$ often cause problems with functionalized substrates. Erreur! Signet non défini. However, triethylborane or $9-\mathrm{BBN}^{138}$ constitute alternative radical initiators active at low temperatures (room temperature to $-78{ }^{\circ} \mathrm{C}$ ) which circumvent these drawbacks. The use of $\mathrm{Ph}_{3} \mathrm{SnH}$ in the presence of a catalytic amount of $\mathrm{Et}_{3} \mathrm{~B}$ provides good stereoselectivity. Thus, phenylacetylene and trimethylsilyl acetylene furnishes $(E)$ - $\beta$-isomers exclusively under these conditions (Scheme 75) ${ }^{37}$ Reactions with $\mathrm{Bu}_{3} \mathrm{SnH}$ and the same terminal alkynes require longer reaction times, and the corresponding alkenylstannanes are formed in lower yields. ${ }^{37}$

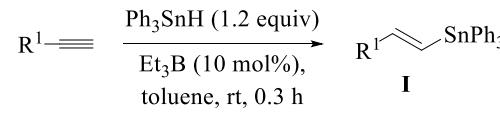

$$
\begin{aligned}
& \begin{array}{lc}
\mathrm{R}^{1} & \text { Yield (\%) I } \\
\hline \mathrm{Ph} & \text { (75) }
\end{array} \\
& \mathrm{Me}_{3} \mathrm{Si} \quad \text { (83) }
\end{aligned}
$$

Scheme 75. Hydrostannation of terminal alkynes in the presence of $\mathrm{Et}_{3} \mathrm{~B}$

The selectivity of hydrostannation on internal alkynes initiated by $\mathrm{Et}_{3} \mathrm{~B}$ has been explored using bulky triorganotin hydrides. ${ }^{140}$ Selectivity for the $(Z)$-alkenylstannane from an anti-addition process is often excellent (Scheme 76), ${ }^{141}$ although inversion of selectivity can occur for substrates in which isomerization to the thermodynamically more stable $(E)$-alkenylstannane is

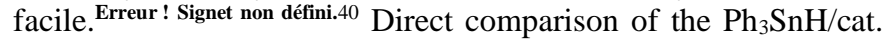

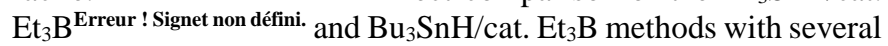
alkynes reveals that the $\mathrm{Ph}_{3} \mathrm{SnH}$ system is uniformly superior in all respects for effecting an $\mathrm{O}$-directed free radical hydrostannation reaction. Not only does the $\mathrm{Ph}_{3} \mathrm{SnH} / \mathrm{cat}$. $\mathrm{Et}_{3} \mathrm{~B}^{\text {Erreur } \text { ! Signet non défini. }}$ combination more readily converts propargyl-oxygenated disubstituted alkynes into $(Z)$-alkenylstannanes, it also delivers products with improved stereo- and regiocontrol. 


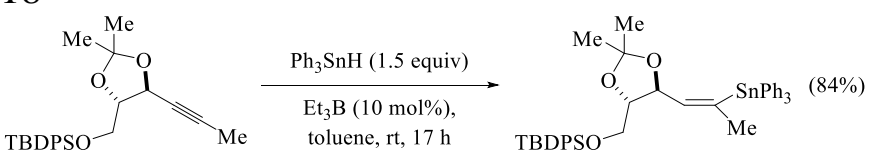

Scheme 76. Hydrostannation of functionalized internal alkynes in the presence of $\mathrm{Et}_{3} \mathrm{~B}$.

A comparative hydrostannation study of $\mathrm{Et}_{3} \mathrm{~B}$ and $\mathrm{AIBN}$ at $80{ }^{\circ} \mathrm{C}$ reveals that in the case of internal propargylic alcohol derivatives, ${ }^{142}$ the $\mathrm{Et}_{3} \mathrm{~B}$ /air system promotes tin hydride addition under very mild conditions with complete preference for the $(Z)$ alkenylstannane. Furthermore, these conditions regioselectively place the tin moiety on the alkyne carbon proximal to the oxygen substituent. Conversely, in all cases employing AIBN, approximately 1:1 mixtures of $Z$ - and $E$-isomers are obtained. Despite decades of acceptance, these observations suggest that the hydrostannation mechanisms employing $\mathrm{Et}_{3} \mathrm{~B}$ and $\mathrm{AIBN}$ appear to be mechanistically distinct.

Given that $\mathrm{Et}_{3} \mathrm{~B}$ autoxidizes rapidly in oxygen at room temperature, ${ }^{143}$ recent studies highlight that the autoxidation products of $\mathrm{Et}_{3} \mathrm{~B}$ (borinic or boronic acids or esters) efficiently promote hydrostannation of internal alkynes. ${ }^{144}$ This highly regioand stereoselective $(Z / E=>99: 1)$ radical-mediated and molecularoxygen $\left(\mathrm{O}_{2}\right)$-dependent hydrostannation works well with several highly functionalized, primary propargylic alcohol derivatives leading to (Z)-olefin products through anti-addition of $\mathrm{Sn}-\mathrm{H}$ across the alkyne (Scheme 77).

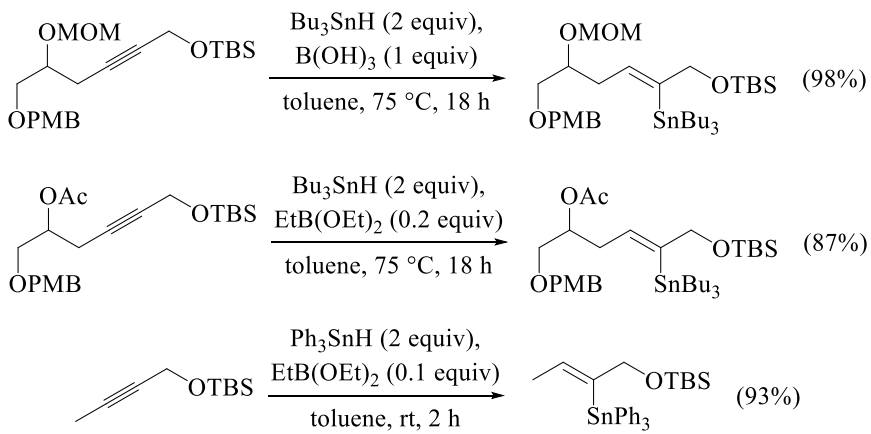

Scheme 77. Hydrostannation of internal propargylic alkynes in the presence of $\mathrm{B}(\mathrm{OH})_{3}$ and $\mathrm{EtB}(\mathrm{OEt})_{2}$.

Remarkable differences in both regio- and stereoselectivity in radical vs non-radical-mediated hydrostannation have been reported. In radical-mediated hydrostannation there is a significant steric effect on the selectivity of the hydrostannation of several phenyl propargylic alcohols and silyl ethers when $n-\mathrm{Bu}_{3} \mathrm{SnH}$ and $\mathrm{Ph}_{3} \mathrm{SnH}$ are compared. In all cases studied using $\mathrm{n}-\mathrm{Bu}_{3} \mathrm{SnH}$, complete $\beta$-regioselectivity is observed, resulting in products with the tin moiety on the alkyne carbon proximal to the oxygen substituent (Scheme 78). ${ }^{44}$ Contrary to the radical-mediated transformation, the regiochemistry of the uncatalyzed addition with $n-\mathrm{Bu}_{3} \mathrm{SnH}$ is completely reversed, as is the stereoselectivity (exclusive $s y n$-addition).

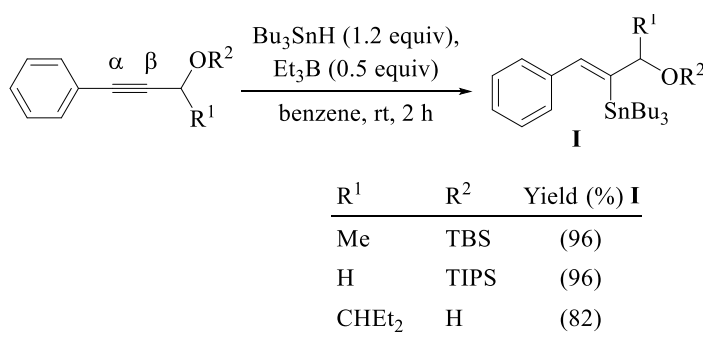

Scheme 78. trans-Hydrostannation of internal aryl propargylic alkynes in the presence of $\mathrm{Et}_{3} \mathrm{~B}$.
The authors highlight that the uncatalyzed addition with $n-\mathrm{Bu}_{3} \mathrm{SnH}$ gives a remarkable $\alpha$-regioselectivity irrespective of the electronic nature of the aryl moiety (Scheme 79), ${ }^{44}$ whereas addition with $\mathrm{Ph}_{3} \mathrm{SnH}$ appears to be driven by the electronic nature of the arylalkynes.

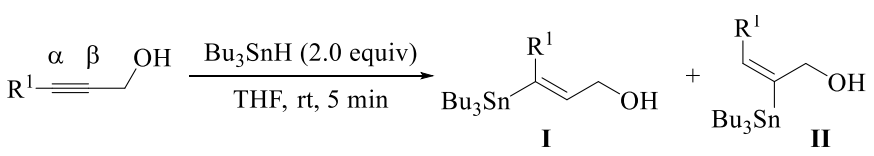

$$
\begin{aligned}
& \begin{array}{lcc}
\mathrm{R}^{1} & \text { Yield (\%) I } & \text { I:II } \\
\hline 4-\mathrm{MeCOC}_{6} \mathrm{H}_{4} & (90) & 95: 5
\end{array} \\
& \text { 4- } \mathrm{CNC}_{6} \mathrm{H}_{4} \quad \text { (87) } \quad 95: 5 \\
& 3-\mathrm{MeOC}_{6} \mathrm{H}_{4} \quad \text { (80) } \quad 85: 15 \\
& 2,2^{\prime}-\mathrm{Me}_{2} \mathrm{C}_{6} \mathrm{H}_{3} \quad \text { (82) } \quad 85: 15
\end{aligned}
$$

Scheme 79. Hydrostannation of substituted arylpropargylic alcohols.

A study with various trifluoromethyl arylalkynes with $\mathrm{Bu}_{3} \mathrm{SnH}$ initiated by $\mathrm{Et}_{3} \mathrm{~B}$ reveals good selectivity for the anti-addition (Scheme 80). ${ }^{145}$ Although the reaction may be conducted under transition metal catalysis, the best results are obtained under radical conditions. Unfortunately, an alkyl derivative displays significantly diminished yield and isomeric purity.

$$
\begin{aligned}
& \mathrm{R}^{1} \stackrel{\alpha \beta}{=} \mathrm{CF}_{3} \frac{\mathrm{Eu}_{3} \mathrm{~B}(20 \mathrm{~mol} \%)}{\text { toluene, } 0{ }^{\circ} \mathrm{C}, 4 \mathrm{~h}} \mathrm{R}^{1} \underset{\mathbf{I}}{\mathrm{SnBu}_{3}}+\underset{\mathbf{I I}}{\mathrm{CF}_{3}}+\mathrm{RF}_{3}^{1} \overbrace{\mathrm{CF}_{3}}^{\mathrm{SnBu}_{3}} \\
& \begin{array}{lcc}
\mathrm{R}^{1} & \text { Yield (\%) I } & \text { I:II } \\
\hline 4-\mathrm{ClC}_{6} \mathrm{H}_{4} & (95) & 95: 5 \\
4-\mathrm{MeC}_{6} \mathrm{H}_{4} & (91) & 98: 2 \\
4-\mathrm{MeOC}_{6} \mathrm{H}_{4} & (90) & 98: 2 \\
2-\mathrm{ClC}_{6} \mathrm{H}_{4} & (55) & 100: 0
\end{array}
\end{aligned}
$$

Scheme 80. Hydrostannation of $\alpha-\mathrm{CF}_{3}$ arylalkynes in the presence of $\mathrm{Et}_{3} \mathrm{~B}$.

Sonochemical generation of tin radical species and subsequent hydrostannation reactions can be initiated at low temperatures, even below $0{ }^{\circ} \mathrm{C} .{ }^{146,147}$ Thus, reactions of excess terminal alkynes (5 equiv) with triphenyltin hydride under an argon atmosphere result in good to excellent yields of the alkenylstannane products with very high kinetic (Z)-selectivity (Scheme 81).

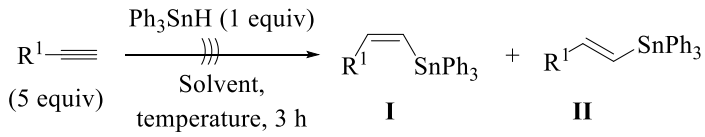

$$
\begin{aligned}
& \begin{array}{lllcl}
\mathrm{R}^{1} & \text { Solvent } & \text { Temperature } & \text { Yield (\%) } \mathbf{I}+\mathbf{I I} & \text { I:II } \\
\hline n \text { - } \mathrm{Bu} & \text { none } & 7{ }^{\circ} \mathrm{C} & (95) & 92: 8
\end{array} \\
& \mathrm{Ph} \quad \mathrm{THF} \quad-55^{\circ} \mathrm{C} \quad \text { (61) } 87: 13
\end{aligned}
$$

Scheme 81. Hydrostannation of terminal lakynes under sonication.

Free-radical hydrostannation of alkynylboranes has been reported. ${ }^{148}$ Boryl substituents play a major role in the course of these reactions, such that only attack at the $\beta$-position is observed. In addition, careful choice of the boron substituent and experimental conditions allow the stereoselective preparation of pure Z- or $E$-isomers (Scheme 82). ${ }^{149}$ 


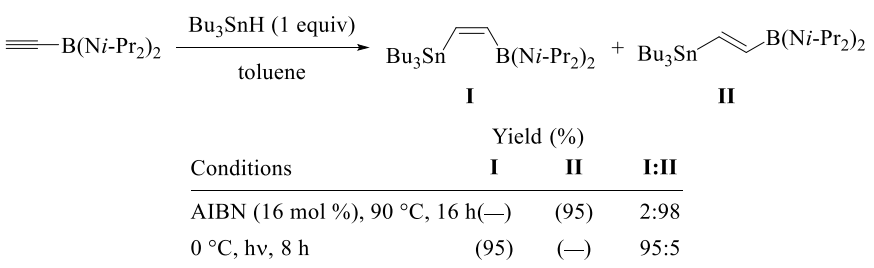

Scheme 82. Hydrostannation of alkynylboranes under radical conditions.

\subsection{Hydrostannation under Lewis acid catalysis.}

Pioneering studies established that excellent regio- and stereocontrol for the ( $Z$ )- $\beta$-isomer may be achieved through the use of $\mathrm{ZrCl}_{4}$-catalyzed anti-hydrostannations of terminal aliphatic and aromatic alkynes, as well as 1-chloroalkynes (Scheme 83). ${ }^{49,50}$ Although the reaction results in high selectivity (>95:5), the alkenylstannane compounds are isolated in moderate yields because of their tendency to undergo protodestannylation processes during purification.

$$
\begin{aligned}
& \mathrm{R}^{1} \rightleftharpoons \mathrm{R}^{2} \underset{\begin{array}{c}
\mathrm{ZrCl}_{4}(20 \mathrm{~mol} \%), \\
\text { toluene, } 0{ }^{\circ} \mathrm{C}, 1 \mathrm{~h}
\end{array}}{\stackrel{\mathrm{HSnBu}_{3}(1.0 \text { equiv })}{\longrightarrow}} \mathrm{R}^{1} \underbrace{\mathrm{SnBu}_{3}}_{\mathbf{I}}+\mathrm{R}^{1} \underbrace{\mathrm{R}^{2}}_{\text {II }} \mathrm{SnBu}_{3} \\
& \begin{array}{llcc}
\mathrm{R}^{1} & \mathrm{R}^{2} & \text { Yield (\%) I } & \text { I:II } \\
\hline \mathrm{TBSO}\left(\mathrm{CH}_{2}\right)_{3} & \mathrm{H} & (48) & >95: 5
\end{array} \\
& \mathrm{Ph} \quad \mathrm{H} \quad(40) \quad>95: 5 \\
& n-\mathrm{C}_{6} \mathrm{H}_{13} \quad \mathrm{Cl} \quad \text { (40) } \quad>95: 5
\end{aligned}
$$

Scheme 83. $\mathrm{ZrCl}_{4}$-catalyzed hydrostannation of alkynes.

This $\mathrm{ZrCl}_{4}$-catalyzed hydrostannation of alkynes is also useful for the synthesis of divinyl tin derivatives by reaction with $\mathrm{Bu}_{2} \mathrm{SnH}_{2}$ (Scheme 84). ${ }^{50} \mathrm{As}$ in the reaction using $\mathrm{Bu}_{3} \mathrm{SnH}$, the hydrostannation leads to anti-addition of $\mathrm{Bu}_{2} \mathrm{SnH}_{2}$, furnishing the $(Z)$ - $\beta$-isomer 60 with high stereoselectivity $(Z / E=>95: 5)$.

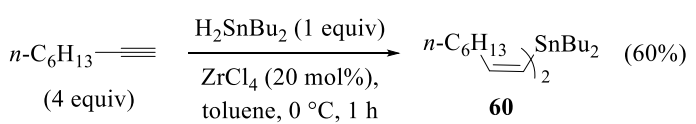

Scheme 84. $\mathrm{ZrCl}_{4}$-catalyzed hydrostannation of alkynes using $\mathrm{H}_{2} \mathrm{SnBu}_{2}$.

Tris(pentafluorophenyl)borane is also an effective Lewis acid catalyst for the hydrostannation of alkynes with tributyltin hydride, prepared in situ from easily handled chlorotributylstannane and triethylhydrosilane (Scheme 85). ${ }^{150}$ The reaction proceeds in a regioselective manner with terminal alkynes, affording the $\beta$-antihydrostannation products almost exclusively. Studies on the mechanism of $\mathrm{B}\left(\mathrm{C}_{6} \mathrm{~F}_{5}\right)_{3}$-catalyzed hydrostannation of internal propargylic alcohols reveal that hydride transfer from $\mathrm{Bu}_{3} \mathrm{SnH}$ to $\mathrm{B}\left(\mathrm{C}_{6} \mathrm{~F}_{5}\right)_{3}$ generates $\left[n \text { - } \mathrm{Bu}_{3} \mathrm{Sn}\right]^{+}\left[\mathrm{HB}\left(\mathrm{C}_{6} \mathrm{~F}_{5}\right)_{3}\right]^{-}$. The authors postulate that both the tributylstannyl cation insertion and hydride delivery by $\mathrm{Bu}_{3} \mathrm{SnH}$ could occur in a more synchronized manner. ${ }^{151}$

$$
\begin{aligned}
& \mathrm{R}^{1}=\frac{\begin{array}{c}
\mathrm{Bu}_{3} \mathrm{SnCl}(1.5 \text { equiv), } \\
\mathrm{Et}_{3} \mathrm{SiH}(1 \text { equiv) }
\end{array}}{\begin{array}{c}
\mathrm{B}\left(\mathrm{C}_{6} \mathrm{~F}_{5}\right)_{3}(10 \mathrm{~mol} \%), \\
\text { toluene, } 0{ }^{\circ} \mathrm{C}, 40 \mathrm{~min}, \\
\text { then, } 25^{\circ} \mathrm{C}, 3 \mathrm{~h}
\end{array}} \mathrm{R}^{1-} \mathrm{SnBu}_{3}+\mathrm{R}^{1} / \mathrm{SnBu}_{3} \\
& \begin{array}{lcc}
\mathrm{R}^{1} & \text { Yield (\%) I + II } & \text { I:II } \\
\hline n-\mathrm{C}_{6} \mathrm{H}_{13} & (78) & >95: 5 \\
\mathrm{PhCH}_{2} & (85) & >95: 5 \\
4-\mathrm{MeC}_{6} \mathrm{H}_{4} & (89) & >95: 5
\end{array}
\end{aligned}
$$

Scheme 85. $B\left(C_{6} F_{5}\right)_{3}$-catalyzed hydrostannation of terminal alkynes.
In a complementary fashion, the selective hydrostannation of simple aliphatic terminal alkynes to provide the $\alpha$-isomer is accomplished using the novel tin hydride system n$\mathrm{Bu}_{2} \mathrm{SnIH} / \mathrm{MgBr}_{2} \cdot \mathrm{OEt}_{2}$ (Scheme 86). ${ }^{152}$ Notably, no $\alpha$-isomer is formed if $n-\mathrm{Bu}_{2} \mathrm{SnIH}$ is used alone, and hydrostannation of 1-ndodecyne gives an almost 1:1 mixture of $\beta-(E)$ and $\beta-(Z)$-isomers. The authors suggest the in situ formation of a pentacoordinated tin hydride complex, $[\mathrm{MgBr}]^{+}\left[n-\mathrm{Bu}_{2} \mathrm{SnBrIH}\right]^{-}$, the structure of which has been suggested by ${ }^{119} \mathrm{Sn}$ NMR spectroscopy.

$$
\begin{aligned}
& \mathrm{Bu}_{2} \mathrm{SnIH} \text { (2.0 equiv), } \\
& \mathrm{R}^{1}=\frac{\mathrm{MgBr}_{2} \cdot \mathrm{OEt}_{2} \text { (4.0 equiv) }}{\mathrm{AcOEt}, \mathrm{rt}, 1 \mathrm{~h}} \mathrm{R}^{1}{\stackrel{\mathrm{I}}{\mathrm{SnBu}_{2} \mathrm{I}}}_{\mathrm{H}} \\
& \begin{array}{lc}
\mathrm{R}^{1} & \text { Yield (\%) I } \\
\hline n-\mathrm{C}_{6} \mathrm{H}_{13} & (77) \\
\mathrm{PhCH}_{2} & (60) \\
i-\mathrm{Bu} & (61)
\end{array}
\end{aligned}
$$

Scheme 86. $\mathrm{MgBr}_{2} \cdot \mathrm{OEt}_{2}$-catalyzed hydrostannation of terminal alkynes in the presence of $\mathrm{Bu}_{2} \mathrm{SnIH}$.

Other dialkyltin hydride halides have recently been introduced as Lewis acidic hydrostannation reagents. ${ }^{138,153,154}$ Among them, $\mathrm{Bu}_{2} \mathrm{Sn}(\mathrm{OTf}) \mathrm{H}$, easily prepared from $\mathrm{Bu}_{2} \mathrm{SnH}_{2}$ and $\mathrm{TfOH}$, is valuable for the highly regio- and stereoselective hydrostannation of various terminal and internal propargylic alcohols (Scheme 87).

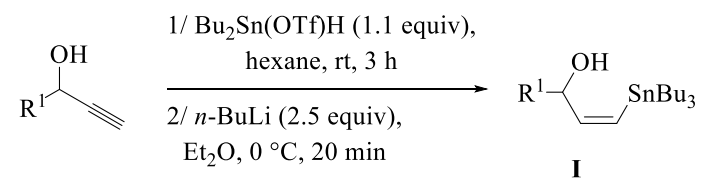

\begin{tabular}{lc}
$\mathrm{R}^{1}$ & Yield (\%) I \\
\hline $\mathrm{H}$ & $(80)$ \\
$n-\mathrm{C}_{8} \mathrm{H}_{17}$ & $(89)$ \\
$\mathrm{Ph}$ & $(85)$
\end{tabular}

Scheme 87. Hydrostannation of propargylic alcohols using $\mathrm{Bu}_{2} \mathrm{Sn}(\mathrm{OTf}) \mathrm{H}$ followed by $n \mathrm{BuLi}$.

\subsection{Miscellanous methods.}

In 2018, a metal- and Lewis acid-free method was reported for the trans-hydrostannation of terminal and internal alkynes catalyzed by a trityl cation ${ }^{155}$ (Scheme 88). A screening of reaction conditions revealed a dramatic influence of the solvent, reaction time and reactional temperature. $n$-Pentane was used as solvent to avoid or reduce the formation of by-product $n$ - $\mathrm{Bu}_{4} \mathrm{Sn}$. Moreover, it was showed that $Z$-to- $E$ isomerization and decomposition occurred at prolonged time. Variously substituted terminal arylalkynes as well as terminal alkylalkynes were good substrates under the experimental conditions depicted in Scheme 88 and were rapidly transformed in $Z$-vinylstannanes in good yields with remarkable regioselectivities and excellent stereoselectivity. Similarly, di-substituted alkynes as 3-phenyl-prop-2-yne, ethyl 3phenylpropiolate and diethyl but-2-ynedioate were successfully transformed into (Z)-vinylstannanes with a total stereo and regioselectivity. It is suggested that the mechanism evolves by a stannilinium cation intermediate formed by a hydride abstraction of $\mathrm{Bu}_{3} \mathrm{SnH}$ by the trityl cation. Then hydrostannane adds anti across the triple bond to furnish a stabilized bridged $\beta$-vinyl cation which is selectively reduced by $\mathrm{Bu}_{3} \mathrm{SnH}$ in a trans manner for steric considerations. In contrast, is it of note that propiolic acid methyl ester (bottom of Scheme 88) added $\mathrm{Bu}_{3} \mathrm{SnH}$ in a trans 
manner but with reverse $\alpha$-regioselectivity to furnish the $\alpha$ branched (Z)-ethyl-3-phenyl-3-(tributylstannyl) acrylate in a good $90 \%$ yield.

\begin{tabular}{|c|c|c|c|c|}
\hline \multirow[t]{15}{*}{$\mathrm{R}^{1} \stackrel{\alpha \beta}{=} \mathrm{R}^{2}$} & \multicolumn{2}{|c|}{$\begin{array}{c}\mathrm{Bu}_{3} \mathrm{SnH}(1.0 \text { equiv }) \\
\underset{\left[\mathrm{Ph}_{3} \mathrm{C}\right]^{+}\left[\mathrm{B}\left(\mathrm{C}_{6} \mathrm{~F}_{5}\right)_{4}\right]^{-}(1 \mathrm{~mol} \%)}{n \text {-pentane, }-20{ }^{\circ} \mathrm{C} \text { to }-\mathrm{rt},} \\
0.5 \text { to } 24 \mathrm{~h}\end{array}$} & \multicolumn{2}{|c|}{$\mathrm{R}^{1 \curvearrowright} \prod_{\mathbf{I}}^{\mathrm{R}^{2}}+\mathrm{R}^{1 \uparrow} \overbrace{\mathrm{R}^{2}}^{\mathrm{SnBu}_{3}} \mathrm{II}^{2}$} \\
\hline & $\mathrm{R}^{1}$ & $\mathrm{R}^{2}$ & Yield (\%) I+II & I:II \\
\hline & $\mathrm{Ph}$ & $\mathrm{H}$ & (96) & $>95: 5$ \\
\hline & $4-\mathrm{FC}_{6} \mathrm{H}_{4}$ & $\mathrm{H}$ & (79) & $92: 8$ \\
\hline & 4- $\mathrm{ClC}_{6} \mathrm{H}_{4}$ & $\mathrm{H}$ & (77) & $89: 11$ \\
\hline & $4-\mathrm{MeOC}_{6} \mathrm{H}_{3}$ & $\mathrm{H}$ & (86) & $>95: 5$ \\
\hline & $2-\mathrm{MeC}_{6} \mathrm{H}_{4}$ & $\mathrm{H}$ & $(82)$ & $>95: 5$ \\
\hline & 4- $\mathrm{PhC}_{6} \mathrm{H}_{4}$ & $\mathrm{H}$ & (78) & $>95: 5$ \\
\hline & $\mathrm{Bn}$ & $\mathrm{H}$ & (76) & $>95: 5$ \\
\hline & $c$-Prop & $\mathrm{H}$ & $(96)$ & $>95: 5$ \\
\hline & $\mathrm{Cy}$ & $\mathrm{H}$ & $(96)$ & $>95: 5$ \\
\hline & $\mathrm{Ph}$ & $\mathrm{Me}$ & (67) & $>95: 5$ \\
\hline & $\mathrm{Ph}$ & $\mathrm{CO}_{2} \mathrm{Et}$ & (59) & $>95: 5$ \\
\hline & $\mathrm{CO}_{2} \mathrm{Et}$ & $\mathrm{CO}_{2} \mathrm{Et}$ & (76) & $>95: 5$ \\
\hline & $\mathrm{CO}_{2} \mathrm{Me}$ & $\mathrm{H}$ & $(90)$ & $0: 100$ \\
\hline $\mathrm{MeO}_{2} \mathrm{C}=$ & $\begin{array}{r}\mathrm{Bu}_{3} \mathrm{SnH} \\
\left.-\mathrm{H} \quad \mathrm{Ph}_{3} \mathrm{C}\right]^{+}\left[\mathrm{B}\left(\mathrm{C}_{6}\right.\right. \\
\end{array}$ & $\begin{array}{l}.0 \text { equiv }) \\
\left.5_{4}\right]^{-}(1 \mathrm{~mol} \%) \\
\mathrm{rt}, 1 \mathrm{~h}\end{array}$ & $\mathrm{MeO}_{2} \mathrm{C}$ & \\
\hline
\end{tabular}

Schema 88. Trityl cation-catalyzed hydrostannation of various alkynes.

Very recently, the first hydrostannation of phenylacetylene in the absence of metal-catalysts, Lewis acids and any additives was reported using tris(pentafloroethyl)tin $\left(\left(\mathrm{C}_{2} \mathrm{~F}_{5}\right)_{3} \mathrm{SnH}\right)^{156}$ (Scheme 89).

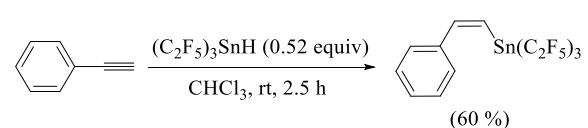

Scheme 89. $\left(\mathrm{C}_{2} \mathrm{~F}_{5}\right)_{3}$ SnH-catalyzed hydrostannation of phenylacetylene.

In contrast to metal-catalyzed hydrostannation of phenylacetylene using trialkyltin hydrides as $\mathrm{Bu}_{3} \mathrm{SnH}$, the reaction occurred in a trans fashion and produced solely the $(Z)$-isomer with no trace of the $(E)$-stereoisomer or the $\alpha$-branched vinyl stannane. The stereochemistry and the regiochemistry of the $(E)$-isomer was checked by NMR and X-ray analyses. However the impact of substituents on regioselectivity has not yet been studied and particularly with arylalkylalkynes having ortho-substituents for a competitive study. One drawback in this methodology is the instability of the electron-deficient tin hydride that oxidizes rapidly to give hexakis(pentafluoroethyl)distannane and $\mathrm{H}_{2}$ as soon as $\left(\mathrm{C}_{2} \mathrm{~F}_{5}\right)_{3} \mathrm{SnH}$ is not perfectly pure.

\section{Applications to synthesis.}

One of the noteworthy applications of the hydrostannation reactions lies in the selective generation of alkenylstannanes, which serve as vinyl anion synthetic equivalents as partners in Stille couplings, ${ }^{157,158}$ or by transformation into vinyl halides and further reaction with nucleophiles to afford stereodefined di- or trisubstituted olefins. ${ }^{141,159-162}$ Cascade hydrostannation /cyclization reactions for the synthesis of spirocyclic heterocycles have been also reported. ${ }^{163,164}$

Hydrostannation reactions have also found frequent uses in natural product synthesis, with some selected examples described in general reviews. ${ }^{15,16}$ Although, free-radical hydrostannations have been implemented in many syntheses of natural products, ${ }^{165,166}$ discussion in this section covers only some applications of transition-metal catalyzed reactions as applied to the total synthesis of natural products.

The palladium-catalyzed hydrostannation of internal propargylic alcohol derivatives ${ }^{167}$ is used efficiently for the construction of the polypropionate segment of Callystatin A, a highly cytotoxic marine polyketide. Reaction with the primary propargylic acetate $\mathbf{6 1}$ followed by iodination gives the alkenyl iodide $\mathbf{6 2}$ in $81 \%$ overall yield (Scheme 90). ${ }^{168}$

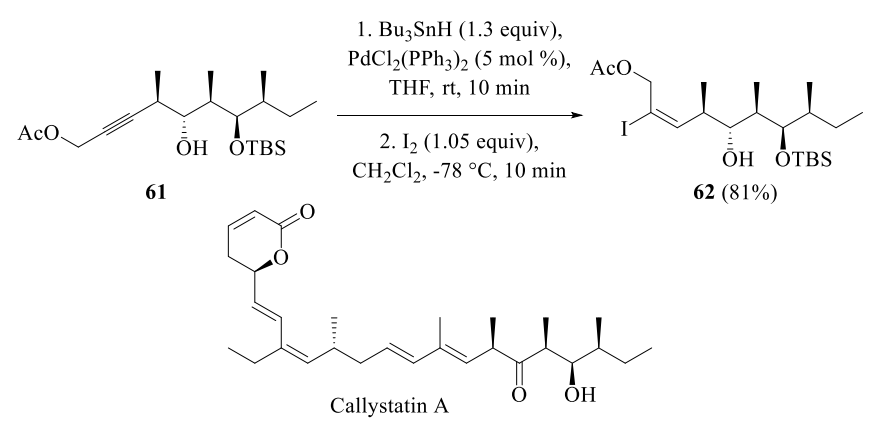

Scheme 90. Pd-catalyzed hydrostannation of 61 .

A palladium-catalyzed hydrostannation of alkynyl esters ${ }^{91,169,170}$ is used in a synthesis of 4-alkylidenebutenolactone $\mathbf{6 5}$, a substructure of the carotenoids pyrrhoxanthin and peridinin. It is suggested that in addition to electronic polarization of the acetylenic bond, the presence of the neighboring isopropylidenedioxy group in $\mathbf{6 3}$ is responsible for the formation of the single stereo- and constitutional isomer 64 (Scheme 91). ${ }^{171}$ Further transacetalization/trans-esterification and Stille coupling of 64 provides $\gamma$-alkylidenebutenolide $\mathbf{6 5}$ with the (Z)-configuration of the exocyclic $\mathrm{C}=\mathrm{C}$ double bond.

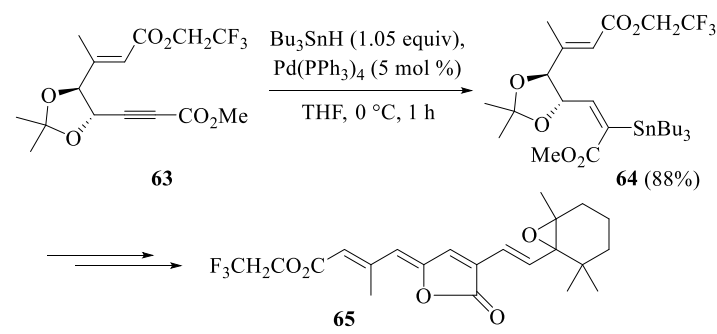

Scheme 91. Pd-catalyzed hydrostannation of 63 .

Similarly, alkynyl amides are also suitable hydrostannation substrates. Thus, hydrostannation of $\mathbf{6 6}$ allows the exclusive formation of the alkenylstannane $\mathbf{6 7}$ in $85 \%$ yield. Stille coupling of this fragment with diodide $\mathbf{6 8}$, followed in a late-stage by double asymmetric intramolecular Heck reaction leads to the synthesis of (-)-Quadrigemine C and psycholeine (Scheme 92). ${ }^{172}$

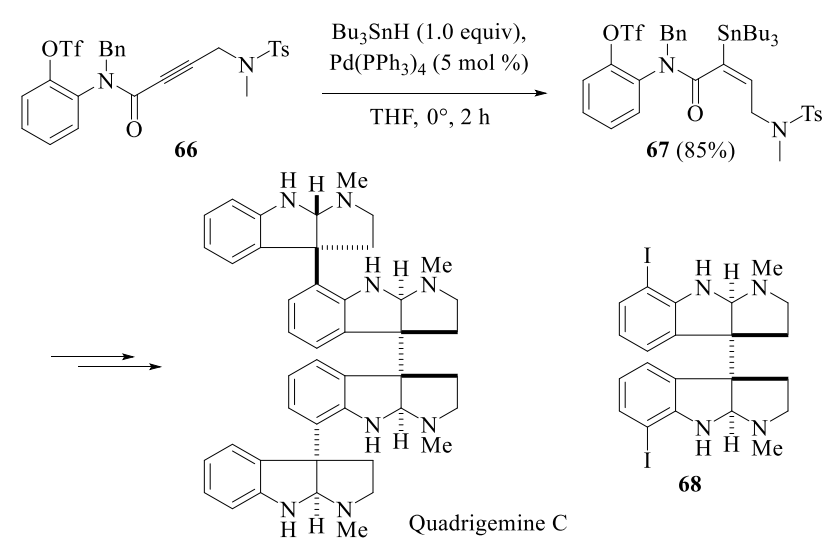

Scheme 92. Pd-catalyzed hydrostannation of 66. 
Examples of the use of the hydrostannation of (phenylthio)alkynes ${ }^{106}$ include the synthesis of the lactone core of 8 -epi-griseoviridin. The authors nicely demonstrate that the unsaturated nine-membered lactone 69 undergoes regio- and stereoselective palladium-catalyzed hydrostannation to provide pure alkenyltin lactone 70 (Scheme 93). Subsequent tin-iodine exchange and palladium-catalyzed carbonylation deliver the propargyl amide $\mathbf{7 1} .{ }^{173}$

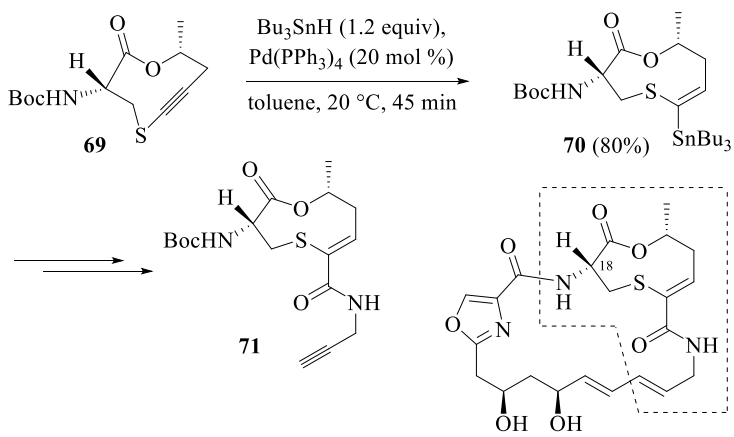

Griseoviridin

Scheme 93. Pd-catalyzed hydrostannation of 69.

The problems associated with non-selective, palladium-catalyzed hydrostannation ${ }^{174}$ of the advanced intermediate enyne $\mathbf{7 2}$ have been remedied through the use of molybdenum catalysis. To achieve the synthesis of $(-)$ Borrelidin, a potent antimitotic and antiangiogenic macrolide, the authors perform the alkyne bond hydrostannation with $\mathrm{Mo}(\mathrm{CO})_{3}(t-\mathrm{BuNC})_{3}$ as the catalyst. Accordingly, the reaction gives a single consitutional isomer in which the tin moiety is proximal to the carbonyl function. The regioselectivity of this addition is influenced by the presence of the carbonyl group; in a related experiment with a macrolide containing an enyne-alcohol motif the hydrostannation is much less regioselective. Subsequent iodination of the $\mathrm{C}-\mathrm{Sn}$ bond delivers the corresponding alkenyl iodide $\mathbf{7 3}$ in $54 \%$ overall yield (Scheme 94). ${ }^{175}$

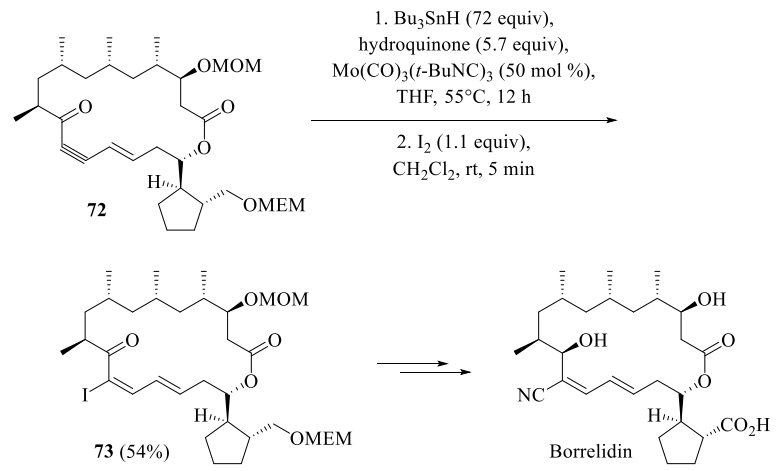

Scheme 94. Mo-catalyzed hydrostannation of $\mathbf{7 2}$.

Application of the molybdenum-catalyzed hydrostannation toward a flexible synthesis of substituted, unsaturated amino acids has been reported. ${ }^{176,177}$

The efficiency of molybdenum pre-catalyst $\mathbf{5 1}$ and its accommodation towards complex molecular structure as Mifepristone, a synthetic steroid that acts as a progesterone receptor antagonist was reported ${ }^{126}$ (Scheme 95).
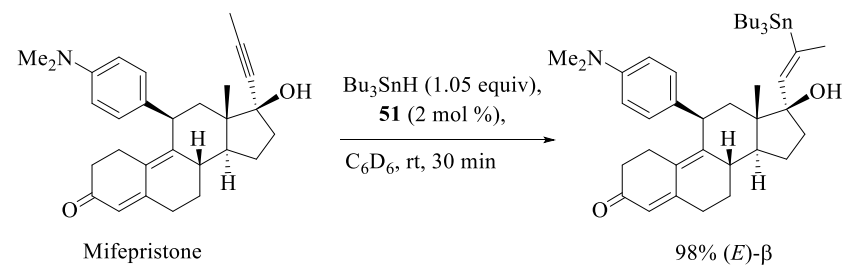

Scheme 95. Mo-complex 51-catalyzed hydrostannation of 61.

Using 1.05 equiv of $\mathrm{Bu}_{3} \mathrm{SnH}$ in the presence of $\mathbf{5 1}(2 \mathrm{~mol} \%)$ in $\mathrm{C}_{6} \mathrm{D}_{6}$ at $\mathrm{rt}$ for $30 \mathrm{~min}$, Mifepristone was transformed into the $(E)$ $\beta$-vinylstannane with a $(\beta: \alpha=98: 2)$ regioselectivity in a nearly quantitative yield $(98 \%)$.

A rhodium-catalyzed hydrostannation of terminal propargylic alcohols has also been described in a synthesis of nicandrenone, a member of a family of structurally complex, steroid-derived natural products. Hydrostannation of substrate $\mathbf{7 4}$ with Wilkinson's catalyst, $\left[\mathrm{RhCl}\left(\mathrm{PPh}_{3}\right)_{3}\right]$ provides alkenylstannae $\mathbf{7 5}$ in a modest $47 \%$ yield but with good $\alpha$-selectivity (Scheme 96). ${ }^{14}$ This compound was later used as a coupling partner for the installation of the side chain onto the steroid skeleton $\mathbf{7 6}$.

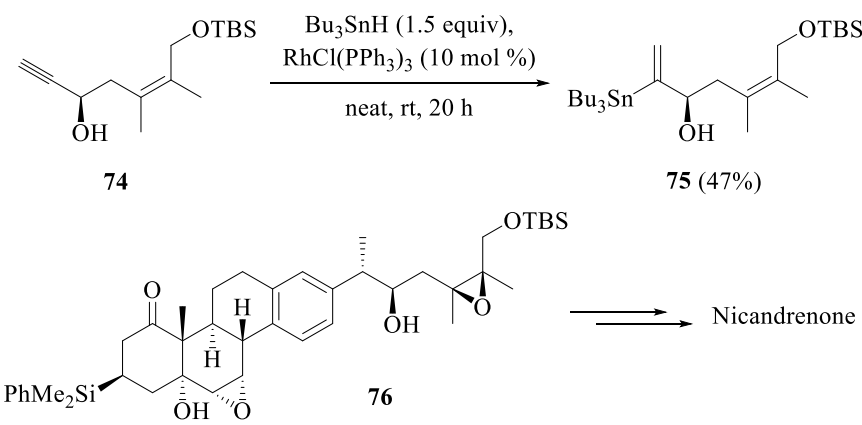

Scheme 96. Rh-catalyzed hydrostannation of $\mathbf{7 4}$.

During the completion of the total synthesis of Nannocystin Ax a potent cytotoxic agent, ${ }^{178}$ the Fürstner group reported the efficiency of the $\left[\mathrm{Cp}^{*} \mathrm{RuCl}\right]_{4}$ catalyst 17 for the transhydrostannation of the polyfunctionalized propargylic alcohol $\mathbf{7 7}$ (Scheme 97). This transformation occurred cleanly to give $\mathbf{7 8}$ as a single regio- and stereoisomer in a $80 \%$ yield. A further methylation of the vinylstannane moiety of $\mathbf{7 8}$ followed by methylation of secondary alcohol ${ }^{179}$ and reduction of the phenacyl group by $\mathrm{Zn}$, led to Nannocystyn Ax. As vinylstannane $\mathbf{7 8}$ was obtained at the end of the synthesis, Fürstner used this opportunity to prepare a panel of non-naturel analogues for a biological evaluation.

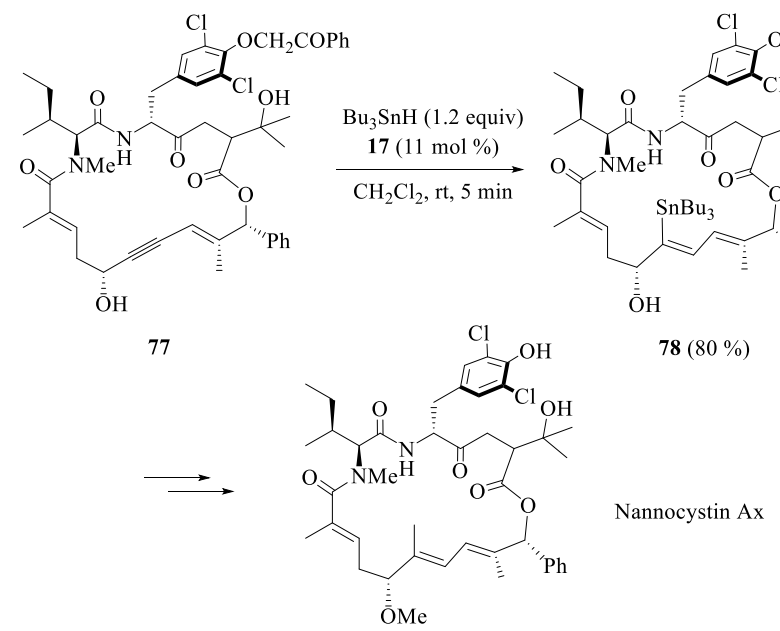

Scheme 97. Ru-complex 17 catalyzed trans-hydrostannation of 77. 
A variety of total syntheses using the trans-hydrostannation of alkynes with comparisons of ruthenium-catalyzed and radical conditions has been compiled very recently by the Fürstner's group. ${ }^{132,180,181}$

\subsection{Comparison with other methods.}

The classical approaches to the synthesis of alkenylstannanes are the reactions of alkenyl metallic reagents with tin halides or the condensation of a tin-metal compounds with electrophiles. In addition to hydrostannation reactions of alkynes, there exists other ways of forming an alkenyl-Sn bond from acetylenic substrates. The more widely used methods include the stoichiometric stannylcupration of alkynes and the catalytic stannylmetalation of alkynes in the presence of a transition metal. ${ }^{64}$ Direct comparisons among the various methods are rare, ${ }^{58,73}$ and they are further complicated by the complexity of the number of factors impacting the selectivity for a given transformation. Accordingly, only general considerations are provided here.

Alkenylstannanes usually are prepared by the reaction of an alkenyllithium or -magnesium reagents with trialkyltin chlorides. In the case of elaborated substrates, this transformation requires the stereoselective preparation of an alkenyl metallic reagent through multi-step synthesis prior to the coupling with $\mathrm{R}_{3} \mathrm{SnX}$, thus generating waste. Because alkenyllithium or -magnesium reagents are very often incompatible with labile functional groups, this synthetic reaction is not suitable for obtaining functionalized alkenylstannanes when compared to the hydrostannation-based process. Another way to achieve the synthesis of alkenylstannanes is the addition of $\mathrm{Bu}_{3} \mathrm{Sn}-\mathrm{M}($ e.g., $\mathrm{Li}, \mathrm{Mg}$ ) with a carbonyl compound followed by an elimination step. This procedure is well suited for the preparation of cyclic alkenylstannanes. ${ }^{182}$

The formation of alkenylstannanes from alkynes is possible by other means, such as stannylmetalation, ${ }^{21}$ using bimetallic reagents of the type $\mathrm{R}_{3} \mathrm{Sn}-\mathrm{MRn}$ in which $\mathrm{M}=\mathrm{B}, \mathrm{Al}, \mathrm{Cu}, \mathrm{Zn}, \mathrm{Si}$, or $\mathrm{Sn}$. A noteworthy feature of these reagents is their low basicity. As a consequence, stannylmetalation may be performed on alkynes that contain functional groups such as hydroxyl, ester, amine, and halide. Stannylmetalation ${ }^{20}$ of alkynes may be divided into two categories: (1) stoichiometric stannylcupration and (2) catalytic stannylmetalation in the presence of a transition metal (e.g., $\mathrm{Cu}$, Pd). Both processes lead to syn-addition of the bimetallic species unless equilibration occurs. The main drawback of these processes is the necessity to use stoichiometric amounts of both the metalloid tin and another metal, thus generating waste from reagents.

Stoichiometric stannylcupration of alkynes ${ }^{64,183}$ followed by protonation of the cuprate species is a complementary process to the Pd-catalyzed hydrostannation of alkynes. Although the two processes proceed with excellent cis-stereoselectivity, the regioselectivity of the addition of stannylcuprates to alkynes is not only dependent on the reaction temperature, proton sources, and the temperature at which the reaction is quenched, but also on the structure of the alkyne and the nature of stannylcopper species. In many instances, stoichiometric stannylcuprations require an excess (1.3-4 equiv) of reagent for the efficient consumption of starting material. The reaction of the mixed higer order cuprate (e.g., $\mathrm{Bu}_{3} \mathrm{Sn}(\mathrm{Bu}) \mathrm{Cu}(\mathrm{CN}) \mathrm{Li}_{2}, \mathrm{Bu}_{3} \mathrm{Sn}(\mathrm{Me}) \mathrm{Cu}(\mathrm{CN}) \mathrm{Li}_{2}$ ) with several monosubstituted alkynes lead regioselectively to the product of syn addition in which the tin moiety is bound to the less hindered acetylenic carbon. In terms of reaction scope, the reaction works well for acetylene itself, for terminal alkynes, propargyl systems, enynes, carbonyl-conjugated alkynes, and even for internal alkynes, though yields are lower in this last case. Depending on the substrate studied, a simple pre-association of the organometallic derivative with an additional polar functional group in the vicinity of the reaction center may completely change the stereochemical outcome of the reaction.

Copper sources are the most popular choice for catalysts in transition metal-catalyzed stannylmetalation, with the second metal often being $\mathrm{Al}, \mathrm{Zn}, \mathrm{Mg}$, etc. ${ }^{21}$ Although terminal alkynes undergo stannylmetalation with a high degree of regio- and stereocontrol, internal alkynes usually require the presence of some activating group such as an ester, to achieve useful control. Reactions utilizing tin-based reagents in which the metal is $\mathrm{Al}$, $\mathrm{Mg}, \mathrm{Zn}$, or $\mathrm{Cu}$ often require a two- or three-fold excess of the reactant to achieve high consumption of the alkyne. Most of the excess of organotin reagents is converted to hexaalkylditins, which often complicate product isolation. ${ }^{184}$ In addition to the inherent bias in the bimetallic reagent, the regio- and stereochemical outcome of the reaction may be influenced by the catalyst and the reaction conditions. A stereo-directing effect through intramolecular coordination also plays a fundamental role in stannylmetalation reactions.

Palladium(II) catalysts have also been used in the stannylation of alkynes. ${ }^{185-186}$ The regiochemistry of the transition metal-catalyzed stannylmetalation depends on a number of factors including the metal partner, catalyst, solvent and other additives. In some instances, the use of copper or palladium as the catalyst in the stannylmetalation of terminal aliphatic and aromatic alkynes may prove to be complementary. ${ }^{186}$ The comparison of the palladiumcatalyzed stannylmetalation to the hydrostannation-based process offers important advantages to the latter process in view of protocol simplicity, reagent preparation, and waste products.

Carbostannation of terminal alkynes, ${ }^{187-189}$ which allows the simultaneous formation of $\mathrm{C}-\mathrm{C}$ and $\mathrm{C}-\mathrm{Sn}$ bonds is also a useful method for the generation of stereo- and regio- defined alkenylstannanes. This catalytic method is best achieved under Pdor Ni-catalysis and occurs with cis-stereoselectivity, furnishing mainly the constitutional isomer in which the stannyl group resides at the less hindered carbon, though the reaction of ynoates and ynones shows the opposite regioselectivity. In many instances, the carbostannation of terminal alkynes is complementary to the conventional hydrostannation of internal alkynes because of the formation of different constitutional and stereoisomers. Carbostannation of internal alkynes offers unique advantages to the hydrostannation-based process in that it allows access to structurally complex trisubstituted alkenylstannanes having alkynyl, alkenyl or acyl groups. These compounds serve as versatile precursors for the synthesis of various tetrasubstituted alkenes that are found in many important pharmaceuticals and bioactive natural products.

\section{Experimental conditions.}

Organotin hydrides (e.g., $\mathrm{Bu}_{3} \mathrm{SnH}, \mathrm{Ph}_{3} \mathrm{SnH}$ ), in general, are toxic and should be handled with care in a fume hood, and that protective clothing and gloves are worn at all times. Care must also be taken in using appropriate waste disposal procedures.

The highest toxicity is observed in triorganotin compounds, whereas diorganotin and monoorganotin compounds show successively lower toxicity. ${ }^{190,191}$ The toxicity of tetraorganotin compounds is low; however under environmental conditions they will decompose to toxic triorganotins. ${ }^{192}$ The organic group attached to tin also plays a significant role in the toxicity. Triethyltin compounds are the most toxic, followed by methyl, propyl, and butyl. ${ }^{190}$ Trioctyltin compounds have very low toxicity, while triphenyl and tricyclohexyltin compounds show considerable toxicity. ${ }^{190}$ 
Trimethyltin hydride $\left(\mathrm{bp}=59{ }^{\circ} \mathrm{C}\right.$ ) is unstable to oxidative and photolytic processes; it is not commercially available and best used immediately upon synthesis. Its preparation involves the reaction of $\mathrm{LiAlH}_{4}$ with $\mathrm{Me}_{3} \mathrm{SnCl}$ in ethereal solvents. Highest yields are obtained by using high boiling solvents such as bis(2-ethoxyethyl) ether. $\mathrm{Me}_{3} \mathrm{SnH}$ is a quite toxic reagent and should be used with utmost care; its use in hydrostannation reactions generated as sideproduct hexamethylditin, a volatile and highly toxic compound upon ingestion, inhalation, or skin contact.

Commercially available as colorless liquids, tributyl- and triphenyltin hydrides can be prepared by reduction of bis(tributylltin) oxide or bis(triphenyltin) oxide with polymethylhydrosiloxane, respectively. ${ }^{193}$ The most commonly used reagent tributyltin hydride has also been generated in situ from $\mathrm{Bu}_{3} \mathrm{SnCl}$ and polymethylhydrosiloxane. ${ }^{55,150,194,195}$ Organotin hydrides can be stored for several months, and are easily repurified by Kugelrohr distillation (oil-pump vacuum) before use. They decompose slowly at $\mathrm{rt}$ and are best stored at $0{ }^{\circ} \mathrm{C}$ or below $\left(\mathrm{Ph}_{3} \mathrm{SnH}\right.$ solidifies in a refrigerator). Decomposition is catalyzed by air, silicone grease, metallic surfaces, amines and, in the case of triphenyltin hydride, by light. It should be kept in brown bottles away from light and air. Manipulations of the compound are usually best done in an inert atmosphere.

Concerns over the toxicity of organotin reagents, products and byproducts, and difficulties associated with the purification of product mixtures containing organotin residues represents a major drawback for use of tin-mediated reactions, especially when testing the biological activity of the products is foreseen. Numerous approaches and methodologies limiting or avoiding contamination by organotin residues have been reviewed very recently. ${ }^{196}$

Transition-metal catalyzed hydrostannation reactions should be carried under an inert atmosphere using anhydrous conditions. The reactions are usually carried out by the dropwise addition of $\mathrm{R}_{3} \mathrm{SnH}$ to a stirred solution of the catalyst and substrate in order to minimize the undesired hexabutyldistannane side-product formation by maintaining a low concentration of tin hydride. Toward the end of the addition, the originally light yellow solution abruptly turned orange-brown then dark-brown, and $\mathrm{H}_{2}$ evolution was observed, signaling the formation of $\left(\mathrm{Bu}_{3} \mathrm{Sn}\right)_{2}$. Protodestannation of alkenylstannanes is often a problem during purification on silica gel giving low isolated yields. This drawback may be limited or even avoided by using basic or neutral alumina or triethylamine-treated silica gel.

The Table below (Table 1) provides the chemist an overview of selected, efficient and general procedures, which can be used as guides to search for "first-attempt" reaction conditions for a planned transformation. Since its first synthesis, ${ }^{197} \mathrm{Bu}_{3} \mathrm{SnH}$ has been the most commonly used reagent for any hydrostannation due to its availability, ease of handling, and reactivity. It should be noted that the $\mathrm{R}$ group attached to the tin atom affects not only the reactivity but also the stereoselectivity of the tin hydride addition. Trimethyltinhydride has been used but its volatility and toxicity make it unattractive for use. The reaction of $\mathrm{Ph}_{3} \mathrm{SnH}$ with alkyne is more sluggish than its tributyl counterpart, and the resulting vinyltriphenylstannane product has a critical drawback to metalcatalyzed Stille coupling reactions due to the difficulty of discriminating the transfer of the vinyl and phenyl groups. ${ }^{198}$ Strategies to generate organotin hydrides in situ so as to carry out hydrostannation of alkynes in more benign ways have been also reported. ${ }^{55,150,194,195}$ The protocol involving in situ generation of $\mathrm{Bu}_{3} \mathrm{SnH}$ from the reduction of $\mathrm{Bu}_{3} \mathrm{SnX}$ with polymethylhydrosiloxane (PMHS) is general and can be applied to a wide array of terminal alkynes in free radical and palladium- catalyzed hydrostannations, producing alkenylstannanes in good to excellent yields. An elegant demonstration is the combination of PMHS, aqueous KF, and catalytic amounts of $\mathrm{Bu}_{3} \mathrm{SnCl}$ in the presence of a terminal alkyne, together with a catalytic amount of $\mathrm{Pd}_{2} \mathrm{dba}_{3} / \mathrm{TFP}$, and iodobenzene effects a one-pot hydrostannation/Stille coupling sequence of the in situ formed alkenylstannane. ${ }^{55}$

\begin{tabular}{|c|c|c|c|}
\hline & \multicolumn{3}{|c|}{ Alkyne hydrostannation procedure under } \\
\hline & metal catalyst & radical conditions & Lewis acid \\
\hline tin reagent & $\begin{array}{l}\mathrm{Bu}_{3} \mathrm{SnH}, \mathrm{Ph}_{3} \mathrm{SnH}, \\
\mathrm{Me}_{3} \mathrm{SnH}, \\
\mathrm{Bu}_{3} \mathrm{SnCl} / \mathrm{PMHS} \\
\mathrm{Bu}_{3} \mathrm{SnF} / \mathrm{PMHS} / \mathrm{TBAF}\end{array}$ & $\begin{array}{l}\mathrm{Bu}_{3} \mathrm{SnH}, \mathrm{Ph}_{3} \mathrm{SnH} \\
\mathrm{Bu}_{3} \mathrm{SnCl} / \mathrm{NaBH}_{4} \\
\left(\mathrm{Bu}_{3} \mathrm{Sn}\right)_{2} \mathrm{O} / \mathrm{PMHS}\end{array}$ & $\begin{array}{l}\mathrm{Bu}_{3} \mathrm{SnH}, \mathrm{Bu}_{2} \mathrm{SnH}_{2}, \\
\mathrm{Bu}_{2} \mathrm{SnIH}, \\
\mathrm{Bu}_{3} \mathrm{SnCl} / \mathrm{Et}_{3} \mathrm{SiH}\end{array}$ \\
\hline $\begin{array}{l}\text { catalyst or } \\
\text { promoter }\end{array}$ & $\begin{array}{l}\mathrm{Pd}\left(\mathrm{PPh}_{3}\right)_{4}, \mathrm{PdCl}_{2}\left(\mathrm{PPh}_{3}\right)_{2}, \\
\mathrm{Pd}(\mathrm{OAc})_{2} / \mathrm{PPh}_{3}, \mathrm{Pd}(\mathrm{OH})_{2} / \mathrm{C} \\
\mathrm{PdCl}_{2}(\mathrm{dppe}), \mathrm{Pd}_{2} \mathrm{dba}_{3} / \mathrm{PAr}_{3}, \\
\mathrm{Pd}_{2} \mathrm{dba}_{3} / \mathrm{Cy}_{3} \mathrm{PHBF}_{4}\end{array}$ & $\begin{array}{l}\text { AIBN } / \mathrm{O}_{2} \\
\mathrm{Et}_{3} \mathrm{~B} / \mathrm{O}_{2} \\
\text { ultrasound }\end{array}$ & $\begin{array}{l}\mathrm{ZrCl}_{4} \\
\mathrm{HfCl}_{4} \\
\mathrm{~B}\left(\mathrm{C}_{6} \mathrm{~F}_{5}\right)_{3} \\
\mathrm{MgBr}_{2} \cdot \mathrm{OEt}_{2}\end{array}$ \\
\hline & $\begin{array}{l}\mathrm{Mo}(\text { allyl })(\mathrm{CO})_{2}(\mathrm{MeCN})_{2} \mathrm{Br} \\
\mathrm{Mo}(\mathrm{CO})_{3}(\mathrm{CN} t-\mathrm{Bu})_{3} \\
{\left[\eta^{5}-\mathrm{C}_{5} \mathrm{Me}_{5} \mathrm{Ru}(\mathrm{MeCN})_{3}\right] \mathrm{PF}_{6} \mathbf{1 6}} \\
{\left[\eta^{5}-\mathrm{C}_{5} \mathrm{Me}_{5} \mathrm{RuCl}\right]_{4} \mathbf{1 7}} \\
\text { Diruthenium complex } \mathbf{1 8}\end{array}$ & & \\
\hline solvent & THF, $\mathrm{CH}_{2} \mathrm{Cl}_{2}$, AcOEt & Toluene, benzene, THF & Toluene, hexane \\
\hline temperature & $20^{\circ} \mathrm{C}$ & $\begin{array}{l}60-80^{\circ} \mathrm{C}\left(\mathrm{AIBN} / \mathrm{O}_{2}\right) \\
20^{\circ} \mathrm{C}\left(\mathrm{Et}_{3} \mathrm{~B} / \mathrm{O}_{2}\right) \\
\text { up to }-50^{\circ} \mathrm{C} \text { (ultrasound) }\end{array}$ & $0{ }^{\circ} \mathrm{C}$ \\
\hline stereochemistry & $\begin{array}{l}\mathrm{Pd}, \mathrm{Mo} \text { : cis-addition } \\
\mathrm{Ru} \text { : anti-addition }\end{array}$ & anti-addition & anti-addition \\
\hline
\end{tabular}

Table 1. General reaction conditions for alkyne hydrostannation.

The radical-induced hydrostannation of alkynes typically requires heating at $60-80{ }^{\circ} \mathrm{C}$ in the presence of a catalytic amount of AIBN. The use of triethylborane ( $v s$ AIBN) as initiator142 at room temperature may improve the selectivity, but the scope of this method is generally limited to the synthesis of vinyltriphenylstannanes. ${ }^{141}$ Ultrasound-promoted radical hydrostannation of terminal alkynes was found to proceed $>100$ times faster than those without it at temperatures as low as -50 ${ }^{\circ} \mathrm{C}$. Erreur ! Signet non défini. In all instances, reactions may be carried out in nonpolar (e.g., toluene, benzene) as well as polar solvents (e.g., THF). In contrast to radical-induced processes, the Lewis acid (e.g., $\mathrm{ZrCl}_{4}$ ) promoted hydrostannation of alkynes requires the use of nonpolar solvents such as toluene or hexane at $0{ }^{\circ} \mathrm{C}$ for obtaining high stereoselectivity and yield. ${ }^{50}$

In transition metal-catalyzed reactions, palladium complexes are the catalyst of choice for hydrostannation of alkynes if $E$ alkenylstannanes are desired. In addition to the most widely used palladium complexes $\mathrm{Pd}\left(\mathrm{PPh}_{3}\right)_{4}$ and $\mathrm{PdCl}_{2}\left(\mathrm{PPh}_{3}\right)_{2}$, many other palladium sources, with or without phosphine ligands, that have been successfully employed including $\mathrm{Pd}(\mathrm{OAc})_{2} / \mathrm{PPh}_{3},{ }^{199}$ $\mathrm{Pd}(\mathrm{OH})_{2} / \mathrm{C},{ }^{24} \quad \mathrm{PdCl}_{2}(\mathrm{dppe}),{ }^{62} \quad \mathrm{Pd}_{2}(\mathrm{dba})_{3} / \mathrm{PAr}_{3},{ }^{84}$ or $\mathrm{Pd}_{2}(\mathrm{dba})_{3} / \mathrm{Cy}_{3} \mathrm{PHBF}_{4}{ }^{54}$ Contrary to early work, ${ }^{23}$ the type of ligand used dramatically affects the regioselectivity of Pd-catalyzed hydrostannation of terminal alkynes ${ }^{54}$ In all these instances, THF is the most commonly used solvent, although other solvents (e.g., EtOAc, $\mathrm{Et}_{2} \mathrm{O}$, toluene, etc.) may be used, but they have modest impact on the regioselectivity with increasing solvent

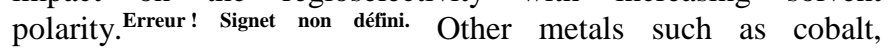
molybdenum, nickel, platinum, rhodium, ruthenium, and tungsten have been employed as well, but only those metal complexes (e.g., $\mathrm{Mo}, \mathrm{Ru}$ ) leading to different selectivities are reported in Figure 2.

\section{Conclusion.}

$\alpha$ - or $\beta$-Vinyl stannanes, easily prepared by hydrostannation of alkynes, are very useful substrates in organic chemistry and in complicated total synthesis. Using metal-catalysis were Pd- 
catalysts predominated, the addition of tin hydride on the triple bond occurred in a syn-fashion to give $(E)$-vinyl adducts as major or sole products. On the contrary, in the presence of Lewis acids, under radical conditions or using Ru-based complexes, the tin addition on the triple bond occurs in anti for different reasons (electronic, steric, thermodynamic,...). The problem of regioselectivity of the tin addition on alkyne triple bond is probably more complicated because depending of alkyne substrates even if a variety of methodologies reported in this review led to a single vinyl stannane isomer useful in complicated syntheses.

\section{References and notes}

1. Stille, J. K. The Palladium-Catalyzed Cross-Coupling Reactions of Organotin Reagents with Organic Electrophiles. Angew. Chem. Int. Ed. Engl. 1986, 25, 508524.

2. Neumann, W. P. The Organic Chemistry of Tin, WileyInterscience: New York 1970.

3. Sawyer, A. Organotin Compounds; Marcel Dekker: New York, 1971.

4. Peyrere, M.; Quintard, J. P.; Rahm, A. Tin in Organic Synthesis; Butterworth: London, 1987.

5. Farina, V.; Krishnamurthy, V.; Scott W. J. The Stille Reaction. Org. React. 1997, 50, 1-562.

6. Espinet, P.; Echavarren, A. M. The Mechanisms of the Stille Reaction. Angew. Chem. Int. Ed. 2004, 43, 4704-4734.

7. Fürstner, A.; Funel, J.A.; Tremblay, M.; Bouchez, L.C.; Nevado, C.; Waser, M.; Ackerstaff, J.; Stimson, C.C. A Versatile Protocol for Stille-Migita Cross Coupling Reactions. Chem. Commun. 2008, 2873-2875.

8. Dalby, S.M.; Goodwin-Tindall, J.; Paterson, I. Synthesis of (-)-Rhizopodin. Angew. Chem. Int. Ed. Engl. 2013, 52, 6517-6521.

9. Mailhol, D.; Willwacher, J.; Kausch-Busies, N.; Rubitski, E.E.; Sobol, Z.; Schuler, M.; Lam, M.H.; Musto, S.; Loganzo, F.; Maderna, A.; Fürstner, A. Synthesis, Molecular Editing, and Biological Assessment of the Potent Cytotoxin Leiodermatolide. J. Am. Chem. Soc. 2014, 136, 15719-15729.

10. Gagnepain, J.; Moulin, E.; Fürstner, A. Gram-Scale Synthesis of Iejimalide B. Chem. Eur. J. 2011, 17, 69646972.

11. O’Neil, G.; Craig, A.M.; Williams, J.R.; Young, J.C.; Spiegel, P.C. Synthesis of the C1-C23 Fragment of the Archazolids and Evidence for V-ATPase but not COX Inhibitory Activity. Synlett 2017, 28, 1101-1105.

12. Heck, R. F. Palladium Reagents in Organic Synthesis; Academic Press: New York, 1985.

13. Volgraf, M.; Gorostiza, P.; Szobota, S.; Helix, M. R.; Isacoff, E. Y.; Trauner, D. Reversibly Caged Glutamate: A Photochromic Agonist of Ionotropic Glutamate Receptors. J. Am. Chem. Soc. 2007, 129, 260-261.

14. Stoltz, B. M.; Kano, T.; Corey, E. J. Enantioselective Total Synthesis of Nicandrenones. J. Am. Chem. Soc. 2000, 122, 9044-9045.

15. Smith, N. D.; Mancuso, J.; Lautens, M. Metal-Catalyzed Hydrostannations. Chem. Rev. 2000, 100, 3257-3282.

16. Trost, B. M.; Ball, Z. T. Addition of Metalloid Hydrides to Alkynes: Hydrometallation with Boron, Silicon, and Tin. Synthesis 2005, 853-887.

17. Kimbrough, R. D. Toxicity and Health Effects of Selected Organotin Compounds: a review. Environ. Health Perspect. 1976, 14, 51-56.

18. Ichinose, Y.; Oda, H.; Oshima, K.; Utimoto, K. Palladium Catalyzed Hydrostannylation and Hydrogermylation of Acetylenes. Bull. Chem. Soc. Jpn. 1987, 60, 3468-3470.
19. Yoshida, H.; Stannylation Reactions under Base Metal Catalysis: Some Recent Advances. Synthesis, 2016, 48, 2540-2552.

20. Casson, S.; Kocienski, P. In Organometallic Reagents in Organic Synthesis; Bateson, J. H.; Mitchell, M. B., Eds.; Academic Press: London, 1994; pp 129-159.

21. Casson, S.; Kocienski, P. The Hydrometallation, Carbometallation, and Metallometallation of Heteroalkynes. Contemp. Org. Synth. 1995, 2, 19-34.

22. Asao, N.; Yamamoto, Y. Lewis Acid-Catalyzed Hydrometalation and Carbometalation of Unactivated Alkynes. Bull. Chem. Soc. Jpn. 2000, 73, 1071-1087.

23. Zhang, H. X.; Guibé, F.; Balavoine, G. Palladium- and Molybdenum-Catalyzed Hydrostannation of Alkynes. A Novel Access to Regio- and Stereodefined Vinylstannanes. J. Org. Chem. 1990, 55, 1857-1867.

24. Lautens, M.; Smith, N. D.; Ostrovsky, D. PalladiumCatalyzed Hydrostannation- Cyclization of 1, 6-Diynes. Generation of 1, 2-Dialkylidenecyclopentanes with a Tributylstannane Moiety. J. Org. Chem. 1997, 62, 89708971.

25. Trebbe, R.; Schager, F.; Goddard, R.; Pörschke, K.-R. cis$\left(\mathrm{R}_{2}{ }_{2} \mathrm{PC}_{2} \mathrm{H}_{4} \mathrm{PR}_{2}\right) \mathrm{PdH}\left(\mathrm{SnR}_{3}\right) \quad$ Complexes: Trapped Intermediates in the Palladium-Catalyzed Hydrostannation of Alkynes. Organometallics 2000, 19, 521-526.

26. Lautens, M.; Mancuso, J. Formation of Homoallyl Stannanes via Palladium-Catalyzed Stannylative Cyclization of Enynes. Org. Lett. 2000, 5, 671-673.

27. Alami, M; Liron, F.; Gervais, M.; Peyrat, J.-F.; Brion, J.-D. Ortho Substituents Direct Regioselective Addition of Tributyltin Hydride to Unsymmetrical Diaryl (or Heteroaryl) Alkynes: An Efficient Route to Stannylated Stilbene Derivatives. Angew. Chem. Int. Ed. 2002, 41, 15781580 .

28. Zhang, H. X.; Guibé, F.; Balavoine, G. Palladium Catalyzed Hydrostannation of Alkynes and Palladium-Catalyzed Hydrostannolysis of Propargyl or Propargyloxycarbonyl Derivatives of Various Functional Groups. Tetrahedron Lett. 1988, 29, 619-622.

29. Rummelt, S. M.; Fürstner, A. Ruthenium-Catalyzed transSelective Hydrostannation of Alkynes. Angew. Chem. Int. Ed. 2014, 53, 3626-3630.

30. Gupta, S.; Do, Y.; Lee, J. H.; Lee, M.; Han, J.; Rhee, Y. H.; Park, J. Novel Catalyst System for Hydrostannation of Alkynes. Chem. Eur. J. 2014, 20, 1267-1271.

31. Fürstner, A. J. Am. Chem. Soc. trans-Hydrogenation, gemHydrogenation, and trans-Hydrometalation of Alkynes: An Interim Report on an Unorthodox Reactivity Paradigm. DOI:10.1021/jacs.8b09782

32. Rummelt, S. M.; Radkovski, K.; Roşca, D. A.; Fürstner, A. Interligand Interactions Dictate the Regioselectivity of trans-Hydrometalations and Related Reactions Catalyzed by [Cp*RuCl]. Hydrogen Bonding to a Chloride Ligand as a Steering Principle in Catalysis. J. Am. Chem. Soc. 2015, 137, 5506-5519.

33. Roşca, D. A.; Radkovski, K.; Wolf, L. M.; Wagh, M.; Goddard, R.; Thiel, W.; Fürstner, A. Ruthenium-Catalyzed Alkyne trans-Hydrometalation: Mechanistic Insights and Preparative Implications. J. Am. Chem. Soc. 2017, 139, 2443-2455.

34. Trost, B. M.; Ball, Z. T. Intramolecular endo-dig Hydrosilylation Catalyzed by Ruthenium: Evidence for a New Mechanistic Pathway. J. Am. Chem. Soc. 2003, 125, 30-31.

35. Fürstner, A. Catalysis for Total Synthesis: A Personal Account. Angew. Chem. Int. Ed. 2014, 53, 8587-8598.

36. Nativi, C.; Taddei, M. Some Observations on the Stereochemical and Regiochemical Outcome of Hydrostannylation of Substituted Propargyl Alcohols. J. Org. Chem. 1988, 53, 820-826. 

Addition of $\mathrm{R}_{3} \mathrm{SnH}$ to Acetylenes and its Application to Cyclization Reaction. J. Am. Chem. Soc. 1987, 109, 25472549.

38. Ensley, H. E.; Buescher, R. R.; Lee, K. Reaction of Organotin Hydrides with Acetylenic Alcohols. J. Org. Chem. 1982, 47, 404-408.

39. Jung, M. E.; Light, L. A. Preparation of iodoallylic alcohols via hydrostannylation: spectroscopic proof of structures. Tetrahedron Lett. 1982, 23, 3851-3854.

40. Leusink, A. J.; Budding, H. A.; Drenth, W. Studies in Group IV Organometallic Chemistry XXVII. Isomerization of the Primary trans-Addition Products Formed in the Hydrostannation of Ethynes. J. Organomet. Chem. 1968, $11,541-547$.

41. Viehe, H. G.; Merenyi, R.; Janousek, Z. Captodative Substituent Effects in Radical Chemistry. Pure Appl. Chem. 1988, 60, 1635-1644.

42. Ruchardt, C. Relations Between Structure and Reactivity in Free-Radical Chemistry. Angew. Chem. Int. Ed. 1970, 9, 830-843.

43. Oderinde, M. S.; Froese, R. D. J.; Organ, M. G. 2,2'Azobis(2-methylpropionitrile)-Mediated Alkyne Hydro Stannylation: Reaction Mechanism. Angew. Chem. Int. Ed. 2013, 52, 11334-11338.

44. Oderinde, M. S.; Froese, R. D. J.; Organ, M. G. On the Hydrostannylation of Aryl Propargylic Alcohols and their Derivatives: Remarkable Differences in both Regio- and Stereoselectivity in Radical- and Nonradical-mediated Transformations. Chem. Eur. J. 2014, 20, 8579-8583.

45 Oderinde, M. S.; Organ, M. G. Pronounced Solvent Effect on the Hydrostannylation of Propargylic Alcohol Derivatives with $n \mathrm{Bu}_{3} \mathrm{SnH}_{/} / \mathrm{Et}_{3} \mathrm{~B}$ at Room Temperature. Chem. Eur. J. 2013, 19, 2615-2618.

46. Pati, K.; dos Passos Gomes, G.; Harris, T.; Hugues, A.; Phan, H.; Banerjee, T.; Hanson, K.; Alabugin, V. Traceless Directing Groups in Radical Cascades: From Oligoalkynes to Fused Helicenes without Tethered Initiators. J. Am. Chem. Soc. 2015, 137, 1165-1180.

47. Dimopoulos, P.; George, J.; Tocher, D.A.; Manaviazar, S.; Hale, J. Mechanistic Studies on the O-Directed Free-Radical Hydrostannation of Disubstituted Acetylenes with $\mathrm{Ph}_{3} \mathrm{SnH}$ and $\mathrm{Et}_{3} \mathrm{~B}$ and on the Iodination of Allylically Oxygenated $\alpha-$ Triphenylstannylalkenes. Org. Lett. 2005, 7, 5377-5380.

48. Curran, D. P.; McFadden, T. R. Understanding Initiation with Triethylboron and Oxygen: The Differences between Low-Oxygen and High-Oxygen Regimes. J. Am. Chem. Soc. 2016, 138, 7741-7752.

49. Gevorgyan, V.; Liu, J.-X.; Yamamoto, Y. Lewis acid Catalyzed trans-hydrostannylation of Acetylenes. J. Chem. Soc. Chem. Commun. 1995, 2405-2406.

50. Asao, N.; Liu, J.-X.; Sudoh, T.; Yamamoto, Y. Lewis AcidCatalyzed Hydrostannation of Acetylenes. Regio- and Stereoselective Trans-Addition of Tributyltin Hydride and Dibutyltin Dihydride. J. Org. Chem. 1996, 61, 4568-4571.

51. Rice, M. B.; Whitehead, S. L.; Horvath, C. M.; Muchnij, J. A.; Maleczka Jr., R. E. The Regiochemical Influence of Oxo-Substitution in Palladium-Mediated Hydrostannations of 1-Alkynes. Synthesis 2001, 1495-1504.

52. Crisp, G. T.; Gebauer, M. G. Accelerated Transmetallation in Stille Couplings Effected by Chelation to the Palladium. Tetrahedron Lett. 1995, 36, 3389-3392.

53. Crisp, G. T.; Gebauer, M. G. The Hydrostannation of a Propargylglycine Derivative. J. Organomet. Chem. 1997, 532, 83-88.

54. Darwish, A.; Lang, A.; Kim, T.; Chong, J. M. The Use of Phosphine Ligands to Control the Regiochemistry of PdCatalyzed Hydrostannations of 1-Alkynes: Synthesis of (E)-1-Tributylstannyl-1-alkenes. Org. Lett. 2008, 10, 861864.
55. Maleczka, Jr. R. E.; Terrell, L. R.; Clark, D. H.; Whitehead, S. L.; Gallagher, W. P.; Terstiege, I. Application of Fluoride-Catalyzed Silane Reductions of Tin Halides to the in Situ Preparation of Vinylstannanes. J. Org. Chem. 1999, 64, 5958-5965.

56. Miyake, H.; Yamamura, K. Palladium(0) Catalyzed Hydrostannylation of Alkynes. Stereospecific Syn Addition of Tributyltin Hydride. Chem. Lett. 1989, 981-984.

57. Dodero, V. I.; Koll, L. C.; Mandolesi, S.D.; Podesta, J. C. Stereoselective Hydrostannation of Substituted Alkynes with Trineophyltin Hydride. J. Organomet. Chem. 2002, 650, 173-180.

58. Betzer, J.-F.; Delaloge, F.; Muller, B.; Pancrazi, A.; Prunet, J. Radical Hydrostannylation, Pd(0)-Catalyzed Hydrostannylation, Stannylcupration of Propargyl Alcohols and Enynols: Regio- and Stereoselectivities. J. Org. Chem. 1997, 62, 7768-7780.

59. Gallagher, W. P.; Maleczka, Jr., R. E. Stille Reactions Catalytic in Tin: a "Sn-F" Route for Intermolecular and Intramolecular Couplings. J. Org. Chem. 2005, 70, 841-846.

60. Kikukawa, K.; Umekawa, H.; Wada, F.; Matsuda, T. Regioselective Hydrostannation of Terminal Acetylenes under Transition Metal Catalysis. Chem. Lett. 1988, 881884.

61. Hamze, A.; Veau, D.; Provot, O.; Brion, J.-D.; Alami, M. Palladium-catalyzed Markovnikov Terminal Arylalkynes Hydrostannation: Application to the Synthesis of 1,1Diarylethylenes. J. Org. Chem. 2009, 74, 1337-1340.

62. Liron, F.; Le Garrec, P.; Alami, M. Regiochemical Control in the Hydrostannylation of Aryl Substituted Alkynes: A Stereoselective Synthesis of Disubstituted Vinylstannanes. Synlett 1999, 246-248.

63. Hamze, A.; Le Menez, P.; Provot, O.; Morvan, E.; Brion, J.D.; Alami M. Regioselective Hydrostannation of Highly Hindered Arylalkynes under Ortho-Directing Effects. Tetrahedron 2010, 66, 8698-8706.

64. Yoshida, Y.; Shinke, A.; Kawano, Y.; Takaki, K. CopperCatalyzed $\alpha$-Selective Hydrostannylation of Alkynes for the Synthesis of Branched Alkenylstannanes. Chem. Commun. 2015, 51, 10616-10619.

65. Lee, Y.-J.; Lee, D.-G.; Rho, H. S.; Krasokhin, V. B.; Shin, H. J.; Lee, J. S.; Lee, H.-S. Cytotoxic 5-Hydroxyindole Alkaloids from the Marine Sponge Scalarispongia sp. $J$. Het. Chem. 2013, 50, 1400-1404.

66. Ansari, N. H.; Söderberg, B. C. G. Short Syntheses of the Indole Alkaloids Alocasin A, Scalaridine A, and Hyrtinadine A-B. Tetrahedron 2016, 72, 4214-4221.

67. Bellina, F.; Carpita, A.; De Santis, M.; Rossi, R. Synthesis of 2-Tributylstannyl-1-alkenes from 2-Tributylstannyl-2propen-1-yl acetate. Tetrahedron 1994, 50, 4853-4872.

68. Cochran, J. C.; Bronk, B. S.; Terrence, K. M.; Phillips, H. K. Palladium(0) Catalysis in Hydrostannation of CarbonCarbon Triple Bonds. Tetrahedron Lett. 1990, 31, 66216624.

69. Cochran, J. C.; Prindle, V.; Young, H. A.; Kumar, M. H.; Tom, S.; Petraco, N. D. K.; Mohoro, C.; Kelley, B. Alkyland acyl-substituted vinylstannanes: Synthesis and Reactivity in Electrophilic Substitution Reactions. Synth. React. Inorg. Met. Org. Chem. 2002, 32, 885-902.

70. Andrews, I. P.; Kwon, O. Highly Efficient PalladiumCatalyzed Hydrostannation of Ethyl Ethynyl Ether. Tetrahedron Lett. 2008, 49, 7097-7099.

71. Minière, S.; Cintrat, J.-C. Stille Cross-Coupling Reaction of an $\alpha$-Stannyl Enamide. Synthesis 2001, 705-707.

72. Naud, S.; Cintrat, J.-C. New Stannyl Enamides. Synthesis 2003, 1391-1397.

73. Magriotis, P. A.; Brown, J. T.; Scott, M. E. A Highly Selective Synthesis of Versatile (E)-1-Phenylthio vinylstannanes. Tetrahedron Lett. 1991, 32, 5047-5050. 
74. Marshall, J. A.; Bourbeau, M. P. Directed Pd(0)-Catalyzed Hydrostannations of Internal Alkynes. Tetrahedron Lett. 2003, 44, 1087-1090.

75. Greeves, N.; Torode, J. S. Regio- and Stereoselective Palladium(0) Catalysed Hydrostannation of Disubstituted Propargyl Alcohols. Synlett 1994, 537-538.

76. Semmelhack, M. F.; Hooley, R. J. Palladium-Catalyzed Hydrostannylations of Highly Hindered Acetylenes in Hexane. Tetrahedron Lett. 2003, 44, 5737-5739.

77. Finch, H.; Pegg, N. A.; Evans, B. The Synthesis of a Conformationally Restrained, Combined Thromboxane Antagonist / Synthase Inhibitor using an Intramolecular 'Stille'- or 'Grigg'-Palladium-Catalysed Cyclisation Strategy. Tetrahedron Lett. 1993, 34, 8353-8356.

78. Manchala, N.; Law, H. Y. L.; Kerr, D. J.; Volpe, R.; Lepage, R. J.; White, J. M.; Krenske, E. H.; Flynn, B. Multistereocenter-Containing Cyclopentanoids from Ynamides via Oxazolidinone-Controlled Nazarov Cyclization. J. Org. Chem. 2017, 82, 6511-6527.

79. Rasolofonjatovo, E.; Provot, O.; Hamze, A.; Bignon, J.; Thoret, S.; Brion, J.-D.; Alami, M. Regioselective Hydrostannation of Diarylalkynes Directed by a Labile Ortho Bromine Atom: An Easy Access to Stereodefined Triarylolefins, Hybrids of Combretastatin A-4 and Isocombretastatin A-4. Eur. J. Med. Chem. 2010, 45, 36173626.

80. Liron, F.; Gervais, M.; Peyrat, J.-F.; Alami, M.; Brion, J.-D. Palladium-Catalyzed Stereoselective Synthesis of $E$ - and $Z$ 1,1-Diaryl or Triarylolefins. Tetrahedron Lett. 2003, 44, 2789-2794.

81. Rubin, M.; Trofimov, A.; Gevorgyan, V. Can Polarization of Triple Bond in Tolanes be Deduced from ${ }^{13} \mathrm{C}$ NMR Shifts? Re-evaluation of Factors Affecting Regiochemistry of the Palladium-Catalyzed Hydrostannation of Alkynes. $J$. Am. Chem. Soc. 2005, 127, 10243-10249.

82. Kleinpeter, E.; Schulenburg, A. Quantification of the Pushpull Effect in Tolanes and a Revaluation of the Factors Affecting the ${ }^{13} \mathrm{C}$ chemical shifts of the Carbon Atoms of the CC Triple Bond. J. Org. Chem. 2006, 71, 3869-3875.

83. Trost, B. M.; Li, C. J. Preparation of Dienylstannanes Via Pd Catalyzed Regio-and Stereocontrolled Addition Reactions. Synthesis 1994, 1267-1271.

84. Wang, P.; Huang, B.; Xie, S.; Tuo, Y.; Cai, M. Highly Regioselective and Stereoselective Hydrostannylation of (Z)-2-Ethoxycarbonyl-1,3-enynes Leading to $(1 E, 3 E)-2-$ Ethoxycarbonyl-3-stannyl-1,3-dienes. J. Chem. Res. 2015, 39, 627-630.

85. Zhao, H.; Yang, W.; Xie, S.; Cai, M. Stereoselective Synthesis of Difunctionalized 1,3-Dienes Containing Tin and Sulfonyl Groups by Palladium-Catalyzed Regio- and Stereocontrolled Addition Reactions. Eur. J. Org. Chem. 2012, 831-836.

86. Alami, M.; Ferri, F. Regio- and Stereocontrolled Hydrostannation of (E) and (Z)-Chloroenynes. An Efficient Preparation of Chlorodienyl Tributyltin Reagents. Synlett 1996, 755-756.

87. Hamze, A.; Provot, O.; Brion, J.-D.; Alami, M. Regiocontrol of the Palladium-Catalyzed Tin Hydride Addition to Z-enynols: Remarkable Z-Directing Effects. $J$. Org. Chem. 2007, 72, 3868-3874.

88. Bujard, M.; Ferri, F.; Alami, M. The First and Convenient Synthesis of Acyclic Dienediynes related to Neocarzinostatin Chromophore. Tetrahedron Lett. 1998, 39, 4243-4246.

89. Ferri, F.; Alami, M. Expeditious Stereo and Regioselective Synthesis of Stannylated Dienynes: Versatile Precursors of Dienediynes Related to Neocarzinostatin Chromophore. Tetrahedron Lett. 1996, 37, 7971-7974.

90. Rossi, R.; Carpita, A.; Cossi. P. New and Efficient Procedures for the Synthesis of Stereodefined 2-(hetero)aryl and 2-methyl Substituted Alkyl 2-alkenoates Having very High Stereoisomeric Purity. Tetrahedron Lett. 1992, 33, 4495-4498.

91. Rossi, R.; Carpita, A.; Cossi. P. Synthetic Applications of Alkyl (E)-2-Tributylstannyl-2-alkenoates: Selective Synthesis of (S)-1-Methylbutyl (E)-2-Methyl-2-pentenoate, an Aggregation Pheromone Component of Rhyzopertha dominica and Prostephanus truncates. Synth. Commun. 1993, 23, 143-152.

92. Cochran, J. C.; Phillips, H. K.; Tom, S.; Hurd, A. R.; Bronk, B. S. Phenyl-Substituted Vinylstannanes: Synthesis and Reactivity in Electrophilic Substitution Reactions. Organometallics 1994, 13, 947-953.

93. Zhao, H.; Dai, R.; Cai, M. Stereoselective Synthesis of (1Z,3E)-2-Ethoxycarbonyl-Substituted 1,3-Dienes via Stille Coupling of (E)- $\alpha$-Stannyl- $\alpha, \beta$-Unsaturated Esters with Alkenyl Halides. Synth. Commun. 2009, 39, 4454-4466.

94. Cai, M.; Fang, X.; Dai, R.; Zha, L. A one-pot, Stereoselective Synthesis of 2-ethoxycarbonyl-substituted 1,3-dienes and 1,3-enynes by Hydrostannylation-Stille Tandem Reaction of Tributyltin Hydride with Alkynyl Esters and Alkenyl or Alkynyl Halides. App. Organomet. Chem. 2009, 23, 229-236.

95. Cochran, J. C.; Terrence, K. M.; Phillips, H. K. Synthesis and Electrophilic Destannylation Reactions of Trimethylstannyl-Substituted Methyl crotonates. Organometallics 1991, 10, 2411-2420.

96. Dodero, V. I.; Koll, L. C.; Faraoni, M. B.; Mitchell, T. N.; Podesta, J. C. Stereoselective Synthesis of Stannyl Enones via Palladium-Catalyzed and Free Radical Hydrostannation of Alkynyl Ketones with Trineophyltin Hydride. J. Org. Chem. 2003, 68, 10087-10091.

97. Tresse, C.; Schweizer, S.; Bisseret, P.; Lavelée, J.; Evano, G.; Blanchard, N. Stereodivergent Hydrosilylation, Hydrostannylation, and Hydrogermylation of $\alpha$ Trifluoromethylated Alkynes and Their Synthetic Applications. Synthesis, 2016, 48, 3317-3330.

98. Cai, M.-Z.; Chen, G.-Q.; Hao, W.-Y.; Wang, D. A Facile Stereoselective Synthesis of 1,3-dienyl Sulfones via Stille Coupling Reactions of $(E)-\alpha$-Stannylvinyl Sulfones with Alkenyl Iodides. J. Organomet. Chem. 2007, 692, 11251128.

99. Cai, M.Z.; Chen, G.; Hao, W.; Wang, D. A Stereoselective Synthesis of (E)- $\alpha$-Stannylvinyl Sulfones via Palladium-Catalyzed Hydrostannylation of Acetylenic Sulfones. Synlett 2006, 3492-3494.

100. Chen, G.; Yu, Y.; Cai, M. One-Pot Stereoselective Synthesis of (Z)-1,2-Disubstituted Vinyl Sulfones by Hydrostannylation-Stille Tandem Reaction of Acetylenic Sulfones. Synth. Commun. 2009, 39, 1478-1487.

101. Huang, X.; Xiong, Z.-C. The Palladium Catalyzed Hydrostannation of 1-Alkenylphosphonates: A New Approach to Stereodefined $\alpha, \beta$-Disubstituted Vinylphosphonates. Synth. Commun. 2003, 33, 2511-2517.

102. Cai, M.; Wang, Y.; Hao, W. Palladium-Catalyzed Hydrostannylation of $\alpha$-Heteroalkynes and Alkynyl Esters in Ionic Liquids. Eur. J. Org. Chem. 2008, 2983-2988.

103. Paley, R. S.; Weers, H. L.; Fernandez, P. Stereocontrolled Synthesis of Enantiomerically Pure 2-dienyl Sulfoxides via Palladium-Catalyzed Coupling Reactions. Tetrahedron Lett. 1995, 36, 3605-3608.

104. Paley, R. S.; de Dios, A.; Estroff, L. A.; Lafontaine, J. A.; Montero, C.; McCulley, D. J.; Rubio, M. B.; Ventura, M. P.; Weers, H. L. Synthesis and Diastereoselective Complexation of Enantiopure Sulfinyl Dienes: The Preparation of Sulfinyl Iron(0) Dienes. J. Org. Chem. 1997, 62, 6326-6336.

105. Lebl, T.; Holecek, J.; Dymak, M.; Steinborn, D. Synthesis, Characterisation and Reactivity of 2-Functionalised Vinylstannanes. J. Organomet. Chem. 2001, 625, 86-94. 
106. Pimm, A.; Kocienski, P.; Street, S. D. A. The Preparation and $\operatorname{Pd}(0)$-Catalysed Cross Coupling Reactions of $\alpha$ (Phenylthio)alkenylzinc Reagents. Synlett 1992, 886-888.

107. Huang, X.; Ma, Y. (E)- $\alpha$-Selanylvinylstannanes as Convenient Precursors for Stereoselective Synthesis of Trisubstituted Alkenes. Synthesis 1997, 417-419.

108. Huang, X.; Ma, Y. Stereoselective Synthesis and Application of (E)- $\alpha$-Selanyl Vinylstannanes. Synth. Commun. 1997, 27, 2407-2412.

109. Casson, S.; Kocienski, P. Palladium(0)-Catalysed Hydrostannylation of 1-Alkoxy-1-alkynes: A Synthesis of $\alpha$-Alkoxyalkenylstannanes and Their Transmetallation to $\alpha$ Alkoxyalkenyllithiums. Synthesis 1993, 1133-1140.

110. Buissonneaud, D.; Cintrat, J.-C. Highly Regio- and Stereocontrolled Synthesis of $\beta$-Substituted $\alpha$ Tributylstannyl Enamides. Tetrahedron Lett. 2006, 47, 3139-3143.

111. Wu, W.; Jiang, H. Haloalkynes: A Powerful and Versatile Building Block in Organic Synthesis. Acc. Chem. Res. 2014, 47, 2483-2504.

112. Boden, C. D. J.; Pattenden, G.; Ye, T. Palladium-Catalysed Hydrostannylations of 1-Bromoalkynes. A Practical Synthesis of (E)-1-Stannylalk-1-enes. J. Chem. Soc., Perkin Trans. 1, 1996, 20, 2417-2419.

113. Bamba, M.; Nishikawa, T.; Isobe, M. Tin-Assisted Cyclization for Chiral Cyclohexane Synthesis, an Alternative Route to (-)-Tetrodotoxin Skeleton. Tetrahedron Lett. 1996, 37, 8199-8202.

114. Kazmaier, U.; Schauss, D.; Pohlman, M. Mo(CO $)_{3}(\mathrm{CN}-t$ $\mathrm{Bu})_{3}\left(\mathrm{MoBI}_{3}\right)$, a New Efficient Catalyst for Regioselective Hydrostannations. Org. Lett. 1999, 7, 1017-1019.

115. Kazmaier, U.; Pohlman, M.; Schauss, D. Regioselective Hydrostannations with $\mathrm{Mo}(\mathrm{CO})_{3}(\mathrm{CN} t \mathrm{Bu})_{3}\left(\mathrm{MoBI}_{3}\right)$ as a New, Efficient Catalyst. Eur. J. Org. Chem. 2000, 27612766.

116. Braune, S.; Kazmaier, U. Regioselective Hydrostannations Catalyzed by Molybdenum Isonitrile Complexes. $J$. Organomet. Chem. 2002, 641, 26-29.

117. Ghosh, B.; Maleczka Jr., R. E. Ni, Co, and Mo-catalyzed Alkyne Hydrostannations using $\mathrm{Bu} 3 \mathrm{SnCl} / \mathrm{PMHS} / \mathrm{KF} / 18$ crown-6 as an in situ Bu3SnH Source. Tetrahedron Lett. 2011, 52, 5285-5287.

118. Maleczka Jr., R. E.; Ghosh, B.; Gallagher, W. P.; Baker, A. J.; Muchnij, J. A.; Szymanski, A. L. Non-Pd Transition Metal-Catalyzed Hydrostannations: $\mathrm{Bu}_{3} \mathrm{SnF} / \mathrm{PMHS}$ as a Tin Hydride Source. Tetrahedron 2013, 69, 4000-4008.

119. Wesquet, A. O.; Kazmaier, U. Improved Protocols for Molybdenum- und Tungsten-Catalyzed Hydrostannations. Adv. Synth. Catal. 2009, 351, 1395-1404.

120. Kazmaier, U.; Dörrenbächer, S.; Wesquet, A.; Lucas, S.; Kummeter, M. Molybdenum-Catalyzed Synthesis of Stannylated Allylic Alcohol Derivatives and Their Synthetic Applications. Synthesis 2007, 320-236.

121. Kazmaier, U.; Wesquet, A. Stannylated Allylsulfones as Versatile New Building Blocks. Synlett 2005, 1271-1273.

122. Wesquet, A. O.; Dörrenbächer, S.; Kazmaier, U. Improved Protocols for the Molybdenum-Catalyzed Hydrostannation of Alkynes. Synlett 2006, 1105-1109.

123. Jena, N.; Kazmaier, U. Synthesis of Stannylated Allyl- and Vinylphosphonates via Molybdenum-Catalyzed Hydrostannations. Eur. J. Org. Chem. 2008, 3852-3759.

124. Maity, P.; Klos, M. R.; Kazmaier, U. Syntheses of $\alpha-$ Stannylated and $\alpha$-Iodinated Enamides via MolybdenumCatalyzed Hydrostannation. Org. Lett. 2013, 15, 6246-6249.

125. Pratap, R.; Kazmaier, U. Synthesis of 1-Stannylated and 1Iodinated 1-Chloroalkenes as Versatile Synthetic Intermediates. Synlett 2010, 3073-3077.

126. Mandla, K. A.; Moore, C. E.; Rheingold, A. L. Figueroa, J. S. Regioselective Formation of $(E)-\beta$-Vinylstannanes with a Topologically Controlled Molybdenum-Based Alkyne
Hydrostannation Catalyst. Angew. Chem. Int. Ed. 2018, 57, 6853-6857.

127. Mitchell, T. N.; Moschref, S.-N. Unexpected Switching between Addition and Substitution in the RhodiumCatalysed Reaction between Tin Hydrides and Propargyl Ethers. Synlett 1999, 1259-1260.

128. Leung, L. T.; Chiu, P. Hydrostannation of Activated Alkynes Mediated by Stryker's Reagent. Pure Appl. Chem. 2006, 78, 281-289.

129. Leung, L. T.; Leung, S. K.; Chiu, P. Copper-Catalyzed Hydrostannation of Activated Alkynes. Org. Lett. 2005, 7, 5249-5252.

130. Miao, R.; Li, S.; Chiu, P. Regioselective Hydrostannation of Activated Alkynes Catalyzed by in situ Generated Copper Hydride. Tetrahedron 2007, 63, 6737-6740.

131. Mo, X.; Letort, A.; Rosca, D. A.; Higashida, K.; Fürstner, A. Site-Selective trans-Hydrostannation of $1,3-$ and $1, n-$ Diynes: Application to the Total Synthesis of Typhonosides $\mathrm{E}$ and F, and a Fluorinated Cerebroside Analogue. Chem. Eur. J. 2018, 24, 9667-9674.

132. Frihed, T.; Fürstner, A. Progress in the trans-Reduction and trans-Hydrometalation of Internal Alkynes. Applications to Natural Product Synthesis. Bull. Chem. Soc. Jpn. 2016, 89, $135-160$

133. Kinart, W. J.; Kinart, C. M.; Sendecki, M. The Effect of Lewis Acid Catalysis and Steric Effects on Reactions of Tin Hydrides. Curr. Organocatal., 2015, 2, 27-36.

134. Tolstikov, G. A.; Miftakhov, M. S.; Danilova, N. A.; Velder, Y. L. Regio- and Stereoselective Hydrostannylation of 3Hydroxy-4-phenoxy-1-butyne: Effective Approach to Intermediates in the Total Synthesis of $\omega$-Aryloxyprostaglandins. Synthesis 1986, 496-502.

135. Konoike, T.; Araki, Y. Concise Allene Synthesis from Propargylic Alcohols by Hydrostannation and Deoxystannylation: A new Route to Chiral Allenes. Tetrahedron Lett. 1992, 33, 5093-5096.

136. Lautens, M.; Huboux, A. H. A Route to the Preparation of $\gamma$-Hydroxyvinylstannanes. Tetrahedron Lett. 1990, 31, 3105-3108.

137. Anderson, J. C.; Roberts, C. A. The Tri-n-butyltin Group as a Novel Stereocontrol Element and Synthetic Handle in the Aza-[2,3]-Wittig Sigmatropic Rearrangement. Tetrahedron Lett. 1998, 39, 159-162.

138. Thiele, C. M.; Mitchell, T. N. Hydrostannylation of Propargylic Alcohols Using Mixed Tin Hydrides. Eur. J. Org. Chem. 2004, 337-353.

139. Nozaki, K.; Oshima, K.; Utimoto, K. Et 3 B induced radical Addition of $\mathrm{Ph}_{3} \mathrm{SnH}$ to Acetylenes and its Application to Cyclization Reaction. Tetrahedron 1989, 45, 923-933.

140. Faraoni, M. B.; Dodero, V. I.; Koll, L. C.; Zuniga, A. E.; Mitchell, T. N.; Podesta, J. C. Stereoselective Hydrostannation of Substituted Alkynes Initiated by Triethylborane and Reactivity of Bulky Triorganotin Hydrides. J. Organomet. Chem. 2006, 691, 1085-1091.

141. Dimopoulos, P.; Athlan, A.; Manaviazar, S.; George, J.; Walters, M.; Lazarides, L.; Aliev, A. E.; Hale, K. J. ODirected Free-Radical Hydrostannations of Propargyl Ethers, Acetals, and Alcohols with $\mathrm{Ph}_{3} \mathrm{SnH}$ and $\mathrm{Et}_{3} \mathrm{~B}$. Org. Lett. 2005, 7, 5369-5372.

142. Oderinde, M. S.; Hunter, H. N.; Organ, M. G. Kinetic versus Thermodynamic Stereoselectivity in the Hydrostannylation of Propargylic Alcohol Derivatives using AIBN and $\mathrm{E}_{\mathrm{t} 3} \mathrm{~B}$ as Promotors. Chem. Eur. J. 2012, 18, 10817-10820.

143. Ollivier, C.; Renaud, P. Organoboranes as a Source of Radicals. Chem. Rev. 2001, 101, 3415-3434.

144. Oderinde, M. S.; Hunter, H. N.; Froese, R. D. J.; Organ, M. G. Highly Stereo- and Regioselective Hydrostannylation of Internal Alkynes Promoted by Simple Boric Acid in air. Chem. Eur. J. 2012, 18, 10821-10824. 
145. Chae, J.; Konno, T.; Kanda, M.; Ishihara, T.; Yamanaka, H. A Highly Regio-and Stereo-Selective Hydrostannation Reaction of Various Fluorine-Containing Internal Acetylene Derivatives. J. Fluorine Chem. 2003, 120, 185-193.

146. Nakamura, E.; Machii, D.; Inubushi, T. Homogeneous Sonochemistry in Radical-Chain Reactions. Sonochemical Hydrostannation and Tin Hydride Reduction. J. Am. Chem. Soc. 1989, 111, 6849-6862.

147. Nakamura, E.; Imanishi, Y.; Machii, D. Sonochemical Initiation of Radical Chain Reactions. Hydrostannation and Hydroxystannation of C-C Multiple Bonds. J. Org. Chem. 1994, 59, 8178-8186.

148. Struble, J. R.; Lee, S. J.; Burke, M. D. Ethynyl MIDA Boronate: a Readily Accessible and Highly Versatile Building Block for Small Molecule Synthesis. Tetrahedron 2010, 66, 4710-4718.

149. Lhermitte, F.; Carboni, B. Radical Reactions in Organoboron Chemistry. III -Addition Reactions to Alkynylboranes as Efficient Routes to New Regio- and Stereodefined Alkenyl Diamino- and Dialkoxyboranes. Synlett 1996, 377-379.

150. Gevorgyan, V.; Liu, J-X.; Yamamoto, Y. Hydrostannation of $\mathrm{C}-\mathrm{C}$ Multiple Bonds with $\mathrm{Bu}_{3} \mathrm{SnH}$ Prepared in situ from $\mathrm{Bu}_{3} \mathrm{SnCl}$ and $\mathrm{Et}_{3} \mathrm{SiH}$ in the Presence of Lewis Acid Catalysts. Chem. Commun. 1998, 37-38.

151. Oderinde, M. S.; Organ, M. G. Studies on the Mechanism of $\mathrm{B}\left(\mathrm{C}_{6} \mathrm{~F}_{5}\right)_{3}$-Catalyzed Hydrostannylation of Propargylic Alcohol Derivatives. Angew. Chem. Int. Ed. 2012, 51, 98349837.

152. Shibata, I.; Suwa, T.; Ryu, K.; Baba, A. Selective $\alpha$ Stannylated Addition of Di- $n$-butyliodotin Hydride Ate Complex to Simple Aliphatic Alkynes. J. Am. Chem. Soc. 2001, 123, 4101-4102.

153. Miura, K.; Wang, D.; Matsumoto, Y.; Fujisawa, N.; Hosomi, A. Regio- and Stereoselective Homolytic Hydrostannylation of Propargyl Alcohols and Ethers with Dibutylchlorostannane. J. Org. Chem. 2003, 68, 8730-8732.

154. Miura, K.; Wang, D.; Hosomi, A. Highly Regio- and Stereoselective Hydrostannylation of Propargyl Alcohols and Ethers Using Dibutylchlorostannane and Lithium Chloride. Synlett 2005, 406-410.

155. Forster, F.; Rendón López, V.M.; Oestreich, M. Z-Selective Hydrostannylation of Terminal and Internal C-C Triple Bonds Initiated by the Trityl Cation. Organometallics 2018, 37, 2656-2659.

156. Wiesemann, M.; Niemann, M.; Klösener, J.; Neumann, B.; Stammler, H.-G.; Hoge, B. Tris(pentafluoroethyl)stannane: Tin Hydride Chemistry with an Electron-Deficient Stannane. Chem. Eur. J. 2018, 24, 2699-2708.

157. Maleczka, R. E. Jr.; Gallagher, W. P.; Terstiege, I. Stille Couplings Catalytic in Tin: Beyond Proof-of-Principle. $J$. Am. Chem. Soc. 2000, 122, 384-385.

158. Maleczka, R. E. Jr.; Terstiege, I. Microwave-Assisted OnePot Hydrostannylation/Stille Couplings. Org. Lett. 2000, 2, 3655-3658.

159. Maleczka, R. E. Jr.; Gallagher, W. P. Stille Couplings Catalytic in Tin: A "Sn-F" Approach. Org. Lett. 2001, 3, 4173-4176.

160. Oikawa, H.; Yoneta, Y.; Ueno, T.; Oikawa, M.; Wakayama, T.; Ichihara, A. Synthetic Study of Tautomycetin: Synthesis of two large Subunits. Tetrahedron Lett. 1997, 38, 78977900.

161. Jung, I.; Lee, T.; Kang, S. O.; Ko, J. Hydrostannation of Diyne and Triyne $\pi$-Electron Bridges: Efficient Stille CrossCoupling of 1,3,5-Tris[(E)-2-(tributylstannyl) vinyl] benzene. Synthesis 2005, 986-992.

162. Kadota, I.; Takamura, H.; Yamamoto, Y. Synthesis of the J Ring Segment of Gambieric Acid. Tetrahedron Lett. 2001, 42, 3649-3651.
163. Casaschi, A.; Grigg, R.; Sansano, J. M.; Wilson, D.; Redpath, J. Palladium Catalysed Tandem CyclisationAnion Capture. Part 5: Cascade Hydrostannylation-biscyclisation-intramolecular Anion Capture. Synthesis of Bridged- and Spiro-Cyclic Small and Macrocyclic Heterocycles. Tetrahedron 2000, 56, 7541-7551.

164. Grigg, R.; Sridharan, V. Palladium Catalyzed Cascade Cyclisation-Anion Capture, Relay Switches and Molecular Queues. J. Organomet. Chem. 1999, 576, 65-87.

165. Cliff, M. D.; Pyne, S. G. Asymmetric Synthesis of 2-Acetyl4(5)-(1,2,4-trihydroxybutyl)imidazoles. J. Org. Chem. 1995, 60, 2378-2383.

165. Bansal, R.; Cooper, G. F.; Corey, E. J. Stereoselective synthesis of an important prostaglandin synthetic intermediate. J. Org. Chem. 1991, 56, 1329-1332.

167. Marshall, J. A.; Schaaf, G. Total Synthesis and Structure Confirmation of Leptofuranin D. J. Org. Chem. 2003, 68, 7428-7432.

168. Marshall, J. A.; Bourbeau, M. P. Second-Generation Synthesis of the Polypropionate Subunit of Callystatin A Based on Regioselective Internal Alkyne Hydrostannation. Org. Lett. 2002, 4, 3931-3934.

169. Sai, H.; Ogiku, T.;Nishitani, T.; Hiramatsu, H.; Horikawa, H.; Iwasaki, T. Stereoselective Syntheses of Taiwanin A and Its Isomers Using a Cross-Coupling Reaction. Synthesis 1995, 582-586.

170. Johansson, M.; Köpcke, B.; Anke, H.; Sterner, O. Synthesis of (-)-Pregaliellalactone, Conversion of (-)Pregaliellalactone to $(-)$-Galiellalactone by Mycelia of Galiella rufa. Tetrahedron 2002, 58, 2523-2528.

171. Schmidt-Leithoff, J.; Brückner, R. Synthesis of the 2Alkenyl-4-alkylidenebut-2-eno-4-lactone $\quad(=\alpha$-Alkenyl- $\gamma$ alkylidenebutenolide) Core Structure of the Carotenoid Pyrrhoxanthin via the Regioselective Dihydroxylation of Hepta-2,4-diene-5-ynoic Acid Esters. Helv. Chim. Acta 2005, 88, 1943-1959.

172. Lebsack, A. D.; Link, J. T.; Overman, L. E.; Stearns, B. A. Enantioselective Total Synthesis of Quadrigemine C and Psycholeine. J. Am. Chem. Soc. 2002, 124, 9008-9009.

173. Kuligowski, C.; Bezzenine-Lafollée, S.; Chaume, G.; Mahuteau, J.; Barrière, J.-C.; Bacqué, E.; Pancrazi, A.; Ardisson, J. Approach Toward the Total Synthesis of Griseoviridin: Formation of Thioethynyl and Thiovinyl Ether-Containing Nine-Membered Lactones through a Thioalkynylation-Macrolactonization-Hydrostannylation Sequence. J. Org. Chem. 2002, 67, 4565-4568.

174. Duffey, M. O.; LeTiran, A.; Morken, J. P. Enantioselective Total Synthesis of Borrelidin. J. Am. Chem. Soc. 2003, 125, 1458-1459.

175. Vong, B. G.; Kim, S. H.; Abraham, S.; Theodorakis, E. A. Stereoselective Total Synthesis of (-)-Borrelidin. Angew. Chem. Int. Ed. 2004, 43, 3947-3951.

176. Kazmaier, U.; Schauss, D.; Pohlman, M.; Raddatz, S. Application of the Molybdenum-CatalyZed Hydrostannation Towards a Flexible Synthesis of Substituted Unsaturated Amino Acids. Synthesis 2000, 914916.

177. Kazmaier, U.; Schaub, D.; Raddatz, S.; Pohlman, M. Preparation and Reactions of Stannylated Amino Acids. Chem. Eur. J. 2001, 2, 456-464.

178. Meng, Z.; Souillart, L.; Monks, B.; Huwyler, N.; Herrmann, J.; Müller, R.; Fürstner, A.; A "Motif-Oriented" Total Synthesis of Nannocystin Ax. Preparation and Biological Assessment of Analogues. J. Org. Chem. 2018, 83, 69776994.

179. Preindl, J.; Jouvin, K.; Laurich, D.; Seidel, G.; Fürstner, A. Heterocycles by $\mathrm{PtCl}_{2}$-Catalyzed Intramolecular Carboalkoxylation or Carboamination of Alkynes. J. Am. Chem. Soc. 2005, 127, 15024-15025. 
180. Sommer, H.; Hamilton, J. Y.; Fürstner, A. A Method for the Late-Stage Formation of Ketones, Acyloins, and Aldols from Alkenylstannanes: Application to the Total Synthesis of Paecilonic Acid A. Angew. Chem. Int. Ed. 2017, 129, 6257-6261.

181. Sommer, H.; Fürstner, A. Hydroxyl-Assisted Carbonylation of Alkenyltin Derivatives: Development and Application to a Formal Synthesis of Tubelactomicin A. Org. Lett. 2016, 18, 3210-3213.

182. Darwish, A.; Chong, J. M. A Practical One-Pot Synthesis of Vinylstannanes from Ketones. J. Org. Chem. 2007, 72, 1507-1509.

183. Barbero, A.; Pulido, F. J. Allylstannanes and Vinylstannanes from Stannylcupration of C-C multiple Bonds. Recent Advances and Applications in Organic Synthesis. Chem. Soc. Rev. 2005, 34, 913-920.

184. Sharma, S.; Oehlschlager, A. C. Control of Regiochemistry in Bismetallation of 1-Decyne. Tetrahedron Lett. 1986, 27, 6161-6164.

185. Piers, E.; Tillyer, R.D. Concise, Stereoselective Preparation and Synthetic Uses of (Z)-4-(Trimethylstannyl)buta-1,3dienes. J. Chem. Soc., Perkin Trans. I, 1989, 11, 2124-2129.

186. Matsubara, S.; Hibino, J.-i.; Morizawa, Y.; Oshima, K. Regio- and Stereo-Selective Synthesis of Vinylstannanes. Transition-Metal Catalyzed Stannylmetalation of Acetylenes and Conversion of Enol Triflates and Vinyl Iodides into Vinylstannanes. J. Organomet. Chem. 1985, 285, 163-172.

187. Fallis, A. G.; Forgione, P. Metal Mediated Carbometallation of Alkynes and Alkenes Containing Adjacent Heteroatoms. Tetrahedron 2001, 57, 5899-5913.

188. Shirakawa, E.; Hiyama, T. Synthesis of Functionalized Alkenes by Transition Metal-Catalyzed Carbostannylations of Alkynes and Dienes Followed by Cross-Coupling Reactions. J. Organomet. Chem. 2002, 653, 114-121.

189. Wakamatsu, T.; Nagao, K. Ohmiya, H.; Sawamura, M. Synthesis of Trisubstituted Alkenylstannanes Through Copper-Catalyzed Three-Component Coupling of Alkylboranes, Alkynoates, and Tributyltin Methoxide. Angew. Chem. Int. Ed. 2013, 52, 11620-11623.

190. Snoeij, N. J.; Penninks, A. H.; Seinen, W. Biological Activity of Organotin Compounds-an Overview. Environ. Res. 1987, 44, 335-353.

191. Pagliarini, A.; Trombetti, F.; Ventrella, V. Biochemical and Biological Effects of Organotins; Eds.; Bentham e Books 2012.

192. Nakanishi, T. J. Potential Toxicity of Organotin Compounds via Nuclear Receptor Signaling in Mammals. Health Sci. 2007, 53, 1-9.

193. Hayashi, K.; Iyoda, J. Shiihara, I. Reaction of Organotin Oxides, Alkoxides and Acyloxides with Organosilicon Hydrides. New Preparative Method of Organotin Hydrides. J. Organomet. Chem. 1967, 10, 81-94.

194. Corey, E. J.; Wollenberg, R. H. Useful New Organometallic Reagents for the Synthesis of Allylic Alcohols by Nucleophilic Vinylation. J. Org. Chem. 1975, 40, 22652266.

195. Corey, E. J.; Suggs, J. W. Method for Catalytic Dehalogenations via Trialkyltin Hydrides. J. Org. Chem. 1975, 40, 2554-2555.

196. Le Grognec, E.; Chrétien, J.-M.; Zammattio, F.; Quintard, J.-P. Methodologies Limiting or Avoiding Contamination by Organotin Residues in Organic Synthesis. Chem. Rev. 2015, 115, 10207-10260.

197. Finholt, A. E.; Bond, A. C.; Wilzbach, K. E.; Schlesinger, H. I. The Preparation and Some Properties of Hydrides of Elements of the Fourth Group of the Periodic System and of their Organic Derivatives. J. Am. Chem. Soc. 1947, 69, 2692-2696.
198. Dimopoulos, P.; Athlan, A.; Manaviazar, S.; Hale, K. J. On the Stereospecific Conversion of Proximally-Oxygenated Trisubstituted Vinyltriphenylstannanes into Stereodefined Trisubstituted Alkenes. Org. Lett. 2005, 7, 5373-5376.

199. Casachi, A.; Grigg, R.; Sansano, J. M.; Wilson, D.; Redpath, J. Palladium Catalyzed Cascade Hydrostannylation-bisCyclisation-Intramolecular Anion Capture. Routes to Bridged- and Spiro-cyclic Small and Macrocyclic Heterocycles. Tetrahedron Lett. 1996, 37, 4413-4416. 